SANDIA REPORT

SAND2001-1809

Unlimited Release

Printed June 2001

\title{
Characterization of Under-Building Contamination at Rocky Flats Implementing Environmental Measurement-While-Drilling Process with Horizontal Directional Drilling
}

Cecelia V. Williams, Grant J. Lockwood, Michael M. Selph, Randy A. Normann, and Thomas Lindsay

Prepared by

Sandia National Laboratories

Albuquerque, New Mexico 87185

Sandia is a multiprogram laboratory operated by Sandia Corporation, A LockHeed Martin Company, for the United States Department of Energy under Contract DE-AC 04-94AL85000.

Approved for public release, further dissemination unlimited. 
Issued by Sandia National Laboratories, operated for the United States Department of Energy by Sandia Corporation.

NOTICE: This report was prepared as an account of work sponsored by an agency of the United States Government. Neither the United States Government nor any agency thereof, nor any of their employees, nor any of their contractors, subcontractors, or their employees, makes any warranty, express or implied, or assumes any legal liability or responsibility for the accuracy, completeness, or usefulness of any information, apparatus, product, or process disclosed, or represents that its use would not infringe privately owned rights. Reference herein to any specific commercial product, process, or service by trade name, trademark, manufacturer, or otherwise, does not necessarily constitute or imply its endorsement, recommendation, or favoring by the United States Government, any agency thereof or any of their contractors or subcontractors. The views and opinions expressed here do not necessarily state or reflect those of the United States Government, any agency thereof or any of their contractors or subcontractors.

Printed in the United States of America. This report has been reproduced directly from the best available copy.

Available to DOE and DOE contractors from

Office of Scientific and Technical Information

PO Box 62

Oak Ridge, TN 37831

Available to the public from

National Technical Information Service

US Department of Commerce

5285 Port Royal Rd

Springfield, VA 22161

NTIS price codes

Printed copy: A05

Microfiche copy: A01 
SAND2001-1809

Unlimited Release

Printed June 2001

\title{
Characterization of Under-Building Contamination at Rocky Flats Implementing Environmental Measurement-While-Drilling Process with Horizontal Directional Drilling
}

\author{
Cecelia V. Williams \\ Technology Development \\ Grant J. Lockwood \\ Michael M. Selph \\ Materials Radiation Science \\ Randy A. Normann \\ Geothermal Research \\ Sandia National Laboratories \\ P.O. Box 5800 \\ Albuquerque, New Mexico 87185-0734 \\ Thomas Lindsay \\ Rocky Mountain Remediation Services, L.L.C. \\ 10808 Highway 93 Unit B Bldg. 116 \\ Golden, CO. 80403-8200
}

\begin{abstract}
Characterization is required on thirty-one buildings at Rocky Flats Environmental Technology Site (RFETS or the Site) with known or suspected under building contamination. The Site has teamed with Sandia National Laboratory (SNL) to deploy Environmental MeasureWhile-Drilling (EMWD) in conjunction with horizontal directional drilling (HDD) to characterize under building contamination and to evaluate the performance and applicability for future characterization efforts. The Environmental Measurement-While-Drilling-Gamma Ray Spectrometer (EMWD-GRS) system represents an innovative blend of new and existing technology that provides the capability of producing real-time environmental and drill bit data during drilling operations.

The project investigated two locations, Building 886 and Building 123. Building 886 is currently undergoing D\&D activities. Building 123 was demolished in 1998; however, the slab is present with under building process waste lines and utilities. This report presents the results of the EMWD Gamma Ray Spectrometer logging of boreholes at these two sites. No gamma emitting contamination was detected at either location.
\end{abstract}




\section{Acknowledgements}

This Environmental Measurement-While-Drilling-Gamma Ray Spectrometer (EMWD-GRS) system technology demonstration was funded by the Office of Science and Technology (OST) under U.S. Department of Energy (U.S. DOE) contract number DE-AC04-94AL85000.

The authors wish to acknowledge the contributions made by the following individuals in support of this demonstration:

Scott McMullen (DOE/Savannah River Site) for his confidence in the EMWD technology and his support in the EMWD Deployment.

Pam Saxman and Missy Klem for their assistance in funding the Rocky Flats deployment of EMWD.

Norma Castaneda(DOE/RFETS) for her support in executing the deployment.

Lane Butler (Kaiser Hill L.L.C., Rocky Flats) for his vision in seeing the potential use for the EMWD Technology at Rocky Flats.

David Strand (Kaiser Hill) for his project and field supervision.

Tim Whited and crew, Corrocon, Inc., for their drilling support.

Cindi Maxwell, Sandia National Laboratories, for administrative support. 


\section{CONTENTS}

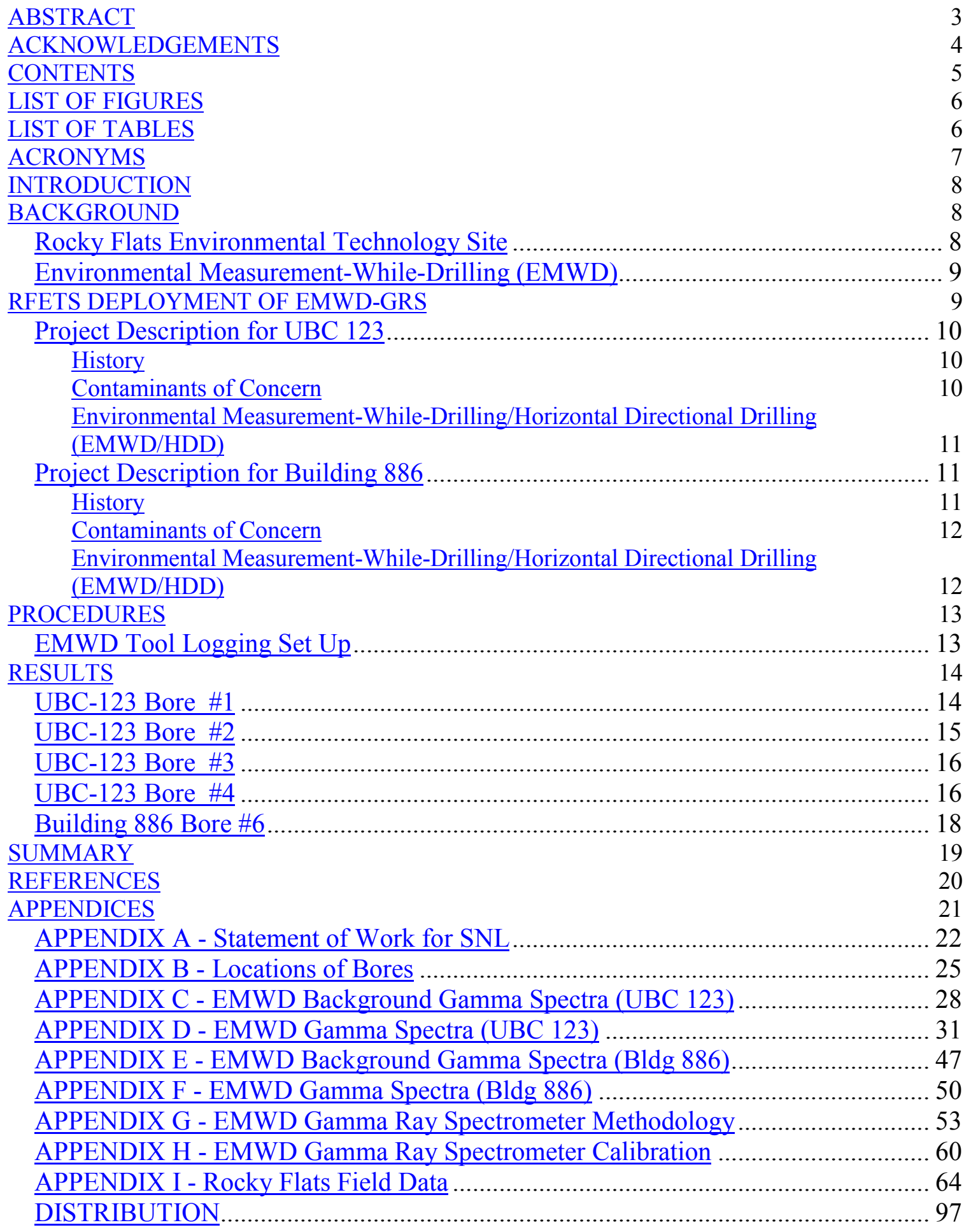




\section{LIST OF FIGURES}

Figure 1. Under Building Contamination 123: the ' $U$ ' shaped concrete slab is located in the center of the photograph.....................................................................................................................................................11

Figure 2. Building 886: building 886 is located behind the trailer..............................................................12

Figure 3. UBC-123 Gamma Spectrum background, Rockv Flats. .......................................................14

Figure 4. Cumulative Gamma Spectrum (13 spectra) from Bore 1 Sample 1, $20 \mathrm{ft}$ into bore...................15

Figure 5. Representative gamma spectrum for UBC-123 Bore \#2: Cumulative Gamma Spectrum (10

spectra) from Bore 2 Sample 6.....................................................................................................16

Figure 6. Representative gamma spectrum for UBC-123 Bore \#3: Cumulative Gamma Spectrum (10

spectra) from Bore 3 Sample 3.......................................................................................................................17

Figure 7. Representative gamma spectrum for UBC-123 Bore \#4: Cumulative Gamma Spectrum (10

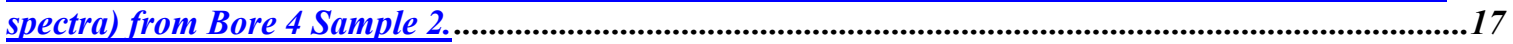

Figure 8. Building 886 Gamma Spectrum background, Rocky Flats...........................................................18

Figure 9. Representative gamma spectrum for Building 886 Bore \#6: Cumulative Gamma Spectrum (10

spectra) from Bore 6 Sample 2..................................................................................................................

\section{LIST OF TABLES}

Table 1: EMWD-GRS results from UBC-123 HDD Line \#2. ..................................................................15

Table 2: EMWD-GRS results from UBC-123 HDD Line \#3. ...................................................................16

Table 3: EMWD-GRS results from UBC-123 HDD Line \#4. ...................................................................117

Table 4: EMWD-GRS results from Building 886 HDD Line \#6. ............................................................18 


\section{ACRONYMS}

$\mathrm{AC}$

Am

$\mathrm{COC}$

Co

$\mathrm{CPM}$

$\mathrm{Cm}$

Cs

DC

D\&D

DOE

Em

EMWD

FM

GRS

HEUN

HDD

IDW

IHSS

$\mathrm{kHz}$

PAC

ppm

$\mathrm{Pu}$

RCRA

RFETS

SNL

UBC

$\mathrm{U}$

V alternating current

americium

contaminants of concern

cobalt

counts per minute

curium

cesium

direct current

Decommissioning and Deactivation

U.S. Department of Energy

Environmental Management

Environmental Measurement-While-Drilling

frequency modulated

Gamma Ray Spectrometer

Highly Enriched Uranyl Nitrate

Horizontal Directional Drilling

Investigative Derived Waste

Individual Hazardous Substance Site

kilo-hertz

Potential Area of Concern

Parts Per Million

Plutonium

Resource Conservation and Recovery Act

Rocky Flats Environmental Technology Site

Sandia National Laboratory

Under Building Contamination

uranium

Volt 


\section{Introduction}

Characterization is required on thirty-one buildings at Rocky Flats Environmental Technology Site (RFETS) with known or suspected under building contamination. (UBC). UBCs are a result of known spills, leaks, or building processes during years of production. Recent demonstrations performed at other Nuclear Weapons Facilities (e.g. Hanford and Savannah River Site) have proven successful in characterization of subsurface contamination using the Environmental Measurement-While-Drilling technology with horizontal directional drilling. Sandia National Laboratories teamed with these sites to conduct the successful demonstrations.

The RFETS has teamed with Sandia National Laboratory (SNL) to deploy Environmental Measure-While-Drilling (EMWD) in conjunction with horizontal directional drilling (HDD) to characterize under building contamination and to evaluate the performance and applicability for future characterization efforts. Data collected using EMWD/HDD will be compared to data collected by conventional geoprobe techniques. The project investigated two locations, Building 886 and Building 123. Building 886 is currently undergoing D\&D activities.

\section{Background}

The U.S. Department of Energy (DOE) Environmental Management (EM-50) has funded the development of the EMWD-GRS. During development, the EMWD-GRS system was tested at the U.S DOE radiation test facility in Grants, New Mexico and at the directional boring test site owned by Charles Machine Works in Perry, Oklahoma. The EMWD-GRS has been demonstrated at the Savannah River Site (SRS) F-Area Retention Basin. The EMWD-GRS with a Position Location Tool (PLT) was demonstrated at Hanford. The characterization activities at Rocky Flats represent the first deployment of the EMWD-GRS funded in part by Environmental Restoration (EM-40).

\section{Rocky Flats Environmental Technology Site}

The Rocky Flats Environmental Technology Site (RFETS or the Site) is located approximately 16 miles northwest of Denver, Colorado, in northern Jefferson County. RFETS comprises approximately 6,550 acres of land in Sections 1 through 4 and 9 through 15 of Township 2 South, Range 70 West, $6^{\text {th }}$ Principal Meridian. Major buildings are located within the industrial area, which encompasses approximately 400 acres and are surrounded by a buffer zone of approximately 6,150 acres. RFETS is government-owned, U.S. Department of Energy (DOE), contractor-operated facility in the nuclear weapons production complex. The former mission at RFETS was to produce components for nuclear weapons from plutonium, uranium, and nonradioactive materials.

The current mission is to safely close the Site under an aggressive schedule. The emphasis of closure is focused on Deactivation and Decommissioning (D\&D) activities for the remaining buildings that have the highest priority and critical path at this time. To accomplish closure in a timely fashion, characterization is required on thirty-one buildings across the Site with suspected or verified Under Building Contamination (UBCs). UBCs resulted from known spills, leaks, or building processes during the years of production. Characterization activities will be required to be conducted in parallel with D\&D activities in-order to meet the aggressive closure schedule. 


\section{Environmental Measurement-While-Drilling (EMWD)}

The Environmental Measurement-While-Drilling Gamma Ray Spectrometer with position location capability (EMWD-GRS) system represents an innovative blend of new and existing technology that produces the capability of providing real-time environmental and drill bit data during drilling operations. These real-time measurements provide technical data for field screening (i.e., "steering" the drill bit in or out of contaminated zones). There are also time, cost, and safety advantages to using the EMWD-GRS system's field screening approach: (1) data on the nature of contamination are available in minutes, as opposed to weeks or months for offsite confirmatory analysis; (2) substantial cost savings result by minimizing the number of samples required for off-site confirmatory analyses; and (3) worker safety is enhanced through the minimization of waste generated during drilling and by quickly alerting field personnel to potentially hazardous conditions; and (4) the amount of investigation derived waste (IDW) is reduced.

The EMWD-GRS system is compatible with a variety of directional drilling techniques that include (1) push systems that use minimal drilling fluids generating little or no secondary waste and (2) mud systems using rotary drilling or mud motors The down hole sensors are located behind the drill bit and are linked by a high-speed data transmission system to a computer at the surface. Windows ${ }^{\mathrm{TM}}$-based software, developed by Sandia National Laboratories, is used for data display and storage. During drilling operations, data on the nature and extent of contamination are collected. Instant access to the data provides information for on-site decisions regarding drilling and sampling strategies.

Down-hole components of the EMWD-GRS system being deployed consist of a gamma ray spectrometer, a multichannel analyzer, a $900 \mathrm{~V}$ power supply, a signal conditioning and transmitter board, and a coil containing coaxial cable for transmitting data to the surface. To protect them from the drilling environment, down-hole components are contained within O-ringsealed stainless steel tubes. The up-hole system consists of a personal computer, a battery pack/coil, a pickup coil, and a receiver. During drilling, the GRS system monitors (1) gamma radiation, (2) the $+12 \mathrm{~V}$ and $-12 \mathrm{~V}$ required at the down-hole signal conditioning and transmitter board, (3) the up-hole battery voltage as measured down-hole, and (4) two temperatures associated with the detector and instrumentation. The system design incorporates data quality assurance techniques to ensure data reliability.

The EMWD system can provide real-time data on an 8 differential/single analog multiplexer and on any number of digital channels. Sampling speed from the analog channels can reach $100 \mathrm{kHz}$. For the EMWD-GRS system, three digital channels are used. Readings are taken at a rate of 20 per second. The telemetry system is programmable firmware that can easily support many different data formats and additional data channels. The currently used format (Digital FM Bi-phase, 4800 baud) provides excellent noise rejection. A Sandia National Laboratories (SNL) designed receiver removes FM carrier noise, generates data clock, and buffers data to be used by an IBM or compatible personal computer. A $28 \mathrm{~V}$ rechargeable battery pack can supply down-hole instrumentation power for more than 18 hours of drilling. The battery pack remains topside for easy maintenance.

\section{RFETS Deployment of EMWD-GRS}

The RFETS teamed with Sandia National Laboratory (SNL) to use EMWD in conjunction with horizontal directional drilling to characterize under building contamination and to evaluate the performance and applicability for future characterization efforts. Data collected 
using horizontal directional drilling with real time measurement-while-drilling will be compared to data collected by conventional geoprobe techniques.

The project investigated two locations, UBC 123 and Building 886. UBC 123 was demolished in 1998; however, the slab is present with under building process waste lines and utilities. Building 886 is currently undergoing D\&D activities. A brief summary of the site history and contaminants of concern is given here.

Field activities met the following objectives:

- Characterize the under building contamination at Buildings 123 and 886

- Implement Sandia National Laboratories' real time measurement-while-drilling system (Environmental Measurement-While-Drilling) in conjunction with horizontal drilling to determine the effectiveness for characterizing under building contamination.

\section{Project Description for UBC 123}

UBC 123 (Figure 1) is located on Central Avenue between Third and Fourth Streets in the RFETS Industrial Area. In 1998 the building, which covered approximately 18,444 square feet, was D\&D. Utilities were either disconnected and abandoned in place or removed in their entirety during the demolition of the superstructure. Remaining structural components are the building slab on grade, perimeter grade beam and spread footings.

\section{History}

Building 123 was constructed in 1953 and was used as the Site Radiological Health Physics Laboratory. The lab analyzed water, biological materials, soil, air, and filter samples for the presence of plutonium, americium, uranium, alpha radiation, beta radiation, gamma radiation, tritium, beryllium, and organics. Personnel radiation badges were counted and repaired and in the building as well. Radiological low-level liquid and chemical wastes were generated at this location and transferred to the Site treatment system, Building 374, via the process waste lines system.

UBC 123 consists of several potential areas of contamination (PACs) and two Individual Hazardous Substance Sites (IHSSs)

- IHSS 121 - Original Process Waste Lines: process waste lines P-1, P-2 and P-3 (see Appendix I: Plates showing locations of Bores at UBC 123 and Building 886, Plate 2).

- IHSS 148 which was established due to possible leaks from line P-2 and reported nitrate-bearing spills along the east side of UBC 123.

\section{Contaminants of Concern}

While in service, the Site Radiological Health Physics Laboratory used a wide variety of chemical including acids, bases, solvents, metals, radionuclides, and other. Wastes from operations were transferred for disposal via the process waste lines. Radionuclides of concern 
include: various isotopes of plutonium $(\mathrm{Pu})$, americium $(\mathrm{Am})$, uranium $(\mathrm{U})$, and curium $(\mathrm{Cm})$. This report only addresses efforts to identify gamma-emitting contamination.

Figure 1. Under Building Contamination 123: the ' $U$ ' shaped concrete slab is located in the center of the photograph.

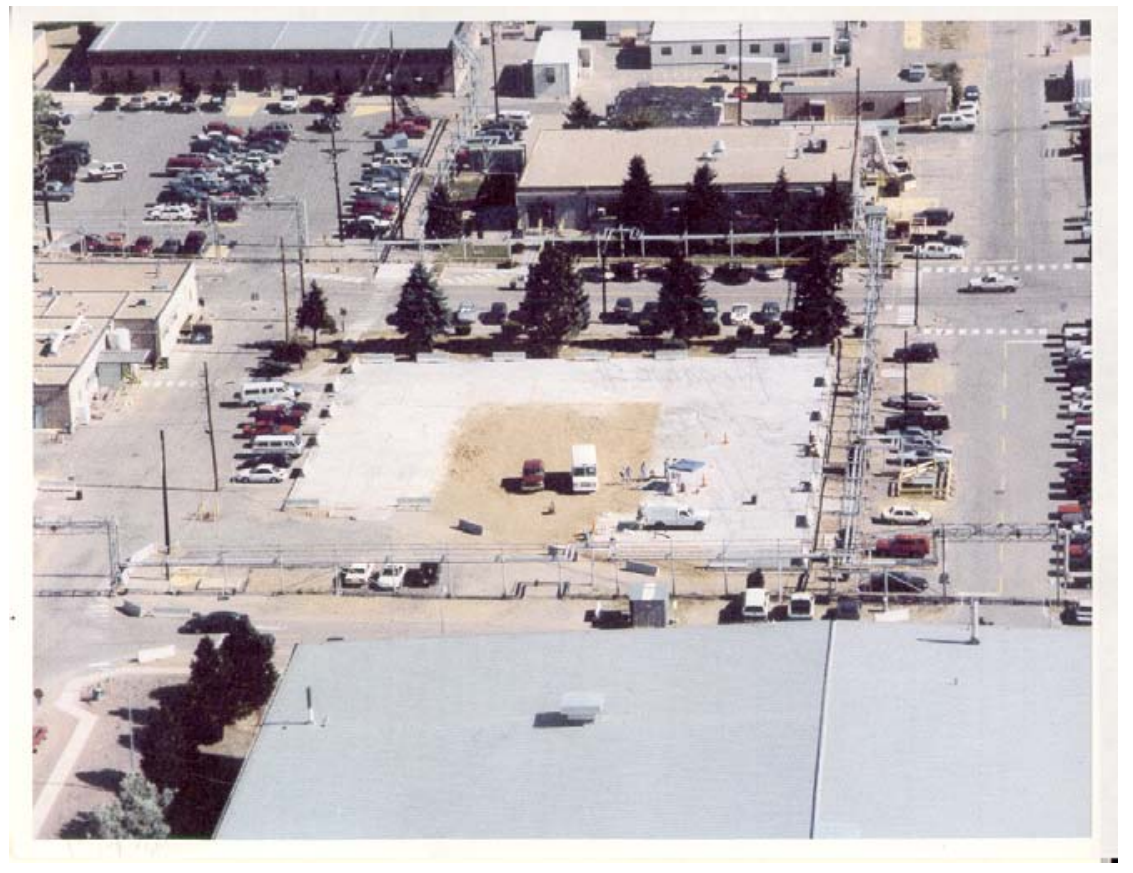

\section{Environmental Measurement-While-Drilling/Horizontal Directional Drilling (EMWD/HDD)}

Four HDD boring line locations (HDD Lines $1-4$ ) have been chosen for characterization of the soils immediately beneath and along the process waste lines, manholes, and sumps of UBC 123. Locations of the bores are shown in Appendix B, Plate \#1.

\section{Project Description for Building 886}

Building 886, located in the northeastern portion of the 800 Area (Figure 2), was put into service in 1965. The building is approximately 14,197 square feet. In approximately 1980, Trailer 886A was built immediately east of the building and was later connected by the existing breezeway. Trailer $886 \mathrm{~A}$ currently houses offices and a small electronics/machine shop. Various underground utilities are adjacent the building on the west side that are process waste lines that feed two underground storage tanks

\section{History}

Building 886 housed the Critical Mass Laboratory where low-level criticality experiments were performed on liquids, powder, and solid forms of fissionable materials. The date of the last criticality experiment was in October 1987. No operations are currently performed in Building 886 except for D\&D activities. Enriched uranium solutions, solid enriched uranium, and plutonium metal have been used in this building. Room 103 contained seven Highly 
enriched uranyl nitrate (HEUN) tanks and a tank storage pit. HEUN solutions were spilled numerous times in rooms 101 and 103 during operations. The HEUN solutions spills were decontaminated and followed by sealing the concrete floor with paint to fix any residual contamination. Fluctuations of high groundwater under the building have periodically permeated the floor slab and have stained the concrete floor in room 103 with yellow cake after groundwater subsidence. The process of decontamination and sealing the concrete surface was repeated a number of times. Individual Hazardous Substance Site 164.2 located around Building 886 perimeter, resulted from an incident on September 26, 1989 where a 500-gallon stainless steel tank was found leaking a colorless liquid from its drain valve onto a concrete surface.

Figure 2. Building 886: building 886 is located behind the trailer.

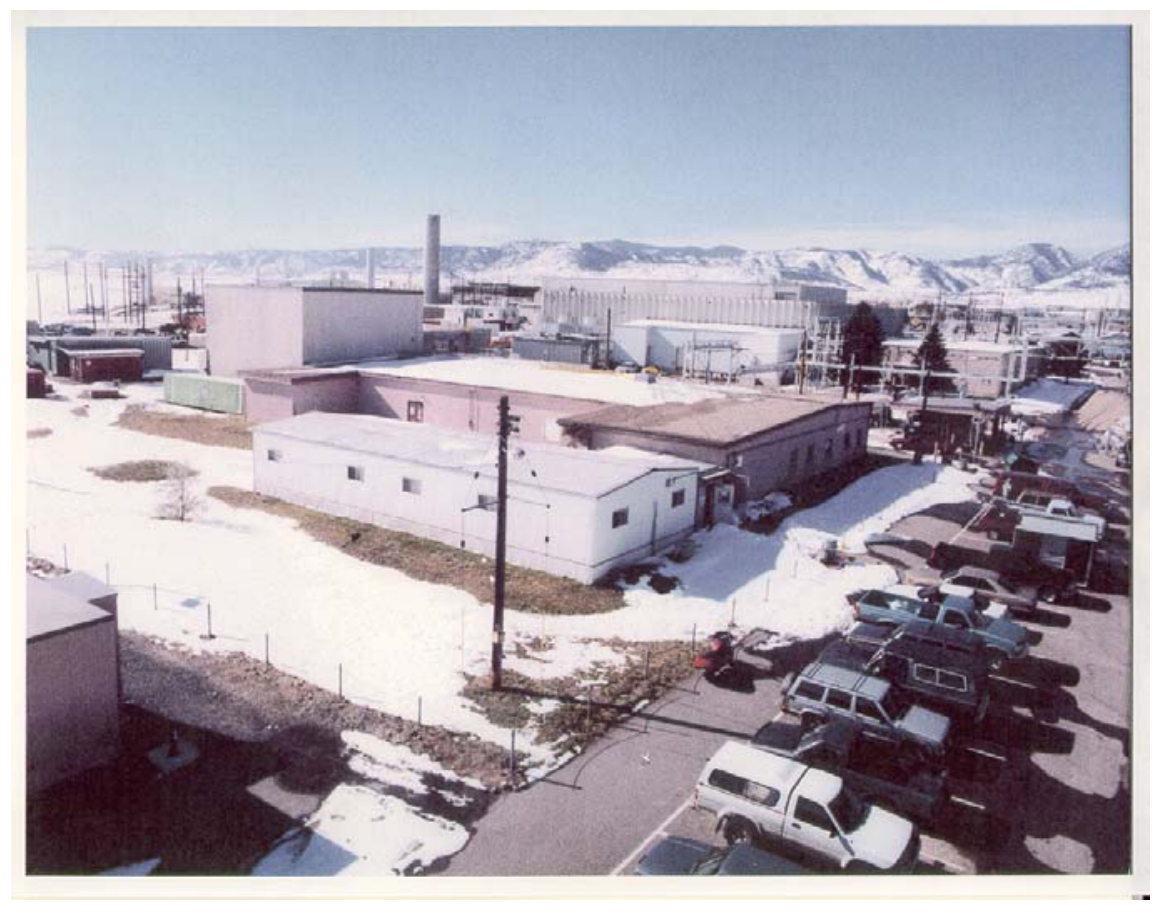

\section{Contaminants of Concern}

The primary contaminants of concern at Building 886 based on past operational history are metals and radionuclides. The specific radionuclides of concern include: $\mathrm{Pu}-239 / 240$, U233/234, U-235, U-238, and Am-241).

\section{Environmental Measurement-While-Drilling/Horizontal Directional Drilling (EMWD/HDD)}

The EMWD/HDD effort was conducted on the east side due to underground utilities on the west side of the building. Two horizontal directional boreholes, HDD line 5-6, were planned for this facility (See Appendix B, Plate \#2). Room 101 is the criticality laboratory with perimeter walls that are constructed of reinforced concrete and 4 feet thick. These walls extend below grade approximately five feet deep and are heavily reinforced with \#6 and \#8 rebar at twelve inches on center each way. HDD Line 5 was not attempted because of the possible high levels of HEUN contamination. 


\section{Procedures}

The calibration of the EMWD-GRS was conducted in a steel pipe. It was calibrated in the laboratory at Sandia National Laboratories using Cs-137, Co-60, and Na-22. It was also calibrated at the Field Calibration Facility for Environmental Measurement of radium, thorium, and potassium, DOE Grants Calibration Site, Grants, NM. The tool was calibrated using the thorium source and the potassium-40 source. The calibration curves age given in Appendix $\mathrm{H}$ : EMWD Gamma Ray Spectrometer Calibration.

RFETS selected Microtunneling as the directional drilling method. The Microtunneling technique uses a pneumatic hammer to develop the bore and install casing. This method was selected because it used no drilling fluid

EMWD, designed for use with rotating drilling methods, has never been tested in this environment. We had the following concerns using EMWD with the microtunneling:

- the pneumatic hammer would subject the EMWD tool to a shock environment for which it has not been tested;

- the magnetometer, for position location, could not be used;

- the Gamma spectrometer will be $\sim 3 \mathrm{ft}$ behind bit;

- cable handling would be a problem; and

- mounting the battery pack, that supplies power to the tool, would be an issue.

An alternative use of EMWD for Rocky Flats Deployment was devised. The following procedure was developed:

- A walkover position indicator is used to track drill bit position

- The casing would be emplaced to the first sampling point with the pneumatic hammer, without EMWD

- Pull out pneumatic hammer

- Push in EMWD, log hole as EMWD tool is withdrawn

- Push in sampler and take soil sample

- Re-insert pneumatic hammer to emplace casing to the next sampling point.

This procedure does not subject the EMWD tool to shock, but provides for real-time data on gamma contamination prior to taking soil sample. This was a completely new type of deployment of the EMWD tool. The method operation of the EMWD tool will not is given here, but can be found in Reference 4 .

\section{EMWD Tool Logging Set Up}

The following procedure was used to collect gamma spectra in the RFETS bores:

1) EMWD tool set-up

a) The EMWD tool is placed in a PVC housing.

b) The tool is secured to the PVC housing so that tool does not turn and twist the cable off.

2) The EMWD tool is pushed into the open hole to the bit face, sampling point.

3) Data collection:

a) Collect EMWD spectra at this point for 5 minutes. 
b) Pull the EMWD tool out 1 foot, collect 1 spectrum. If no contamination is detected, continue this procedure until the tool reaches the next sampling point or exits the hole.

c) Repeat this procedure for each sampling point.

\section{Results}

\section{UBC-123 Bore \#1}

UBC-123 HDD Line \#1, located on the west side of UBC-123 and runs north-south (See Appendix B: Plates Showing Locations of Bores at UBC-123 and Building 886) was to be approximately 110 feet long and with seven soil samples to be taken. Background gamma spectra of the UBC-123 area were collected (Figure 3). The next spectra were taken at $20 \mathrm{ft}$ (not a soil sampling point) into the bore (Figure 4). Comparison of Figures 3 and 4 indicate no readings above background at the $20 \mathrm{ft}$ location. (Note: Only representative gamma spectra are included in the body of the report. The complete set of gamma spectra for all the soil sampling points are provided in Appendix D: EMWD Gamma Spectra for UBC 123 and Appendix D: EMWD Gamma Spectra for Building 886).

The next tool insertion was to be at $80 \mathrm{ft}$, the first soil sample point 1-01. Eighty feet was not achieved. A concrete footer was hit at $\sim 40 \mathrm{ft}$ and could not be penetrated and the driller was having trouble getting depth reading from his locator tool. UBC-123HDD Line \#1 was abandoned in place at the $40 \mathrm{ft}$ point because the foundation wall of the building extension could not be penetrated.

Before pulling away from the first bore site, bore \#1 was logged. The tool was pulledback one foot at a time and a spectrum was taken. This was the technique use to fully log the remaining bores. A few representative samples of these spectra are given in Appendix D: EMWD Gamma Spectra for UBC 123 HHD \#1. These spectra are essentially the same as the background spectra.

Figure 3. UBC-123 Gamma Spectrum background, Rocky Flats.

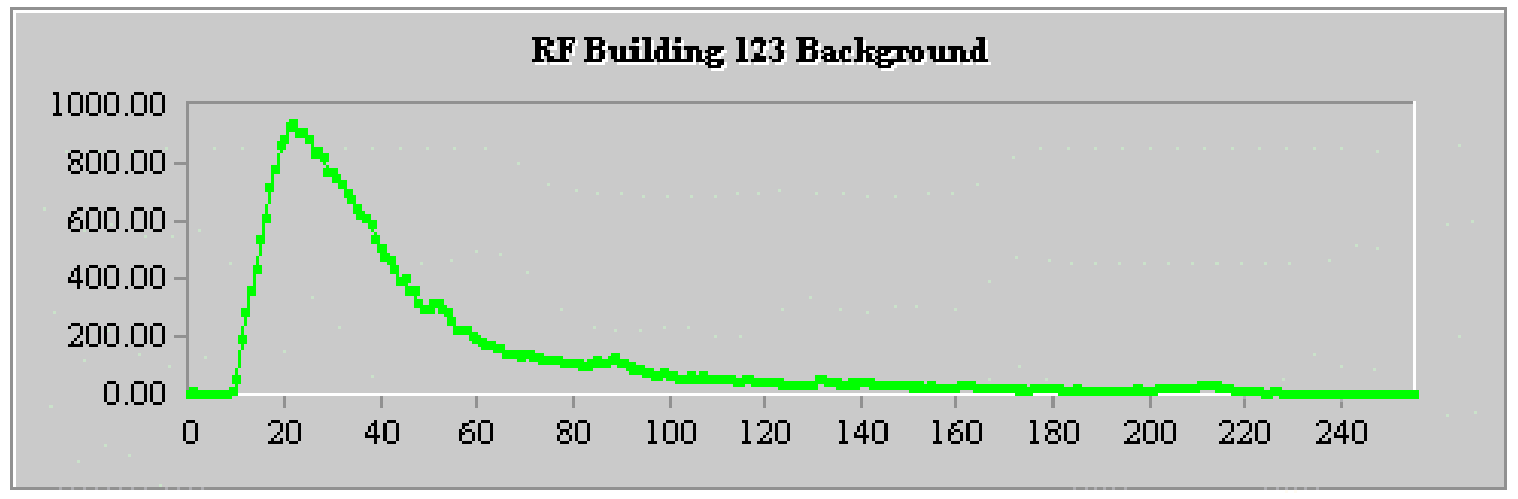


Figure 4. Cumulative Gamma Spectrum (13 spectra) from Bore 1 Sample 1, 20 ft into bore.

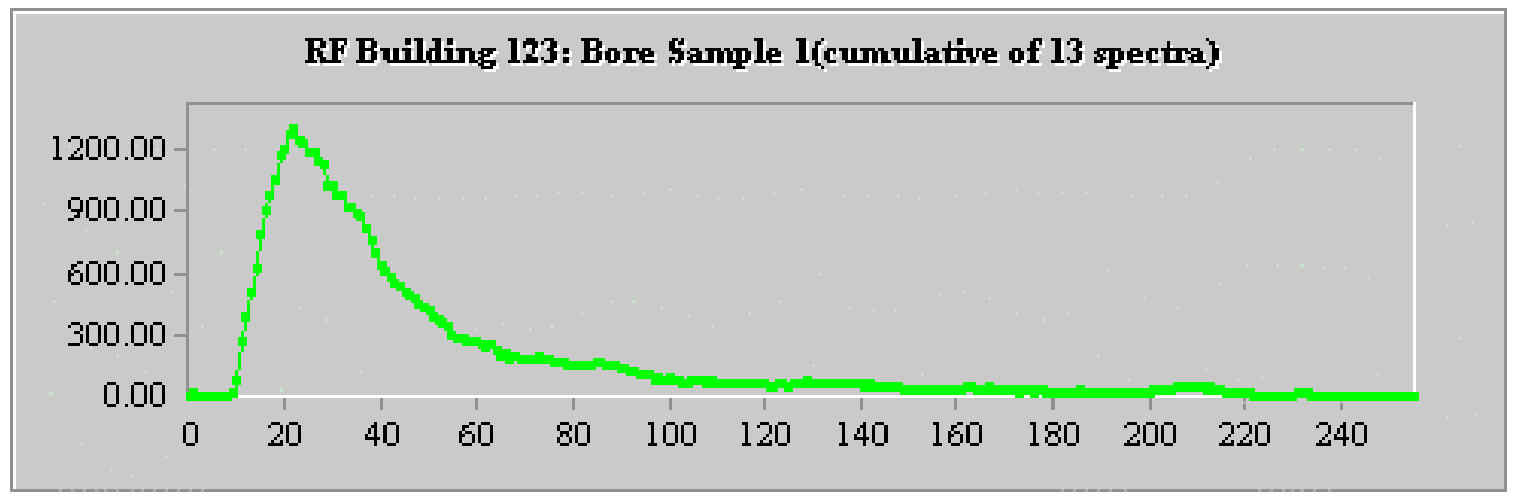

\section{UBC-123 Bore \#2}

UBC-123 HDD Line \#2 was to be approximately 190 feet long and thirteen soil samples were to be extracted (See Appendix B: Plates Showing Locations of Bores at UBC-123 and Building 886). HDD Line \#2 is on the east side of the site and runs north south. This bore was completed to 126 feet at HDD \#2 soil sample point 10. This bore was abandoned at this point because the casing was bent and further advancement could not be achieved.

Table 1 correlates the gamma spectra sampling locations with the soil sample locations and feet advanced. Sample point HDD Line \#2-02 coincides with sampling point HDD Line \#406 . No gamma spectra were taken at UBC-123 HDD Line \#2-02. Gamma spectral data for this point was taken onUBCu-123 HDD Line \#4-06. Gamma spectra were collected at the soil sampling points and at $1-\mathrm{ft}$ intervals between the soil sampling points. No gamma emitting contamination was detected anywhere along this bore. A representative gamma spectrum from UBC-123 HDD Line \#2 indicating this fact is shown in Figure 5. Figure 5 is accumulative gamma spectrum of 10 gamma spectra collected at soil sampling point UBC-123 HHD Line \#206 The gamma spectra for each soil sampling point of UBC-123 HDD Line \#2 are given in Appendix D: EMWD Gamma Spectra for UBC-123. The gamma spectra gathered at the 1-ft intervals are not included in this report since no gamma contamination was detected.

Table 1: EMWD-GRS results from UBC-123 HDD Line \#2.

\begin{tabular}{|c|c|c|c|}
\hline Soil Sampling Number & Location (feet advanced) & EMWD-GRS Number & Results of GRS Reading \\
\hline HDD \#2-01 & 10 & 1 & No contamination detected \\
\hline HDD \#2-03 & 27 & 2 & No contamination detected \\
\hline HDD \#2-04 & 42.3 & 3 & No contamination detected \\
\hline HDD \#2-05 & 54.4 & 4 & No contamination detected \\
\hline HDD \#2-06 & 74 & 5 & No contamination detected \\
\hline HDD \#2-07 & 92.3 & 6 & No contamination detected \\
\hline HDD \#2-08 & 100 & 7 & No contamination detected \\
\hline HDD \#2-08 & 102 & 8 & No contamination detected \\
\hline HDD\#2-10 & 126 & 9 & No contamination detected \\
\hline
\end{tabular}


Figure 5. Representative gamma spectrum for UBC-123 Bore \#2: Cumulative Gamma Spectrum (10 spectra) from Bore 2 Sample 6.

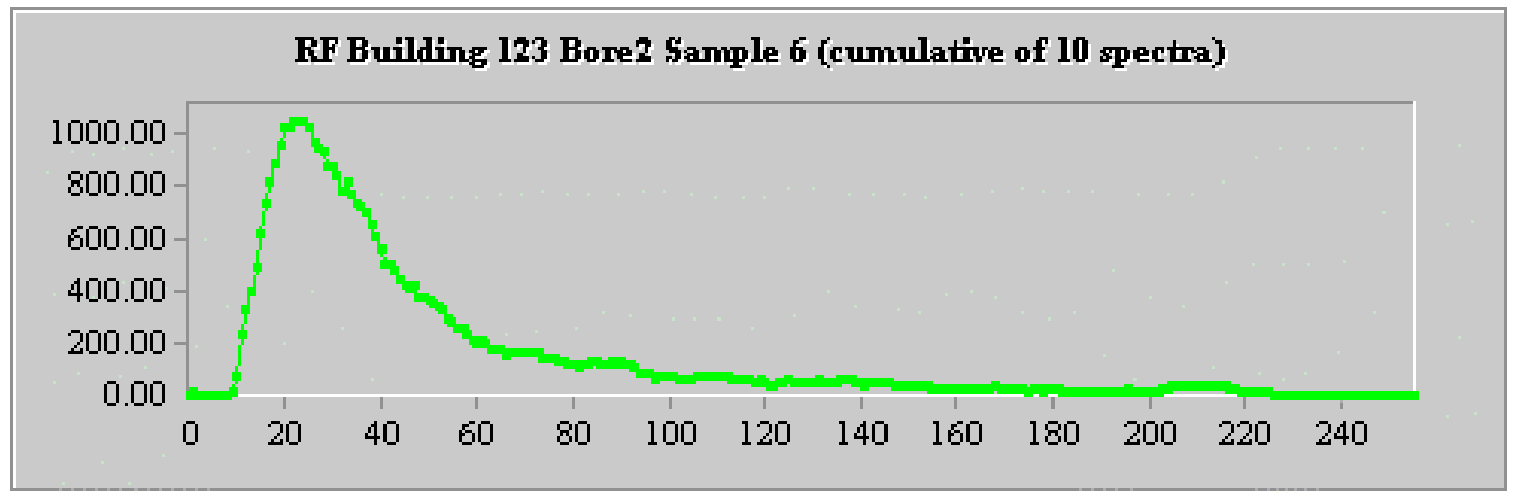

\section{UBC-123 Bore \#3}

UBC-123 HDD Line \#3 was to be approximately 150 feet long and eleven soil samples were to be extracted. HDD Line \#3 is on the south side of the site and runs east-west (See Appendix B: Plates Showing Locations of Bores at UBC-123 and building 886). This bore was completed to 63 feet at HDD \#3 soil sample point 5. This bore was abandoned at this point because the casing was bent and further advancement could not be achieved.

Table 2 correlates the gamma spectra sampling locations with the soil sample locations and feet advanced. Gamma spectra were collected at the sampling points and at 1-ft intervals between the sampling points. No gamma emitting contamination was detected anywhere along this bore. A representative gamma spectrum from UBC-123 HDD Line \#3 indicating this fact is shown in Figure 6. Figure 6 is accumulative gamma spectrum of 10 gamma spectra collected at soil sampling point UBC-123 HHD Line \#3-03. The gamma spectra for each soil sampling point of UBC-123 HDD Line \#3 are given in Appendix D: EMWD Gamma Spectra for UBC 123.

Table 2: EMWD-GRS results from UBC-123 HDD Line \#3.

\begin{tabular}{|c|c|c|c|}
\hline Soil Sampling Number & Location (feet advanced) & EMWD-GRS Number & Results of GRS Reading \\
\hline HDD \#3-02 & 18 & 2 & No contamination detected \\
\hline HDD \#3-03 & 33 & 3 & No contamination detected \\
\hline HDD \#3-04 & 48 & 4 & No contamination detected \\
\hline HDD \#3-05 & 63 & 5 & No contamination detected \\
\hline
\end{tabular}

\section{UBC-123 Bore \#4}

UBC-123 HDD Line \#4 was to be approximately 85 feet long and six soil samples were to be extracted. HDD Line \#4 is on the north side of the site and runs east-west (See Appendix B: Plates Showing Locations of Bores at UBC-123 and Building 886). This bore was completed in its entirety. 
Figure 6. Representative gamma spectrum for UBC-123 Bore \#3: Cumulative Gamma Spectrum (10 spectra) from Bore 3 Sample 3.

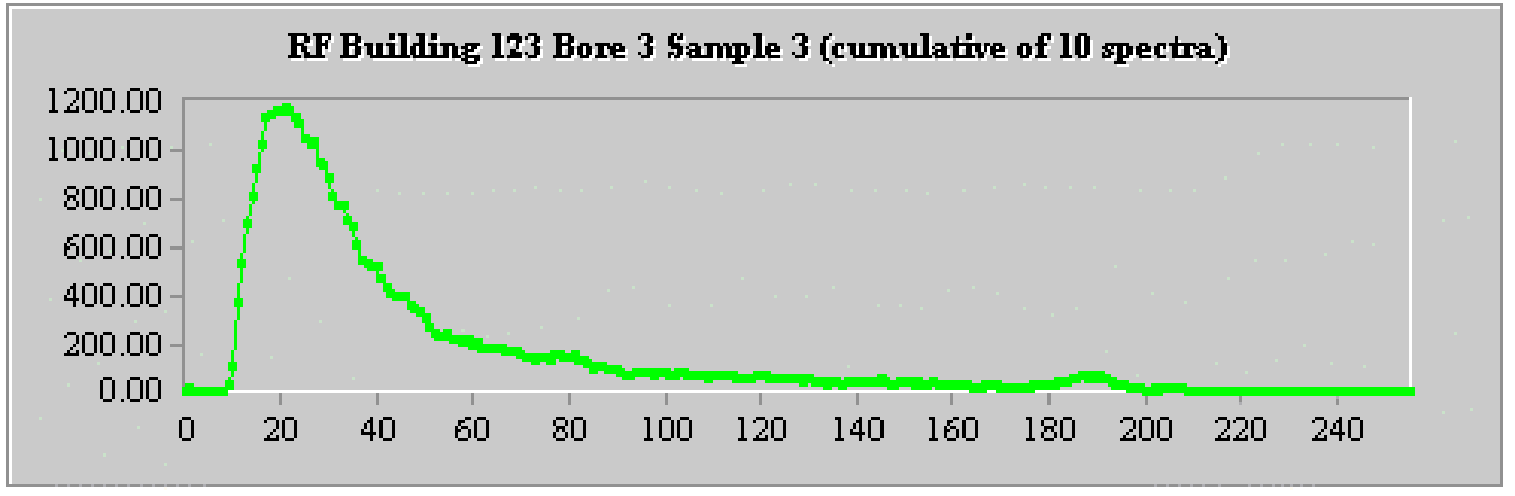

Table 3 correlates the gamma spectra sampling locations with the soil sample locations and feet advanced. Gamma spectra were collected at the soil sampling points and at 1-ft intervals between the soil sampling points. No gamma emitting contamination was detected anywhere along this bore. A representative gamma spectrum from UBC-123 HDD Line \#4 indicating this fact is shown in Figure 7. Figure 7 is accumulative gamma spectrum of 10 gamma spectra collected at soil sampling point UBC-123 HHD Line \#3-03. The gamma spectra for each soil sampling point of UBC-123 HDD Line \#3 are given in Appendix D: EMWD Gamma Spectra for UBC 123.

Table 3: EMWD-GRS results from UBC-123 HDD Line \#4.

\begin{tabular}{|c|c|c|c|}
\hline Soil Sampling Number & Location (feet advanced) & EMWD-GRS Number & Results of GRS Reading \\
\hline HDD \#4-01 & 112 & 6 & No contamination detected \\
\hline HDD \#4-02 & 102 & 5 & No contamination detected \\
\hline HDD \#4-03 & 87 & 4 & No contamination detected \\
\hline HDD \#4-04 & 72 & 3 & No contamination detected \\
\hline HDD \#4-05 & 53 & 2 & No contamination detected \\
\hline HDD \#4-06 & 42 & 1 & No contamination detected \\
\hline
\end{tabular}

Figure 7. Representative gamma spectrum for UBC-123 Bore \#4: Cumulative Gamma Spectrum (10 spectra) from Bore 4 Sample 2.

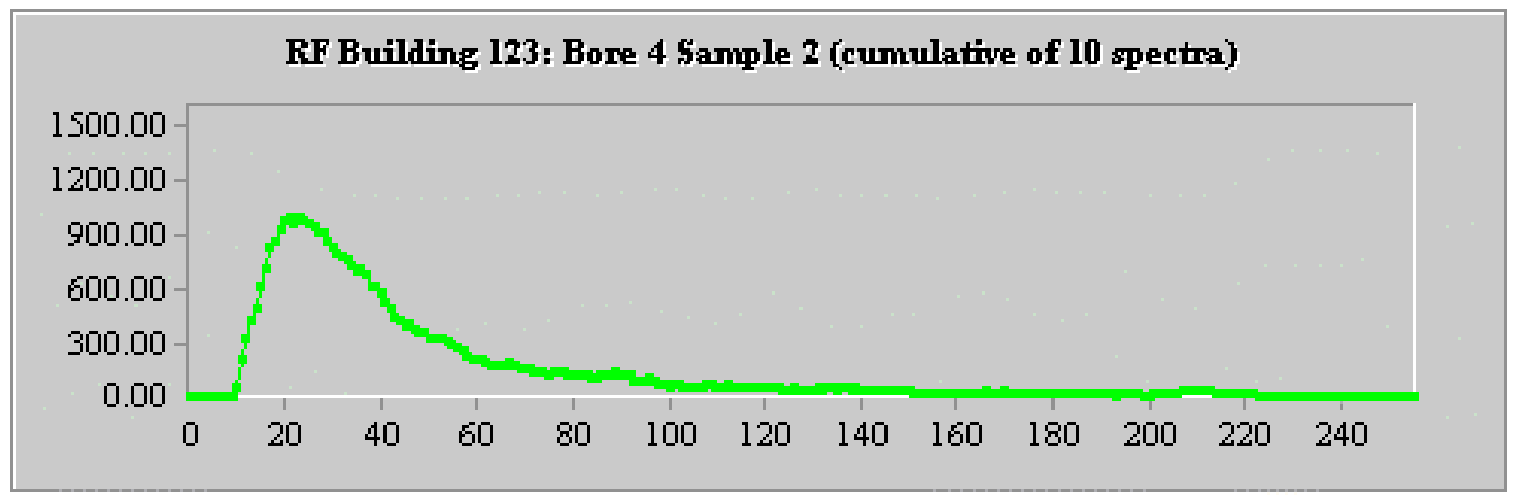




\section{Building 886 Bore \#6}

Building 886 HDD Line \# 6 was to be approximately 40 feet long and extract four soil samples as shown on Plate. This line went under the north end room 101 and runs east-west. (See Appendix B: Plates Showing Locations of Bores at UBC-123 and Building 886). This bore was completed to 18 feet at HDD \#6 soil sample point 2. This bore was abandoned at this point because further advancement could not be achieved.

Background gamma spectra of the Building 886 area were collected (Figure 8). Table 4 correlates the gamma spectra sampling locations with the soil sample locations and feet advanced. Gamma spectra were collected at the sampling points and at 1-ft intervals between the sampling points. No gamma emitting contamination was detected anywhere along this bore. A representative gamma spectrum from Building 886 HDD Line \#6 indicating this fact is shown in Figure 9. Figure 9 is accumulative gamma spectrum of 10 gamma spectra collected at soil sampling point Building 886 HHD Line \#6-03. The gamma spectra for each soil sampling point of Building 886 HDD Line \#6 are given in Appendix F: EMWD Gamma Spectra for Building 886.

Table 4: EMWD-GRS results from Building 886 HDD Line \#6.

\begin{tabular}{|c|c|c|c|}
\hline Soil Sampling Number & Location (feet advanced) & EMWD-GRS Number & Results of GRS Reading \\
\hline HDD \#6-02 & 18 & 1 & No contamination detected \\
\hline HDD \#6-01 & 10 & 2 & No contamination detected \\
\hline HDD \#6-bore opening & 0 & 2 & No contamination detected \\
\hline
\end{tabular}

Figure 8. Building 886 Gamma Spectrum background, Rocky Flats.

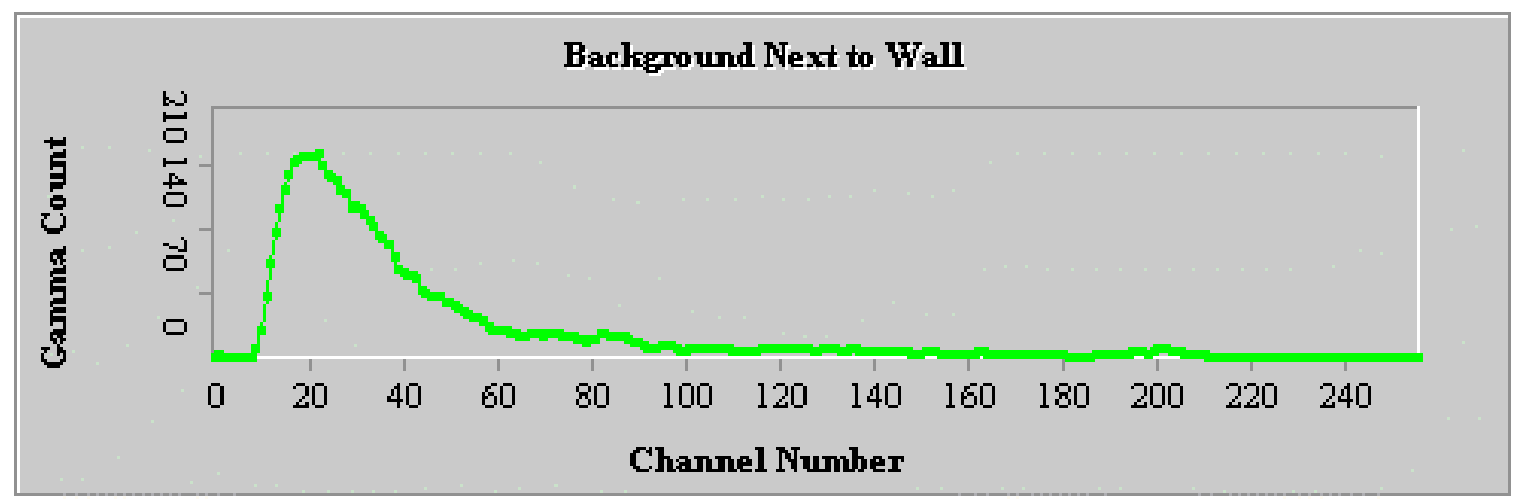


Figure 9. Representative gamma spectrum for Building 886 Bore \#6: Cumulative Gamma Spectrum (10 spectra) from Bore 6 Sample 2.

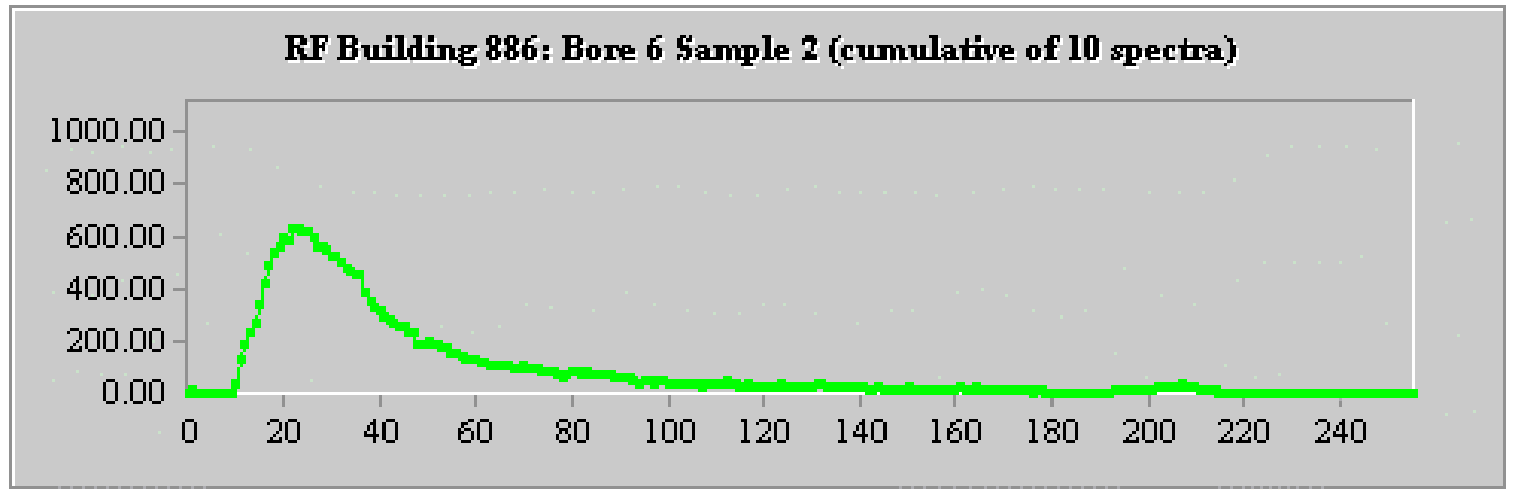

\section{SUMMARY}

Five bores were drilled at two sites at the Rocky Flats Environmental Technology Site, four under UBC-123 and one under Building 886. The bores were developed using a microtunneling technique that uses a pneumatic hammer with no drilling fluid to advance the bore and install casing. Since the EMWD-GRS tool was not designed for this type of drilling, there were several concerns not the least of which the EMWD-GRS tool has never been tested in this type of shock environment. Additionally, since steel casing was installed, the EMWD-GRS position location capability could not be used. The EMWD-GRS tool was used to log the boreholes for gamma emitting contaminants prior to taking each soil sample.

Only one of the five bore attempted was completed in its entirety. The EMWD-GRS tool was used to $\log$ the bores for gamma emitting contaminants. No gamma emitting contaminants were detected. 


\section{REFERENCES}

1. G. J. Lockwood, R. A. Normann, L. K Bishop, R. J. Floran, and C. V. Williams, (1995) Environmental Measurement-While-Drilling System for Real-Time Field Screening Contaminants, NO-DIG '95, Toronto, Canada, April 30-May 3, 1995.

2. G. J. Lockwood, R. A. Normann, L. B. Bishop, M. M. Selph, and C. V. Williams, (1996) Environmental Measurement-While-Drilling System for Real-Time Field Screening of Contaminant IIs, SAND 99-0460C, presented at the ADPA 22nd Environmental Symposium and Exhibition, Orlando, FL, March 1996.

3. C. V. Williams, G. J. Lockwood, and R. A. Normann, Environmental Measurement-WhileDrilling System for Real-Time Field Screening of Contaminants III, (1996) SAND99-0461C, Spectrum '96, Seattle, WA, August 18-23, 1996.

4. C. V. Williams, G. J. Lockwood, R. A. Normann, and R. Gruebel, (1996) Environmental Measurement-While-Drilling-Gamma Ray Spectrometer System Technology Demonstration Plan for use at Savannah River Site F-Area Retention Basin, SAND-2019. Sandia National Laboratories, Albuquerque, NM.

5. G. J. Lockwood, R. A. Normann, and C. V. Williams (1997) Final Report of the Environmental Measurement-While Drilling-Gamma Ray Spectrometer System Technology Demonstration at the Savannah River Site F-Area Retention Basin, SAND97-2028, Sandia National Laboratories, Albuquerque, New Mexico.

6. R. A. Normann, G. J. Lockwood, C. V. Williams, and M. M. Selph (1998) "Integration and Evaluation of a Position Sensor with Continuous Read-out for use with the Environmental Measurement-While-Drilling Gamma Ray Spectrometer System, SAND98-0476C, North American No Dig '98, Albuquerque, NM, April 1998.

7. C. V. Williams, G. J. Lockwood, and R. A. Normann, D. A. Myers. M. G. Gardner, T. Williamson, and J Huffman, Environmental Measurement-While-Drilling System and Horizontal Directional Drilling Technology Demonstration, Hanford Site, SAND99-1479, Sandia National Laboratories, Albuquerque, New Mexico.

8. R. Leino, D. C. George, B. N. Key, L. Knight, and W. D. Steele, (1994) Field Calibration Facilities of Environmental Measurement of Radium, Thorium, and Potassium, Doe/ID/12584179; GJ/TMC-01 (Third Edition). RUST Geotech, Inc., Grand Junction, CO, 1994.

9. B. Shleien, (1992) The Health Physics and Radiological Health Handbook (Revised Edition). Scinta Inc., Silver Spring, MD, 1992.

10. Statement of Work for Characterization for Characterization of Under-building Contamination (UBC) at UBC 123 and Building 886 Implementing Horizontal Directional Drilling (HDD) Environmental Measurement-While-Drilling (EMWD) Process, Kaiser Hill L.L.C., February 2000 


\section{APPENDICES}

A. Statement of Work for Sandia National Laboratories Implementing Environmental Measurement-While-Drilling at UBC 123 and Building 886.

B. Plates showing locations of Bores at UBC 123 and Building 886

C. EMWD Background Gamma Spectra: UBC 123

D. EMWD Gamma Spectra for UBC 123

E. EMWD Background Gamma Spectra: Building 886

F. EMWD Gamma Spectra for Building 886

G. EMWD Gamma Ray Spectrometer Calibration Methodology

H. EMWD Gamma Ray Spectrometer Calibration

I. Rocky Flats Field Notes 


$$
\text { APPENDIX A - Statement of Work for SNL }
$$

Statement of Work for Sandia National Laboratories Implementing Environmental Measurement-While-Drilling at UBC 123 and Building 886 


\section{Statement of Work}

\subsection{Introduction}

Sandia National Laboratories is working jointly with personnel at Rocky Flats to deploy the Environmental Measurement-While-Drilling (EMWD) system. The EMWD system is normally used while drilling. A number of factors resulted in the EMWD tool not being used while drilling for this deployment. In stead, the Rocky Flats drilling contractor will drill the hole without the EMWD tool. When the hole is completed or before a soil sample is taken, the Sandia EMWD tool will be manually placed into the hole using plastic tubing. With the tool in the hole, Sandia and Sandia contracted personnel will measure the wellbore gamma radiation levels.

The gamma radiation measurement is a full 256-channel spectrum. This data will be recorded in a Sandia supplied PC and Sandia software. If any notable radiation levels are detected, Sandia personnel will report and document their reading to Rocky Flats personnel. The Rocky Flats personnel will take appropriate action.

\subsection{Scope of Work}

2.1 Prior to deployment, Sandia will calibrate the EMWD for sub-surface gamma measurement. This calibration will be performed at the DOE calibration facility in Grants, NM.

\subsection{Field Deployment of the EMWD}

Sandia will supply one EMWD system and two appropriately trained personnel to the Rocky Flats Environmental Technology site. The Sandia and Sandia contracted personnel will support and/or assist in the deployment of the EMWD system to survey possible radioactive waste. Typical Sandia personnel duties may include:

- Assist in or perform placing the EMWD tool into the hole

- Record the measured results

- Report results to appropriate personnel

\subsection{Training}

The Sandia personnel are required to have a combination of 40-hour HAZWOPER with current HAZWOPER 8-hour refresher, DOE certificate of radiological training RW II, and complete site specific training ON site at Rocky Flats prior to start of work. 


\subsection{Task Control}

Cecelia Williams, Department 6803, is the designated Task Leader and will be consulted for approval if technical decisions concerning the scope of the work are needed. Randy Normann will provide the day-to-day interface.

4.0 Deliverables

4.1 Sandia will provide radiation spectrums from calibration testing at Grants NM.

4.2 Sandia will provide timely radiation measurements prior to drilling contractor soil sampling.

4.3 Sandia will provide a record of gamma reading taken within 6 months following completion of the Rocky Flats deployment.

5.0 Expected level of funding from Rocky Flats to support this activity is $\$ 55 \mathrm{~K}$.

5.1 Calibration at Grants NM

5.2 Field support personnel for up to consecutive 6 weeks

5.3 Final report providing the entire gamma record for the deployment 
APPENDIX B - Locations of Bores

\section{Plates showing locations of Bores at UBC 123 and Building 886}


APPENDIX C - EMWD Background Gamma Spectra (UBC 123)

\section{EMWD Background Gamma Spectra Calibration:}

UBC 123 
Figure C1a: Lab Calibration-Gamma Spectrum of K-40.

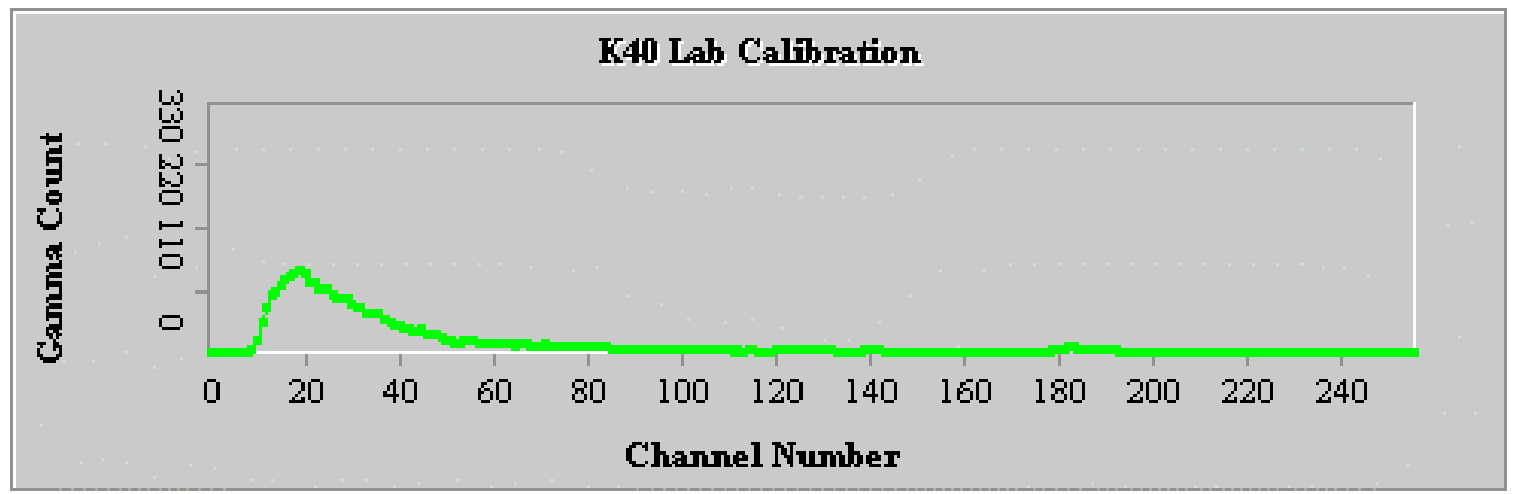

Figure C1b: Lab Calibration-Cumulative Gamma Spectrum (14 spectra) of K-40.

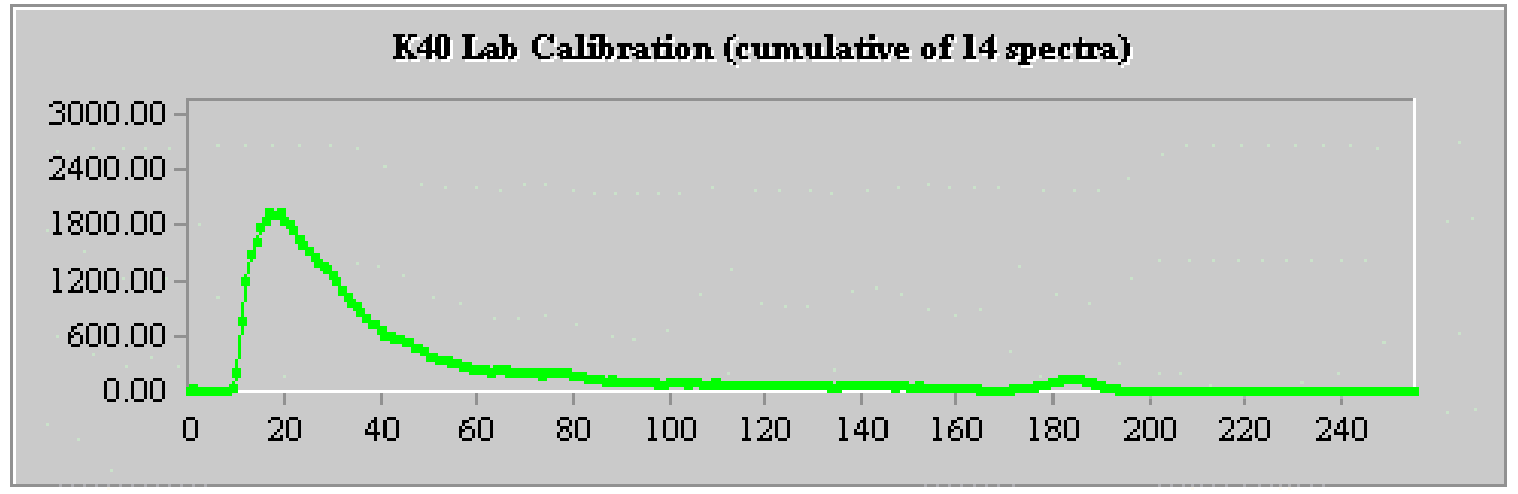

Figure C2a: Field Calibration-Gamma Spectrum of K-40 at UBC 123

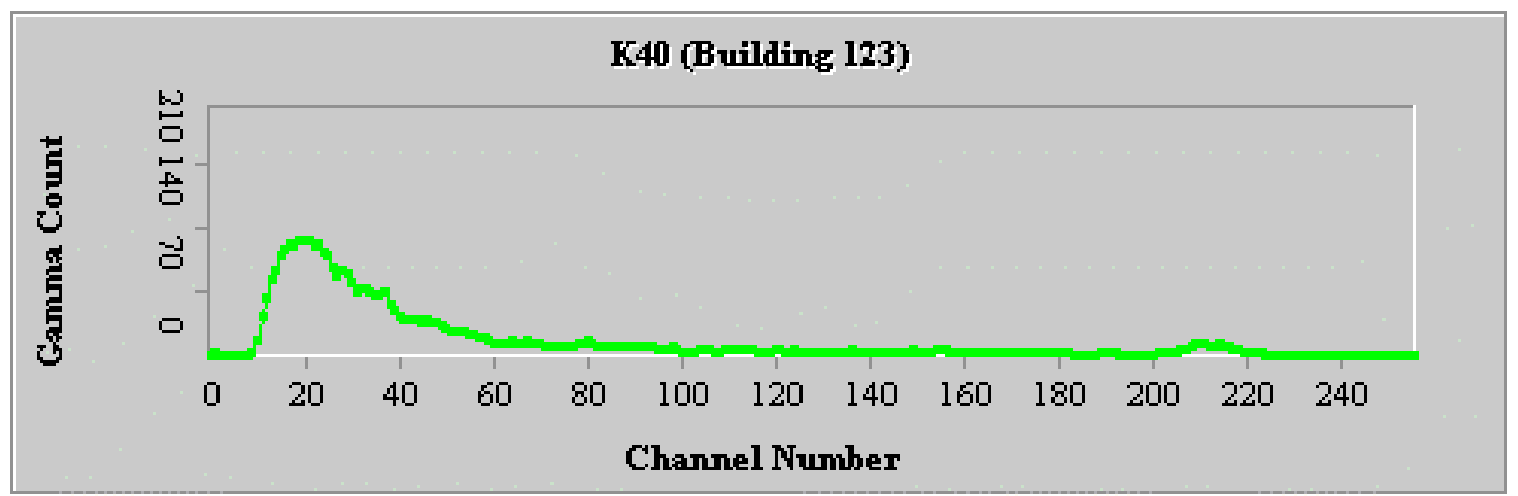


Figure C2b: Field Calibration-Cumulative Gamma Spectrum (8 spectra) of K-40 at UBC 123

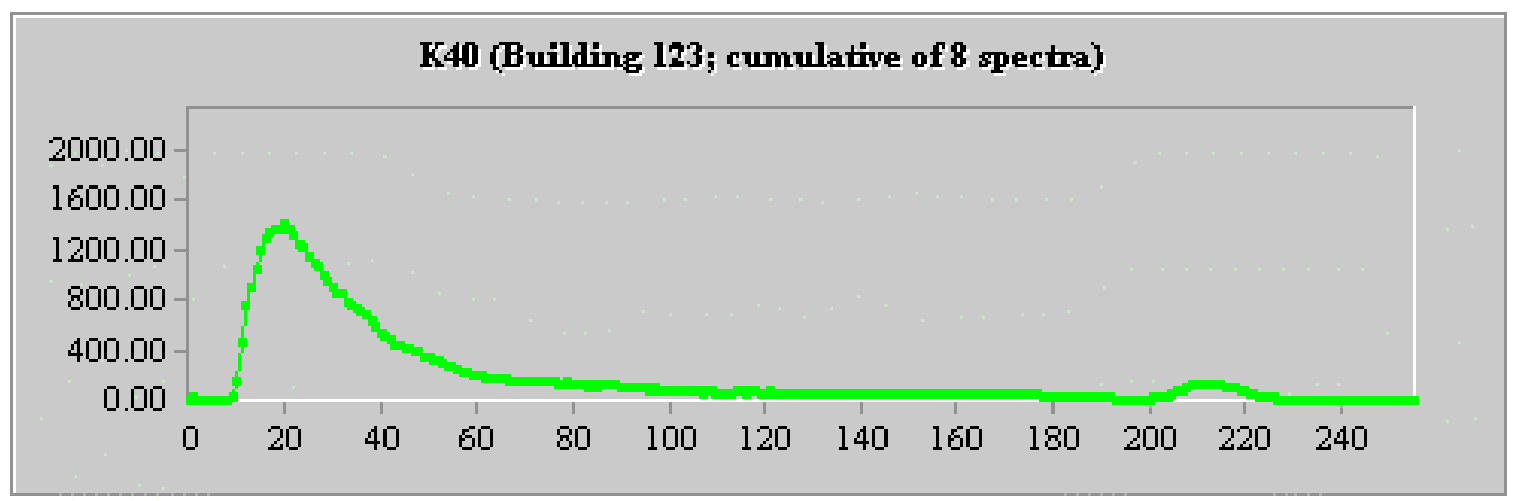

Figure C3a: Field Background Calibration-Gamma Spectrum of K-40 at UBC 123

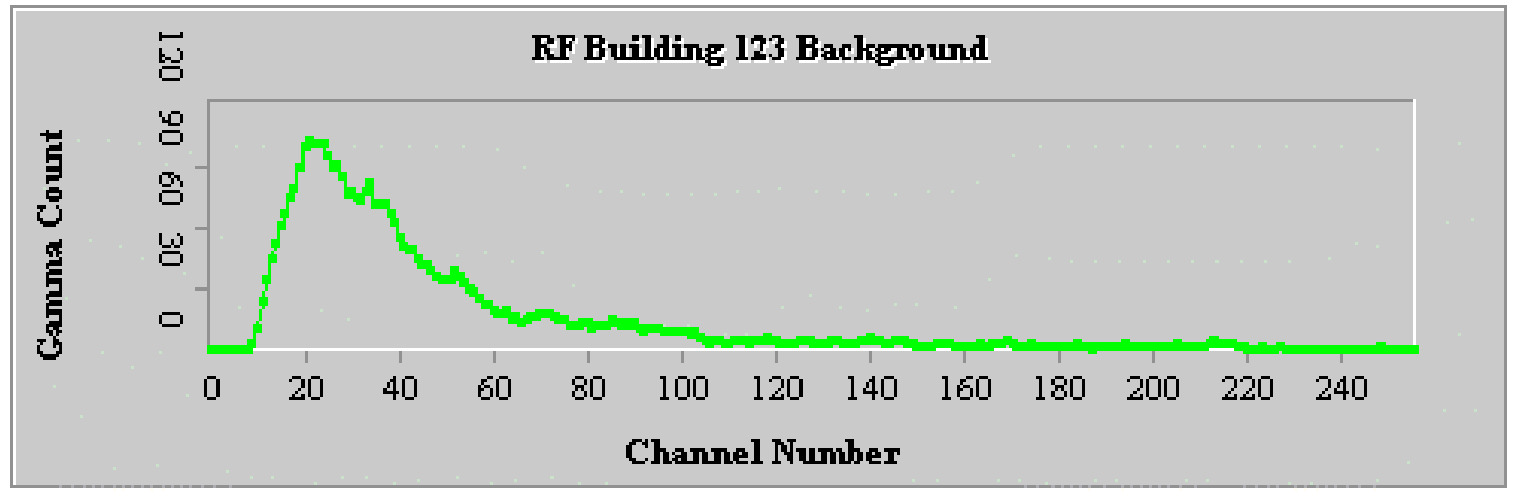

Figure C2b: Field Background Calibration-Cumulative Gamma Spectrum ( 8 spectra) of K-40 at UBC 123

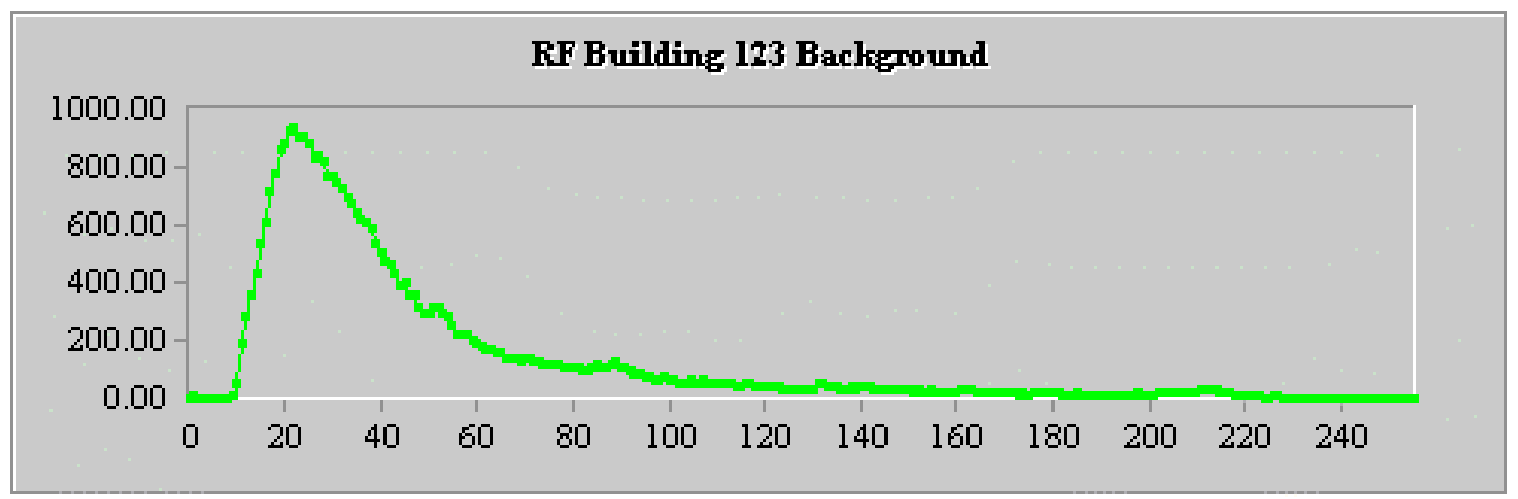


APPENDIX D - EMWD Gamma Spectra (UBC 123)

EMWD Gamma Spectra for UBC 123 


\section{UBC 123-Bore Number 1}

Figure D 1-1a: Gamma Spectrum from Bore 1 Sample 1.

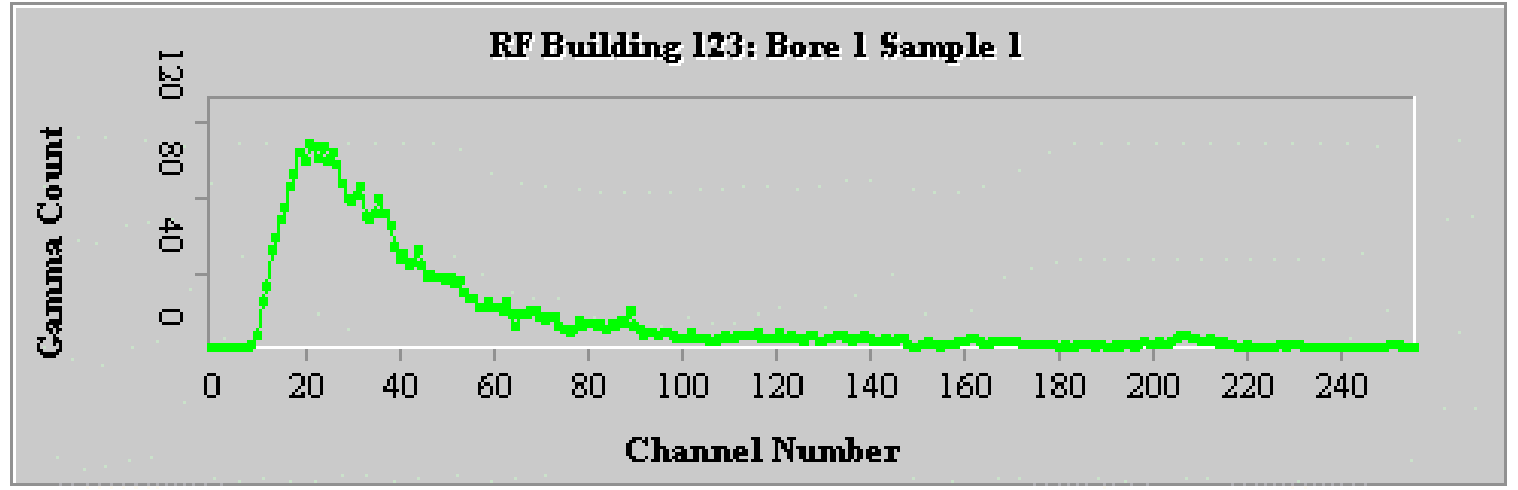

Figure D 1-1b: Cumulative Gamma Spectrum (13 spectra) from Bore 1 Sample 1.

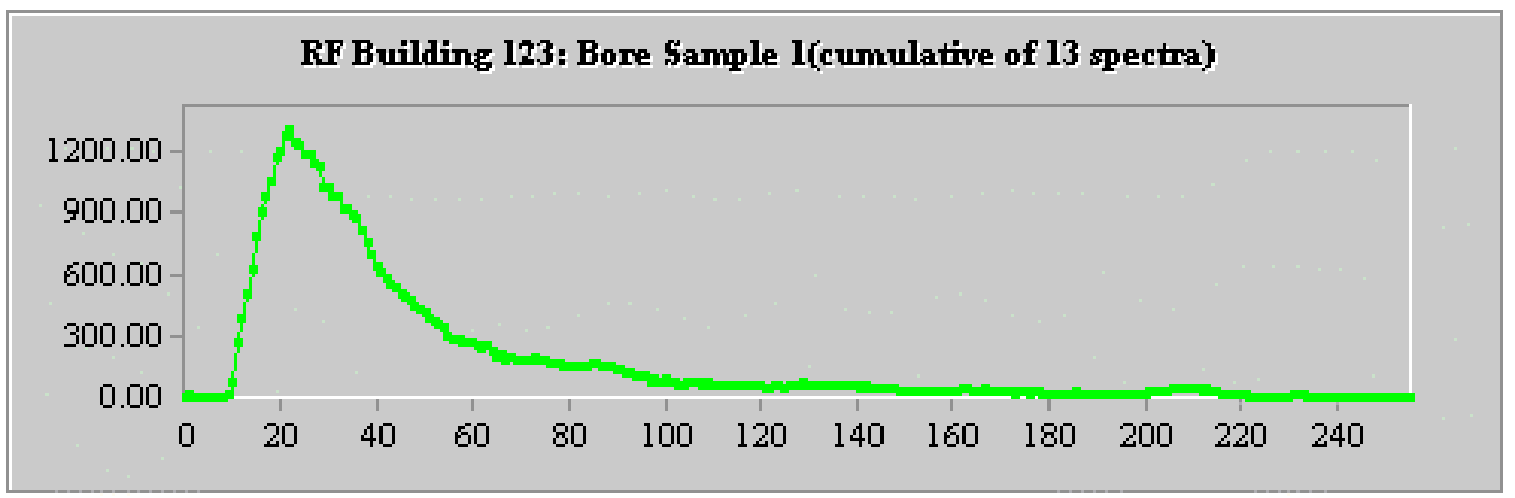

Figure D 1-2a: Gamma Spectrum from Bore 1 Sample 2.

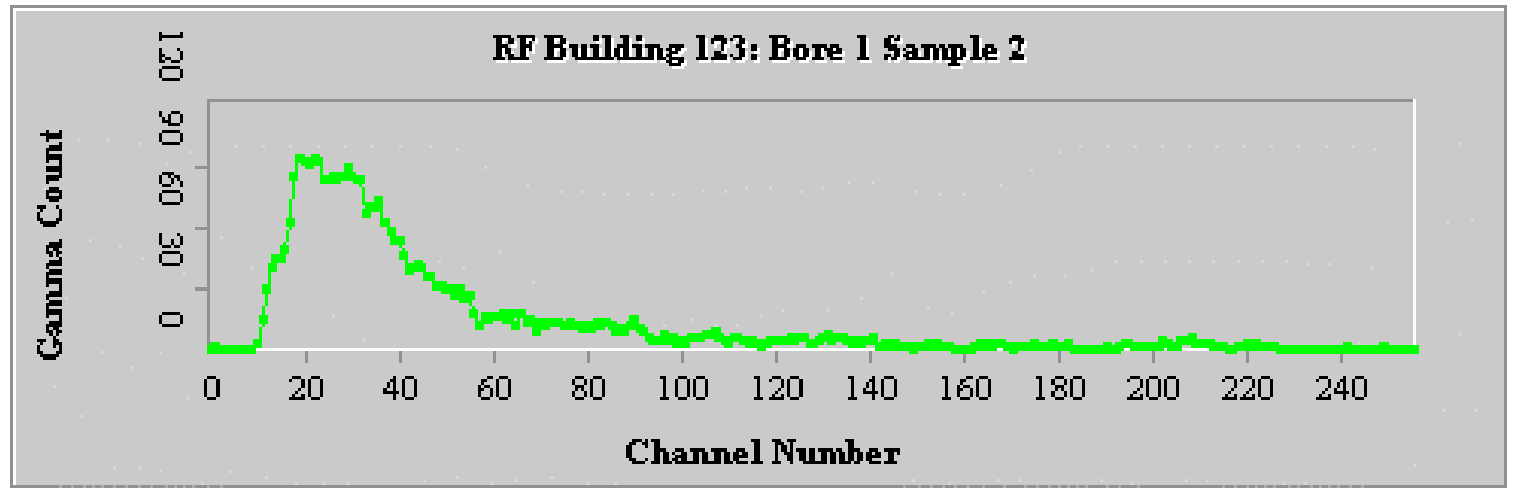


Figure D 1-2b: Cumulative Gamma Spectrum (15 spectra) from Bore 1 Sample 2.

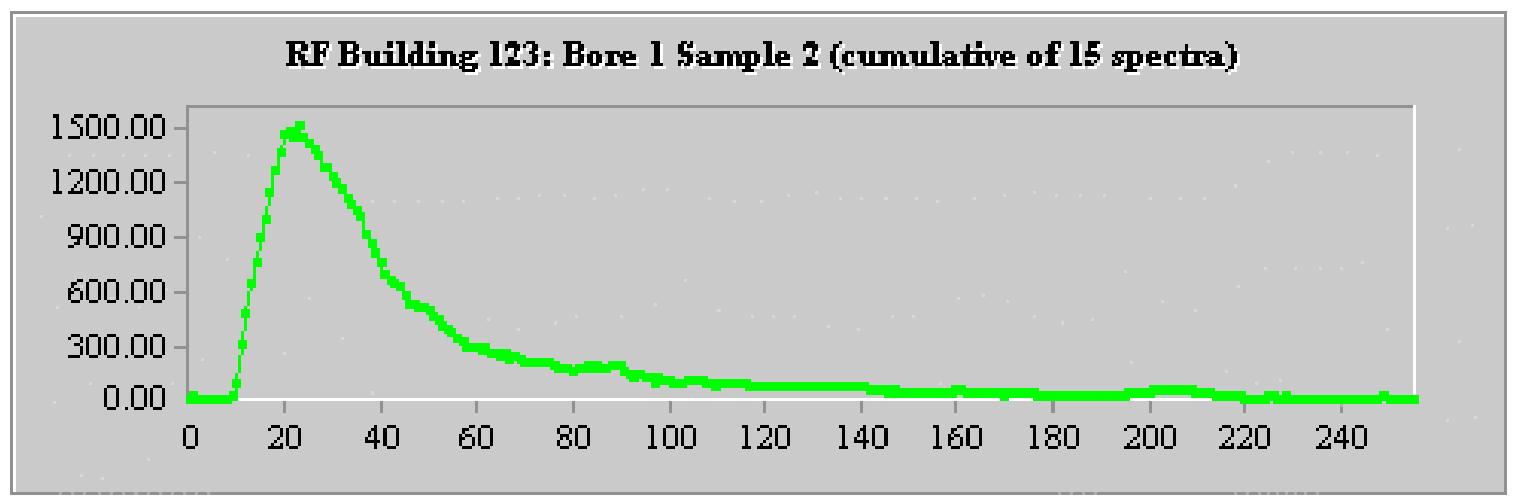

Figure D 1-3a: Gamma Spectrum from Bore 1 Sample 3.

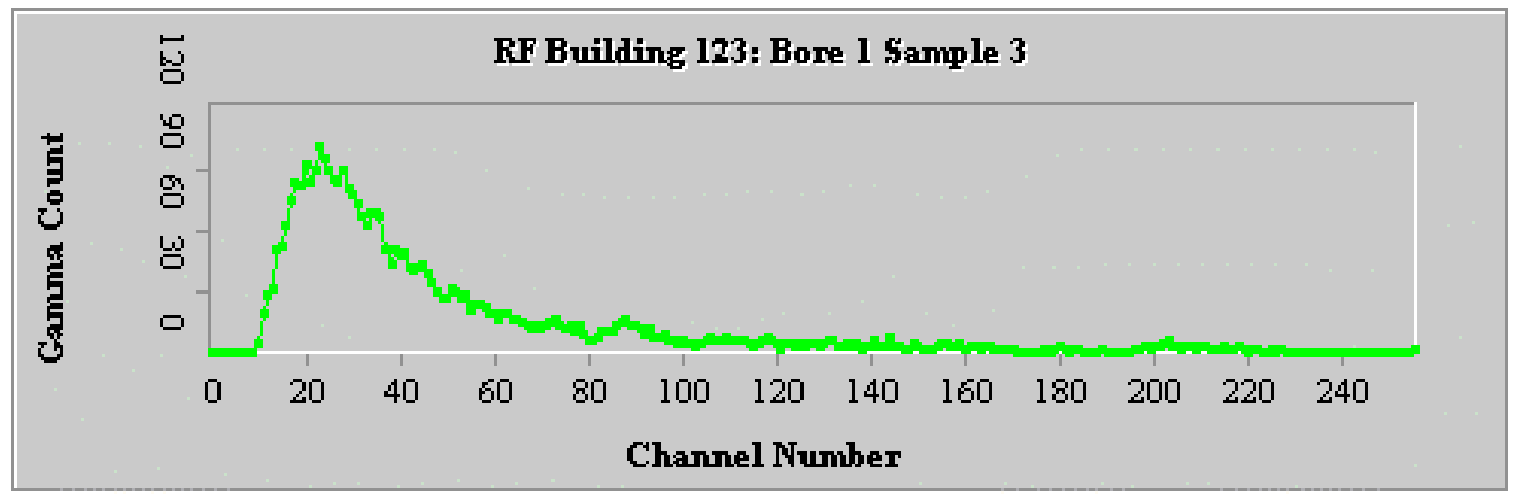

Figure D 1-3b: Cumulative Gamma Spectrum (11 spectra) from Bore 1 Sample 3.

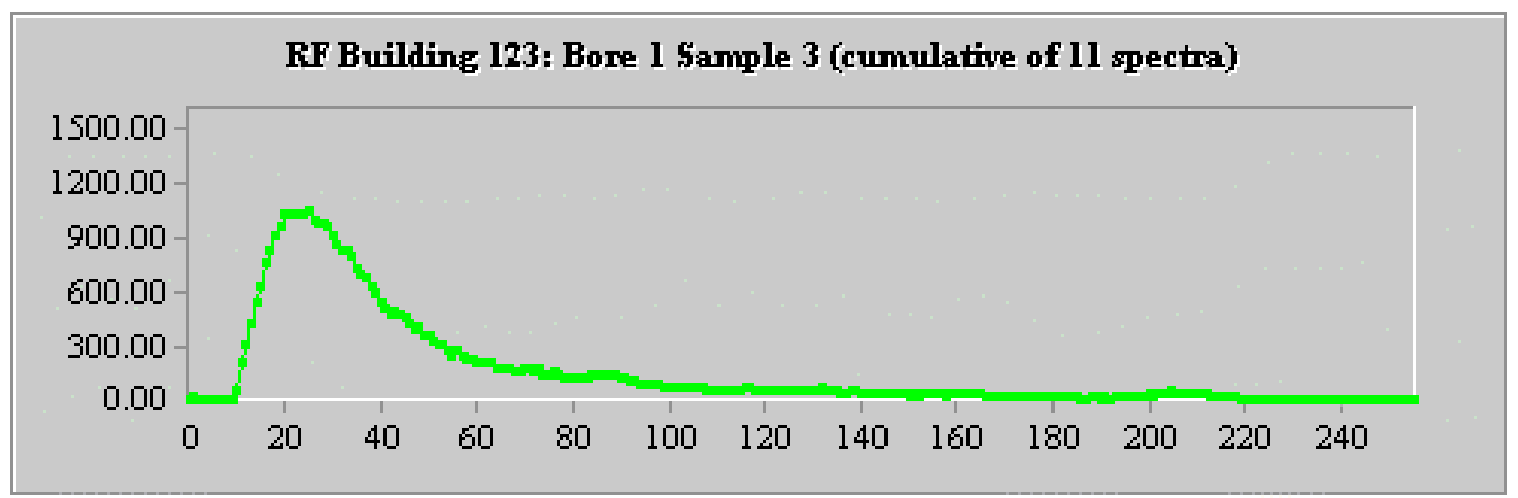




\section{UBC 123-Bore Number 2}

Figure D 2-1a: Gamma Spectrum from Bore 2 Sample 1.

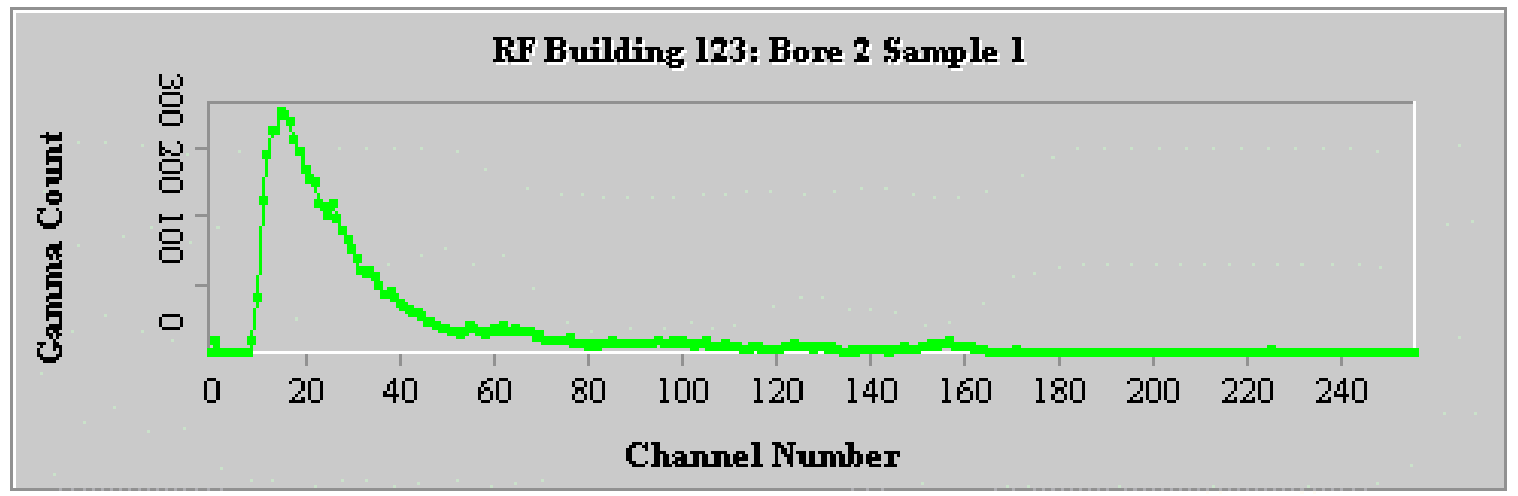

Figure D 2-1b: Cumulative Gamma Spectrum (10 spectra) from Bore 2 Sample 1.

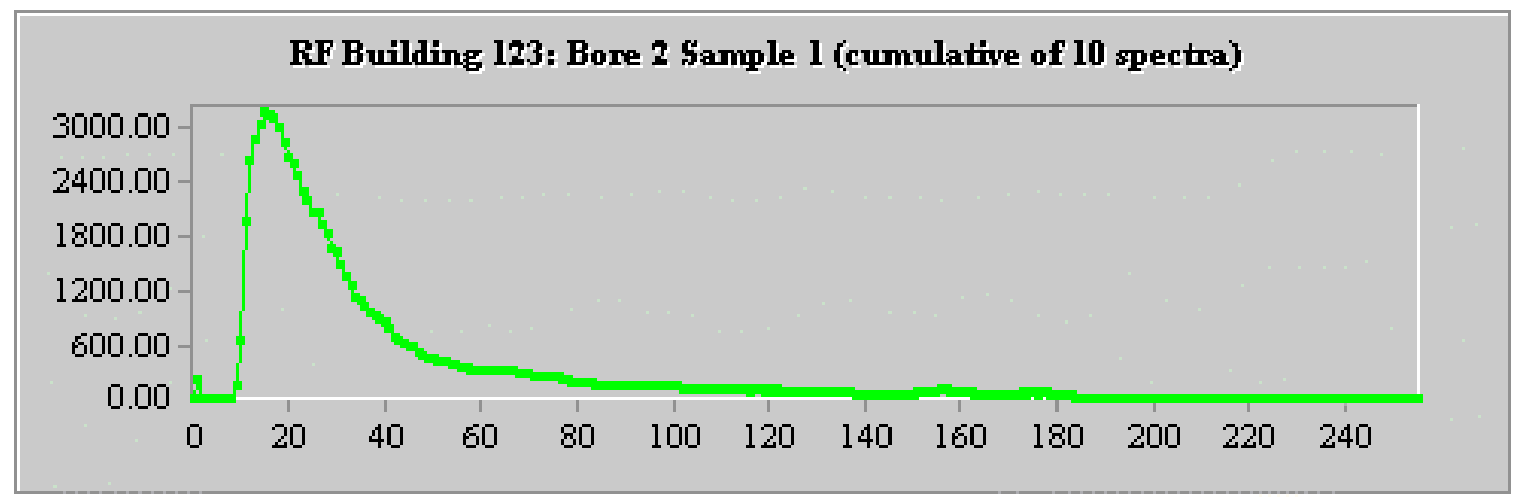

Figure D 2-2a: Gamma Spectrum from Bore 2 Sample 2.

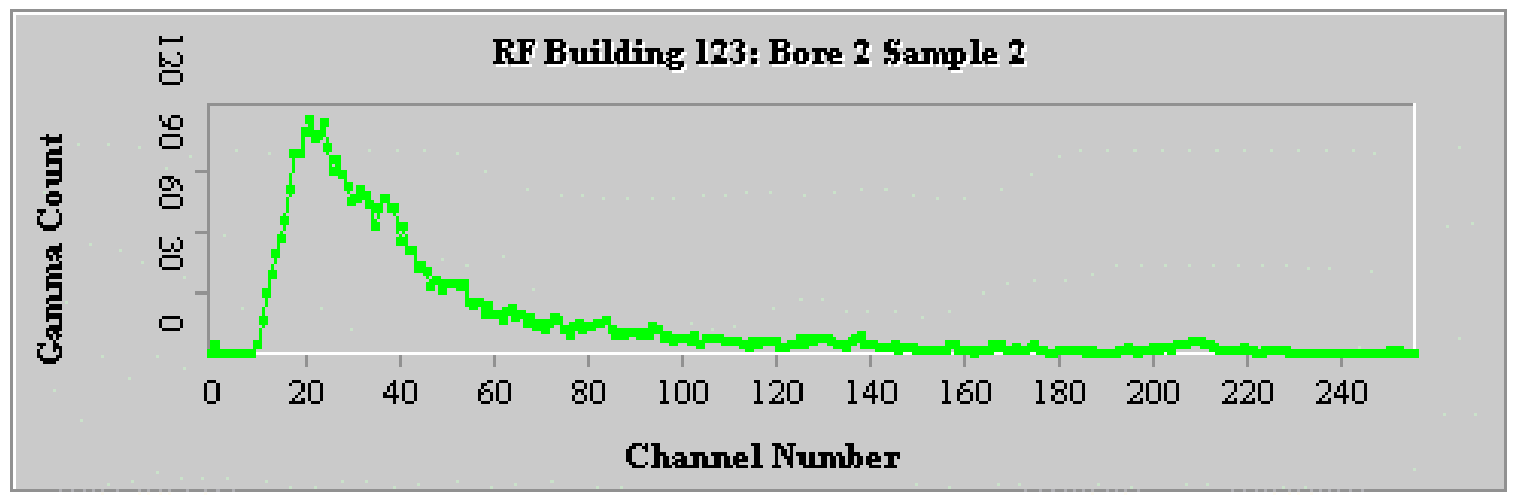


Figure D 2-2b: Cumulative Gamma Spectrum (10 spectra) from Bore 2 Sample 2.

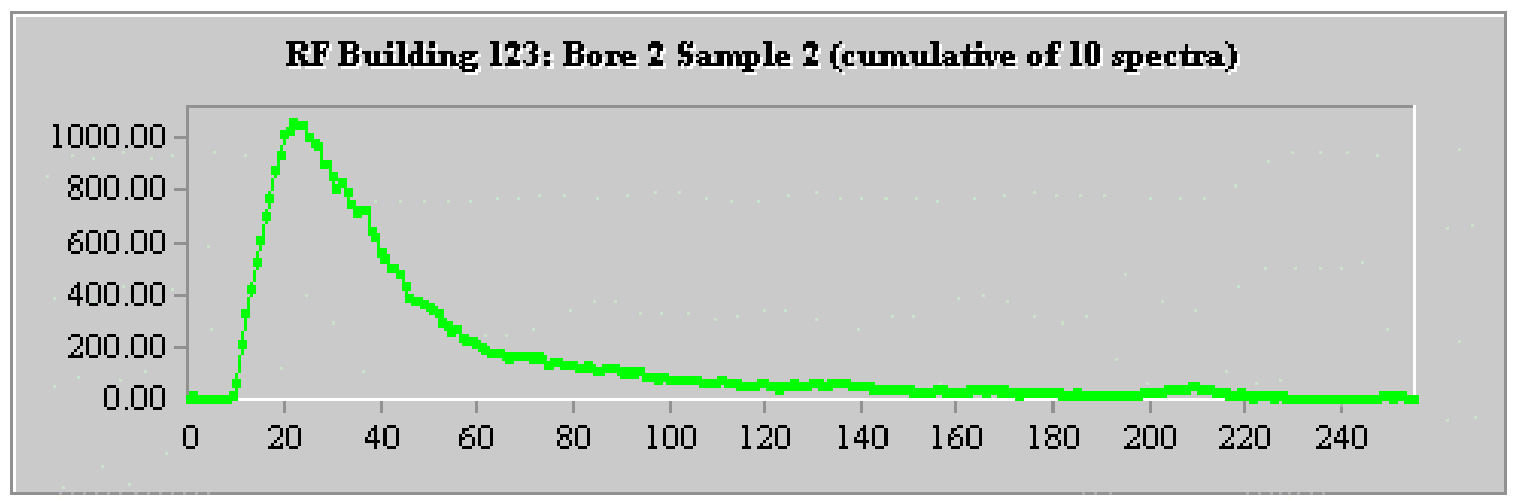

Figure D 2-3a: Gamma Spectrum from Bore 2 Sample 3.

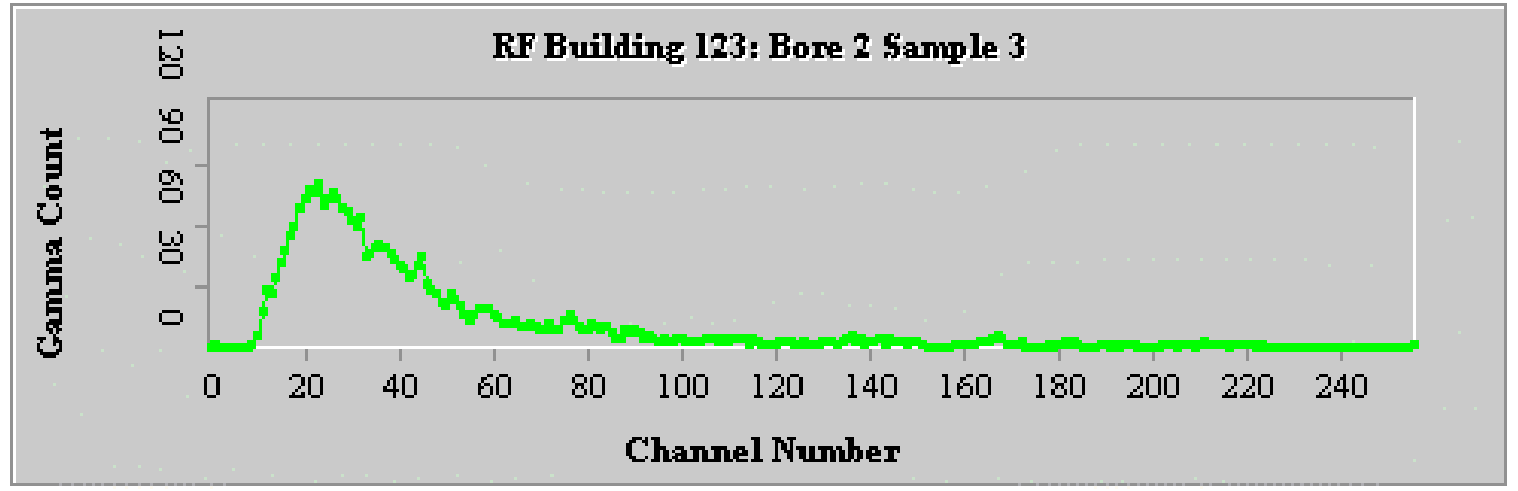

Figure D 2-3b: Cumulative Gamma Spectrum (10 spectra) from Bore 2 Sample 3.

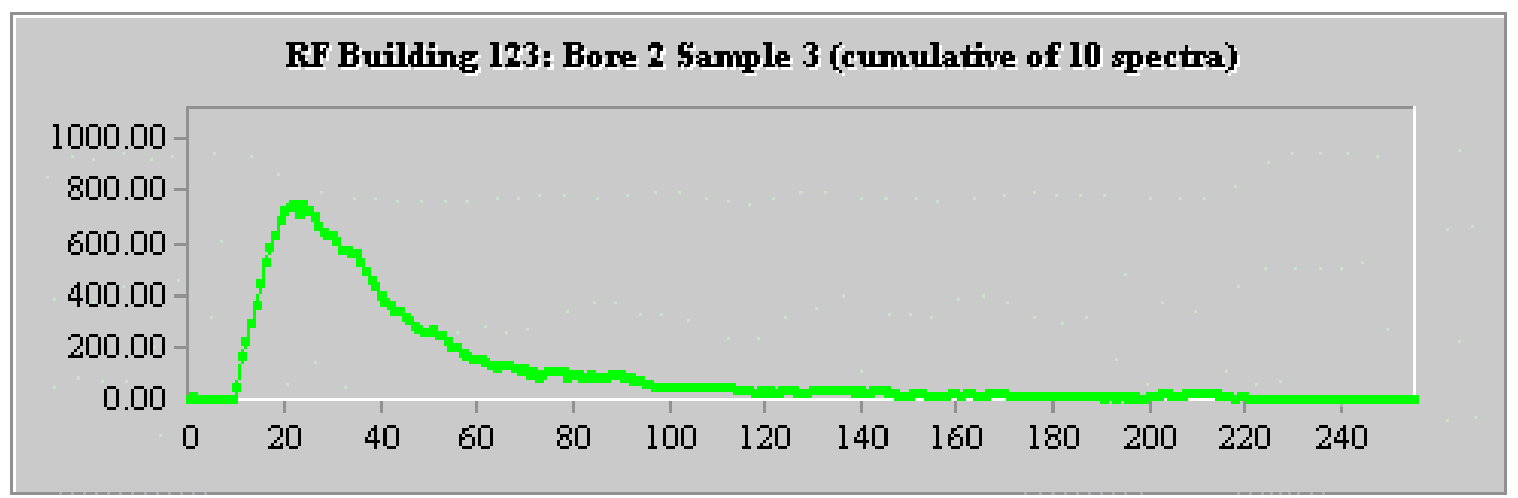


Figure D 2-4a: Gamma Spectrum from Bore 2 Sample 4.

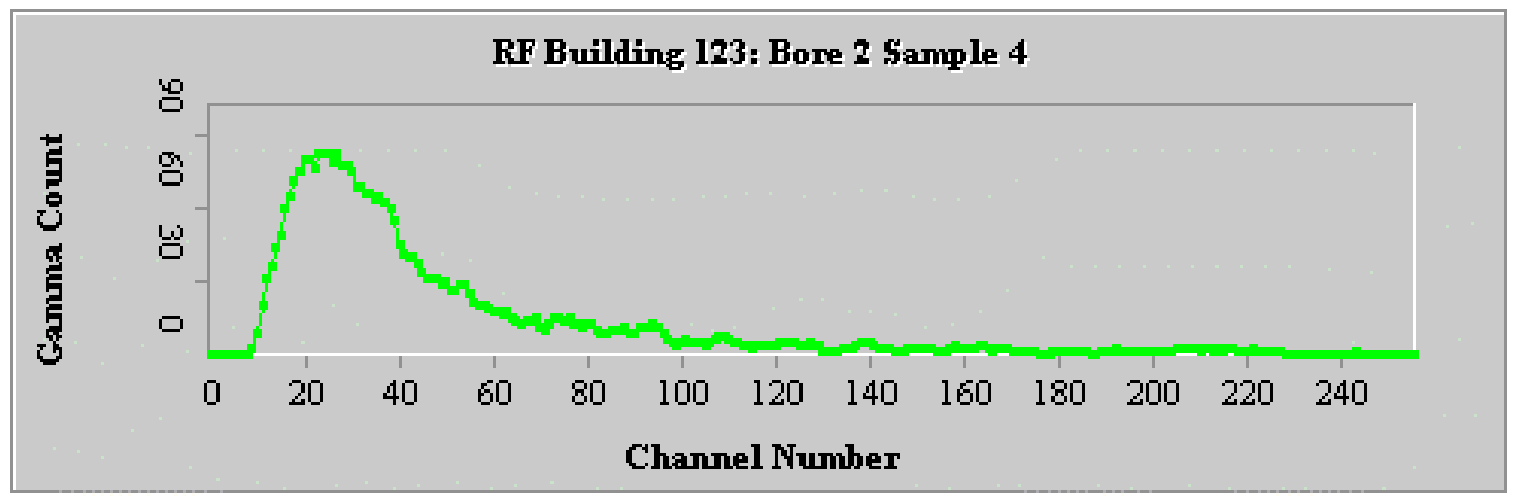

Figure D 2-4b: Cumulative Gamma Spectrum (9 spectra) from Bore 2 Sample 4.

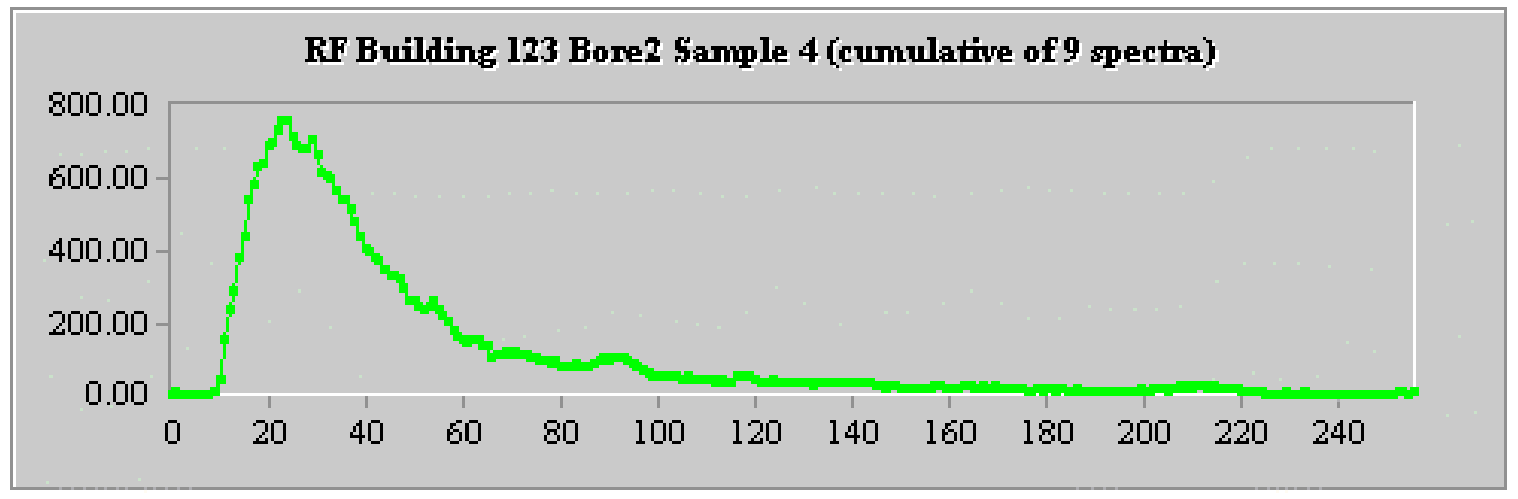

Figure D 2-5a: Gamma Spectrum from Bore 2 Sample 5.

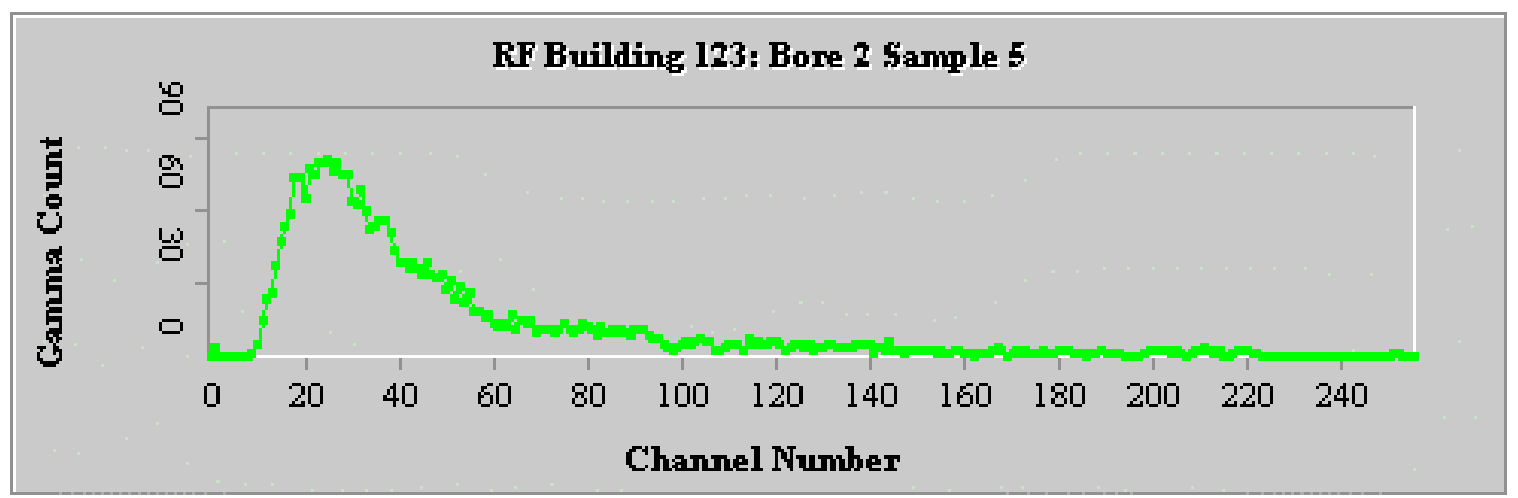


Figure D 2-5b: Cumulative Gamma Spectrum (10 spectra) from Bore 2 Sample 5

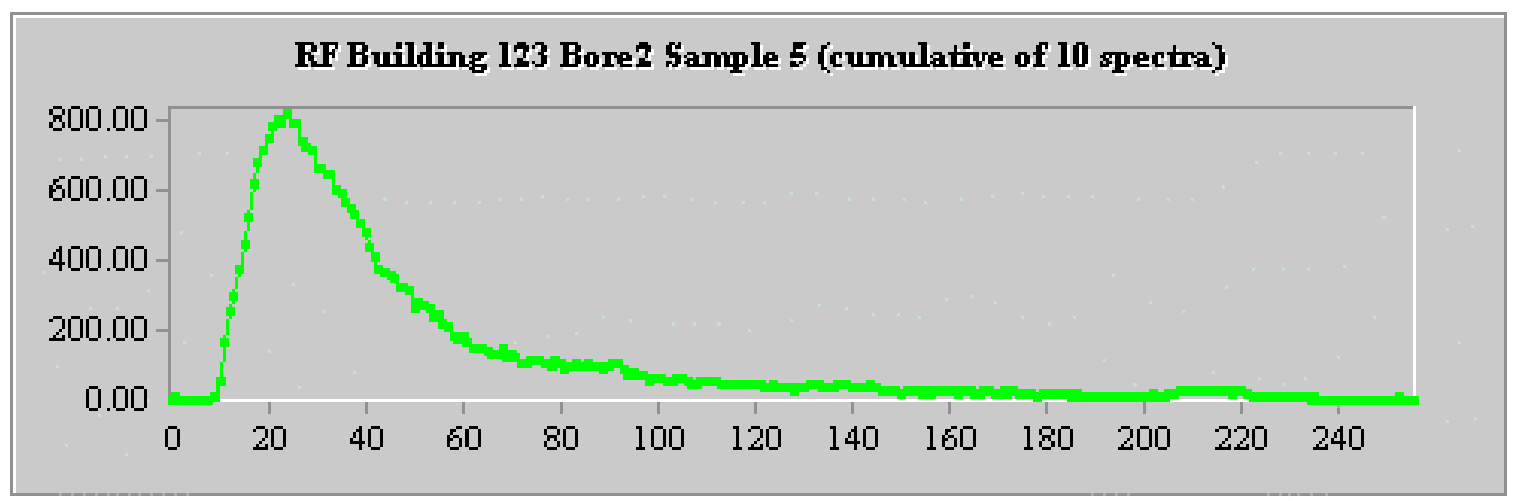

Figure D 2-6a: Gamma Spectrum from Bore 2 Sample 6.

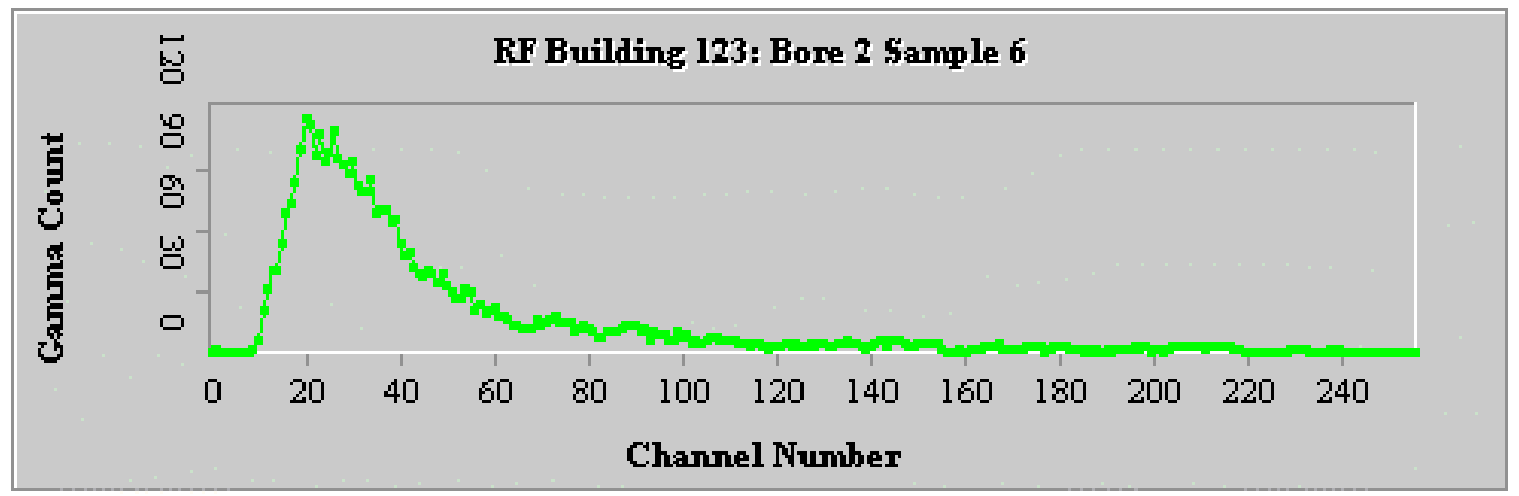

Figure D 2-6b: Cumulative Gamma Spectrum (10 spectra) from Bore 2 Sample 6 .

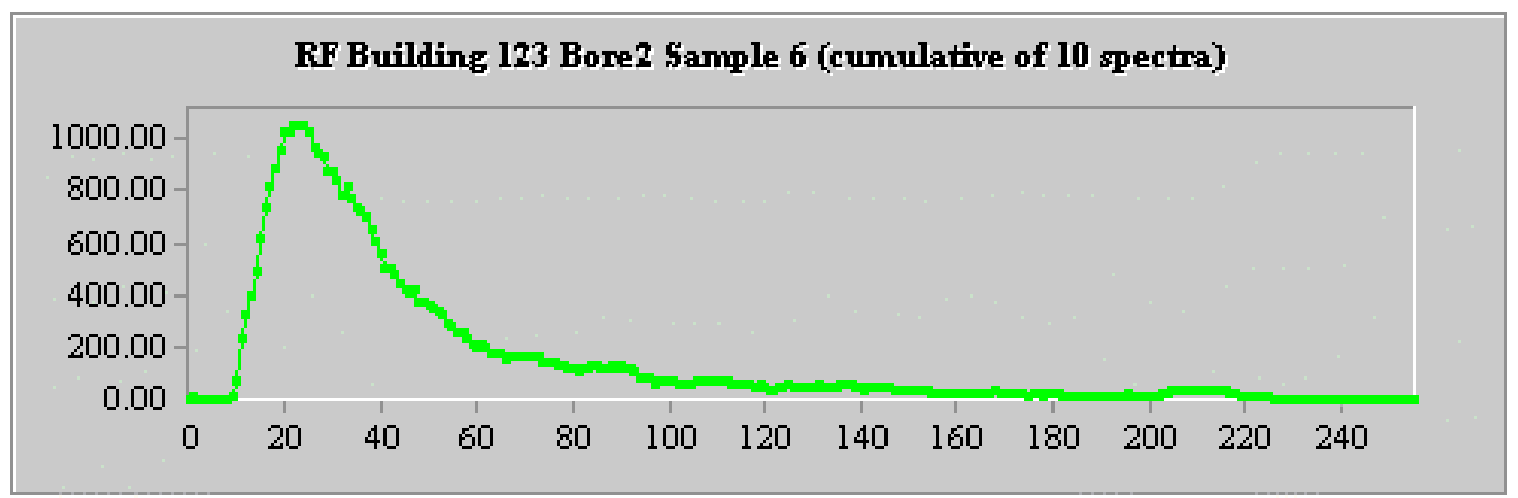


Figure D 2-7a: Gamma Spectrum from Bore 2 Sample 7.

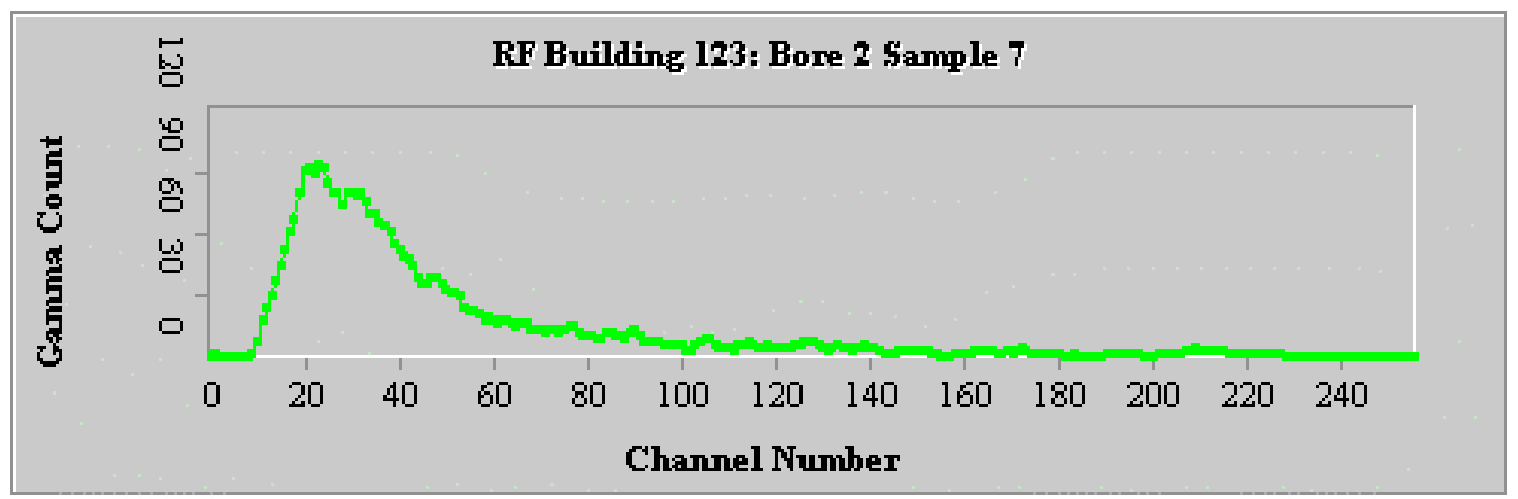

Figure D 2-7b: Cumulative Gamma Spectrum (10 spectra) from Bore 2 Sample 7.

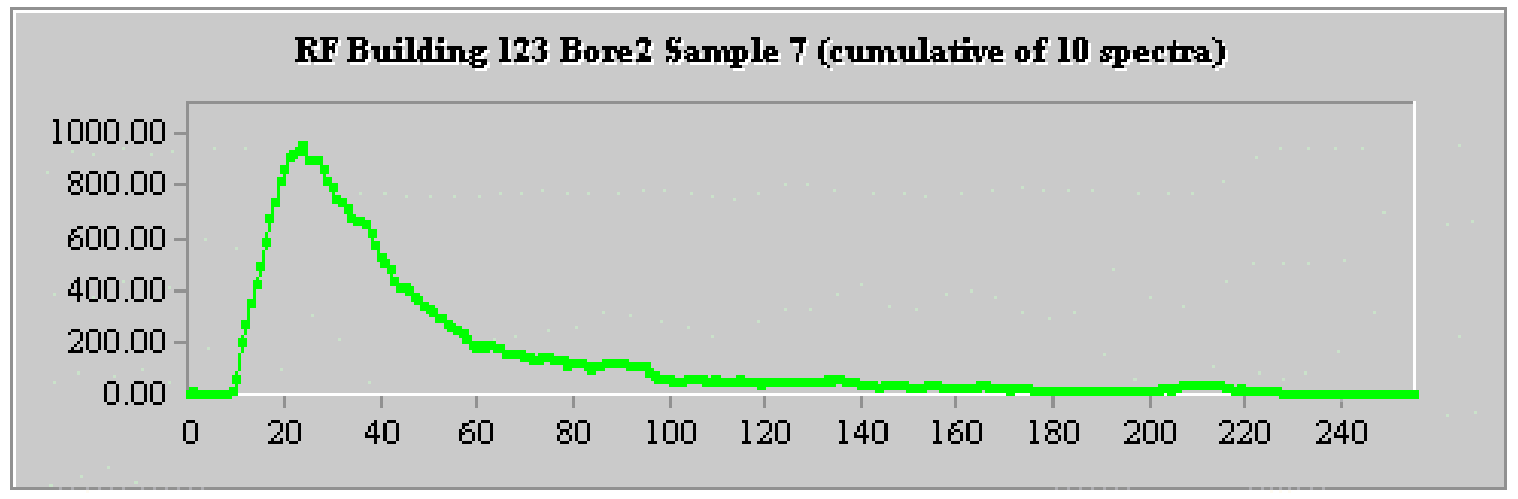

Figure D 2-8a: Gamma Spectrum from Bore 2 Sample 8.

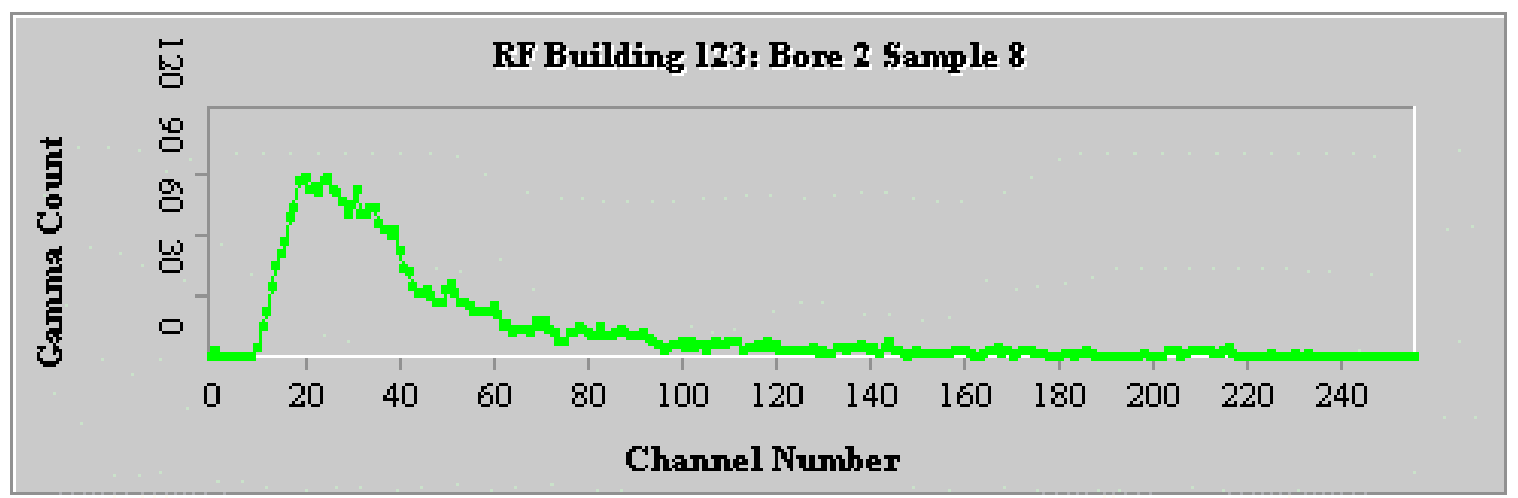


Figure D 2-8b: Cumulative Gamma Spectrum (10 spectra) from Bore 2 Sample 8.

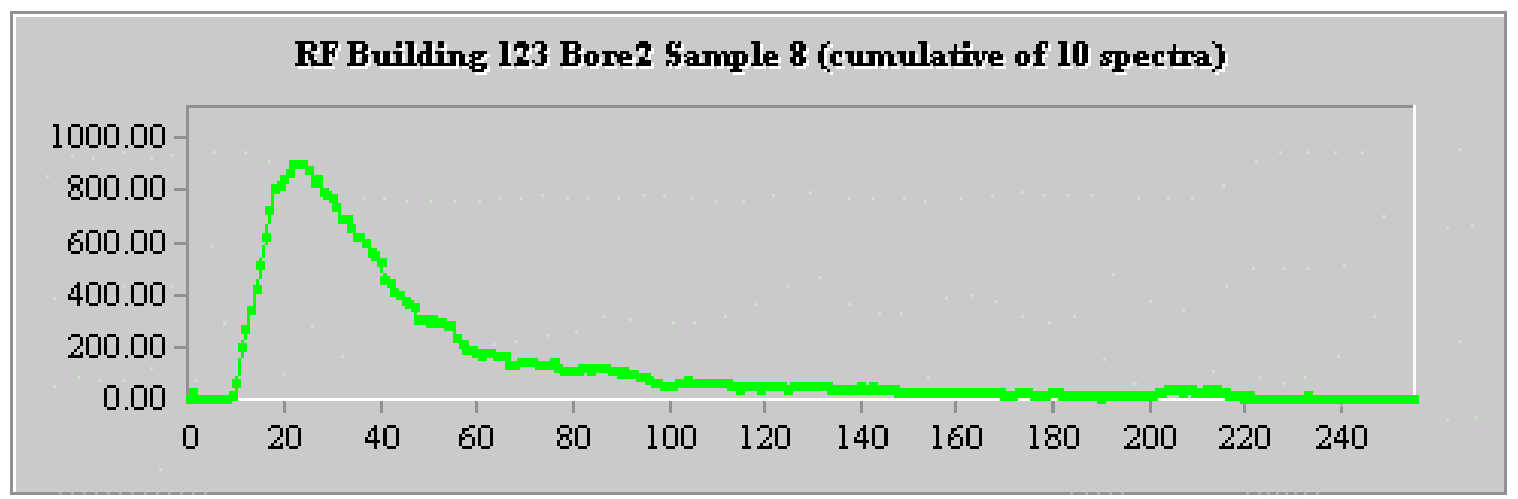

Figure D 2-9a: Gamma Spectrum from Bore 2 Sample 9.

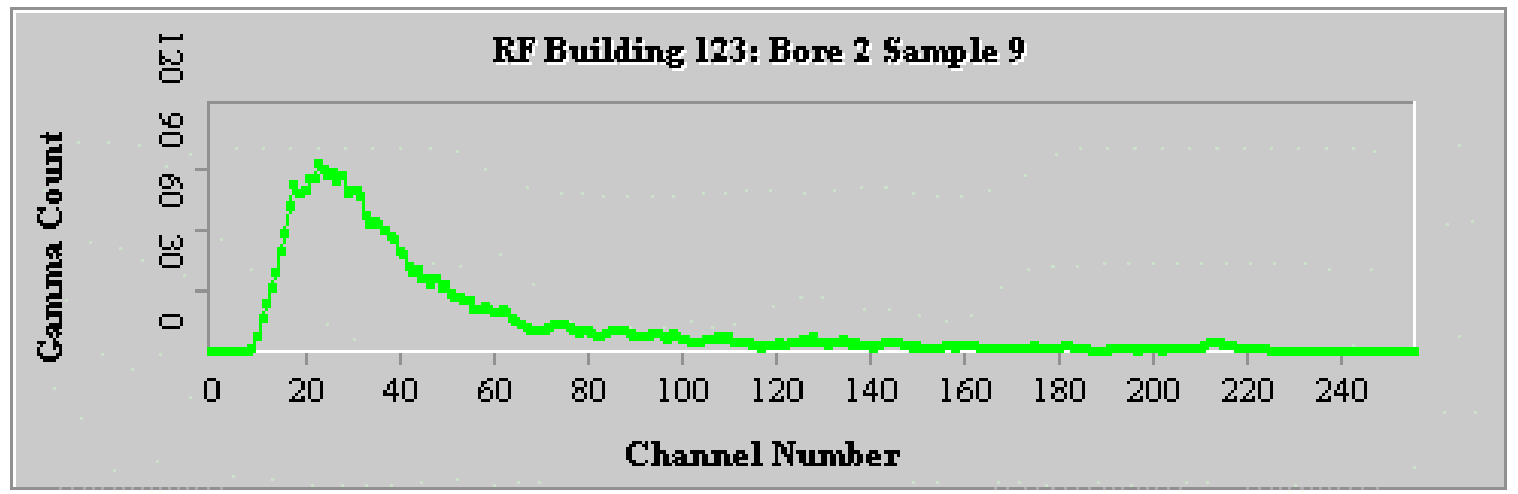

Figure D 2-9b: Cumulative Gamma Spectrum (9 spectra) from Bore 2 Sample 9.

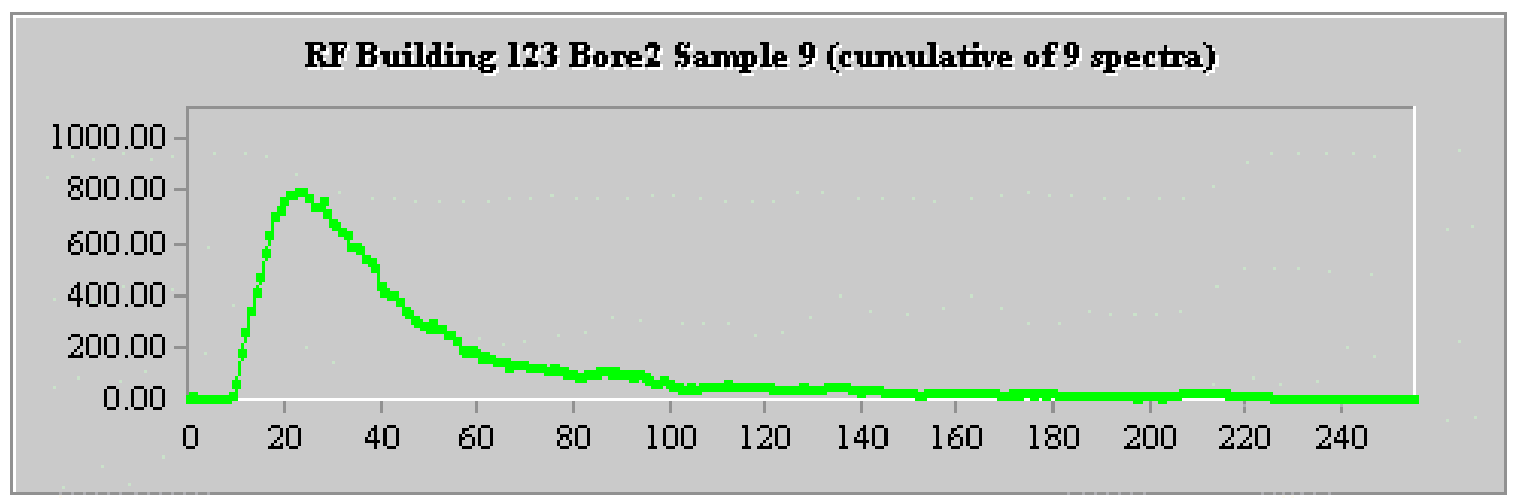




\section{UBC 123-Bore Number 3}

Figure D 3-2a: Gamma Spectrum from Bore 3 Sample 2.

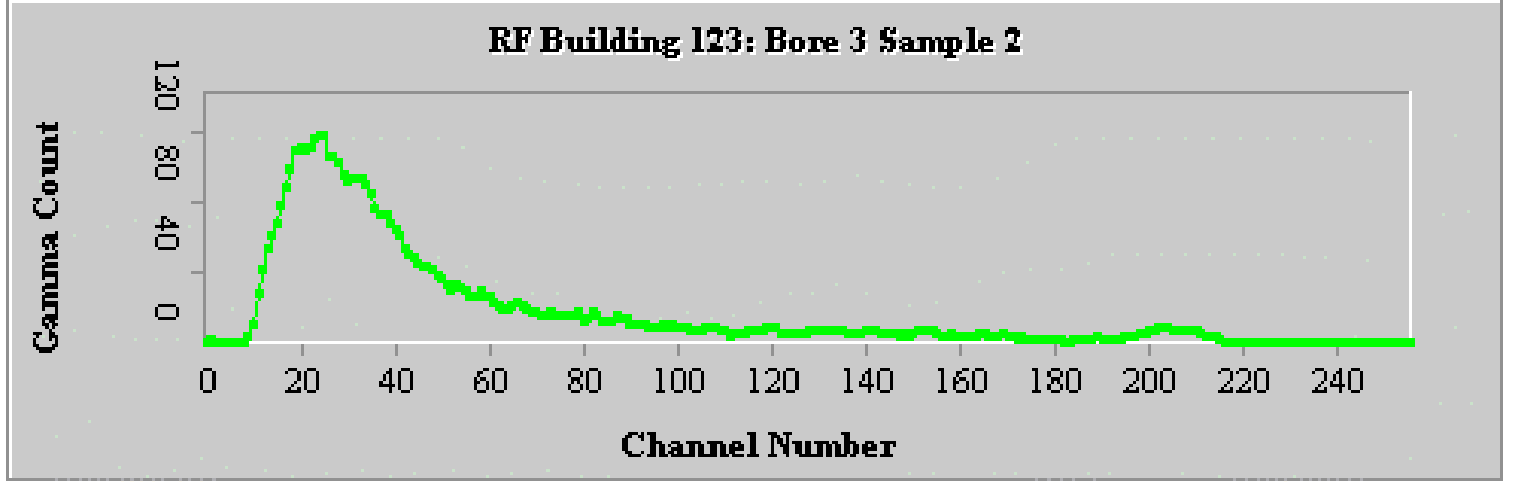

Figure D 3-2b: Cumulative Gamma Spectrum (6 spectra) from Bore 3 Sample 2.

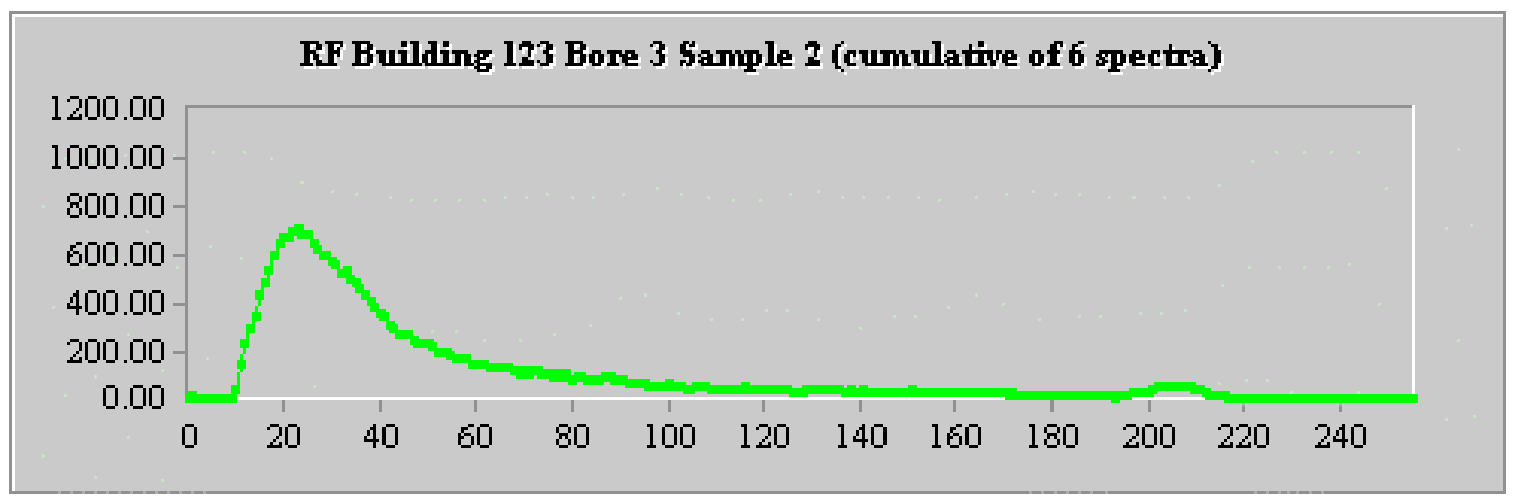

Figure D 3-3a: Gamma Spectrum from Bore 3 Sample 3.

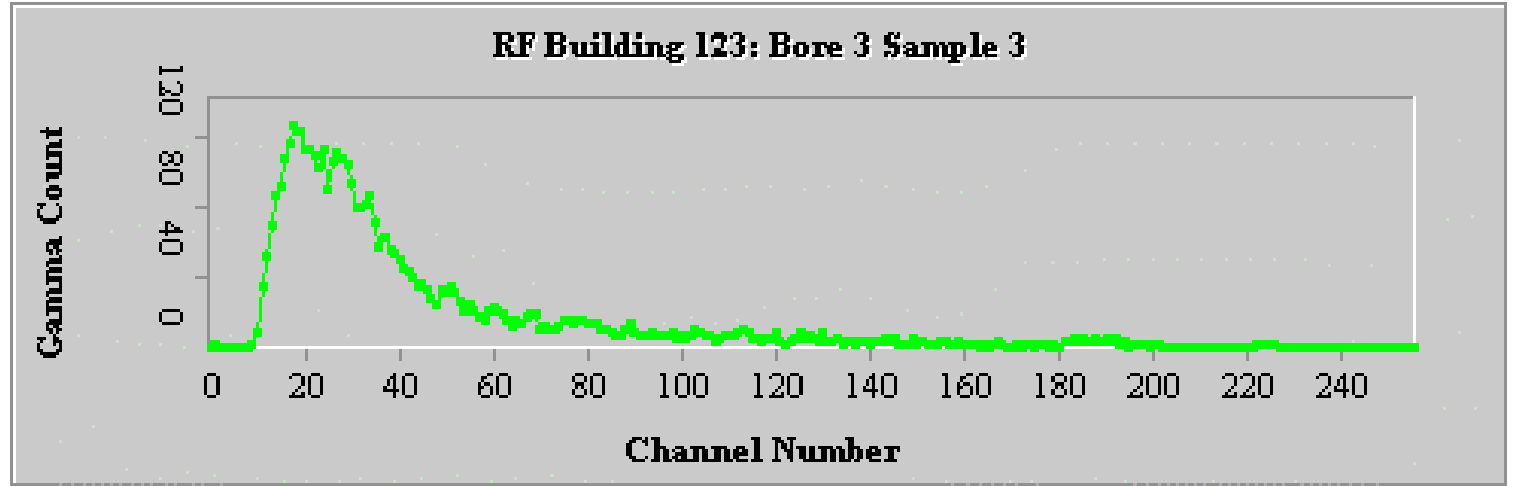


Figure D 3-3b: Cumulative Gamma Spectrum (10 spectra) from Bore 3 Sample 3.

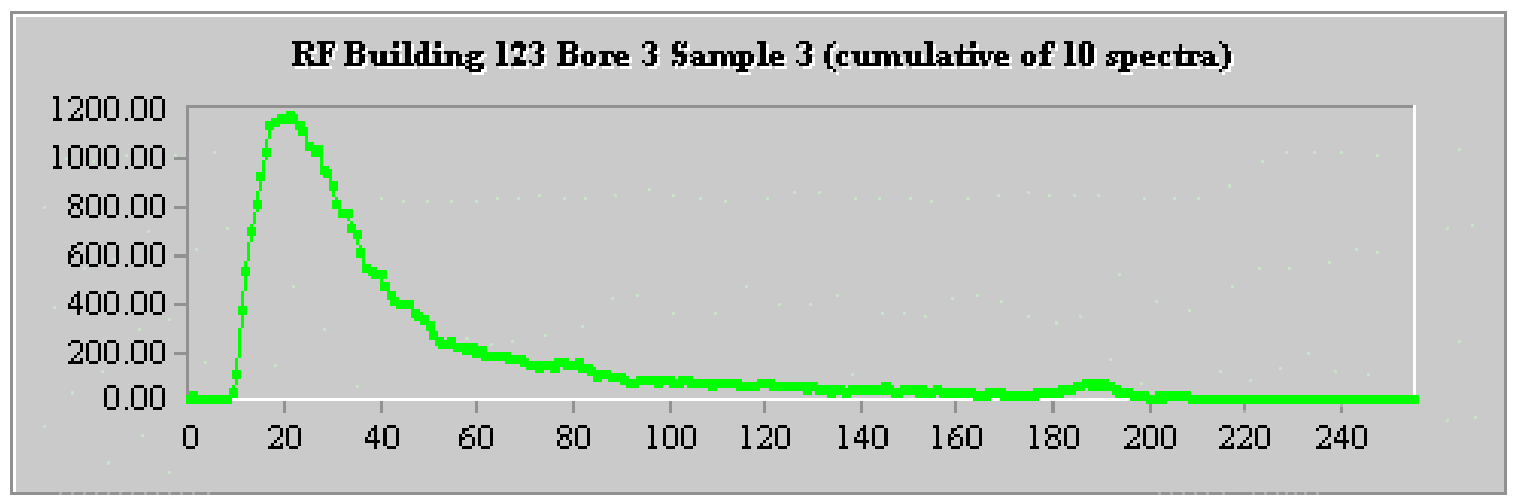

Figure D 3-4a: Gamma Spectrum from Bore 3 Sample 4.

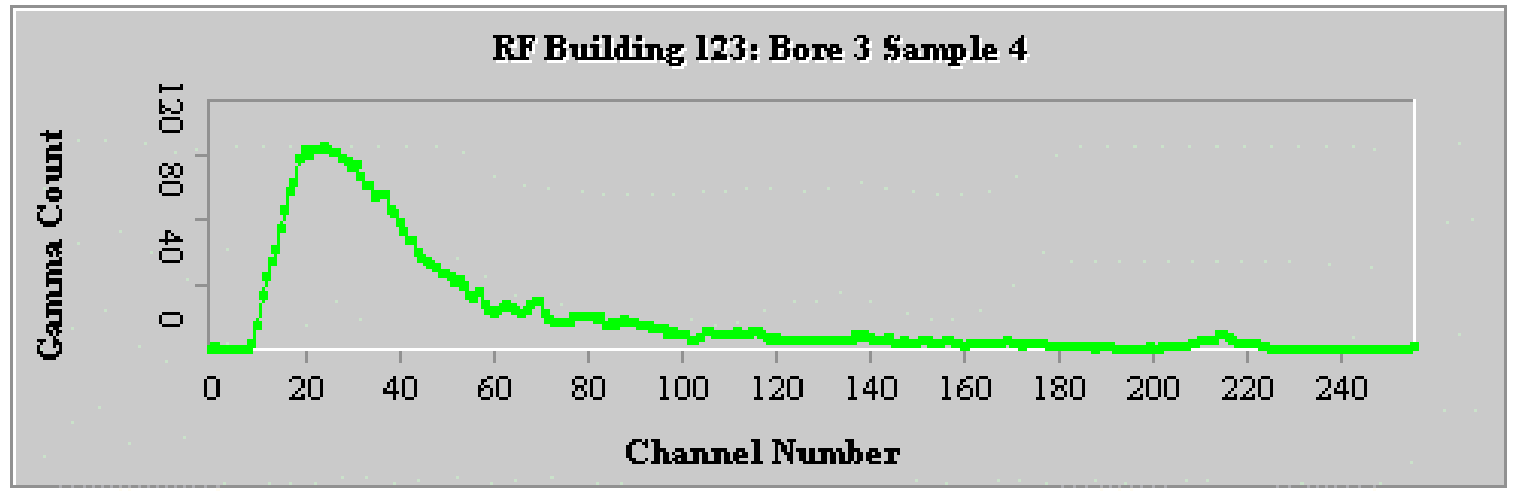

Figure D 3-4b: Cumulative Gamma Spectrum (8 spectra) from Bore 3 Sample 4.

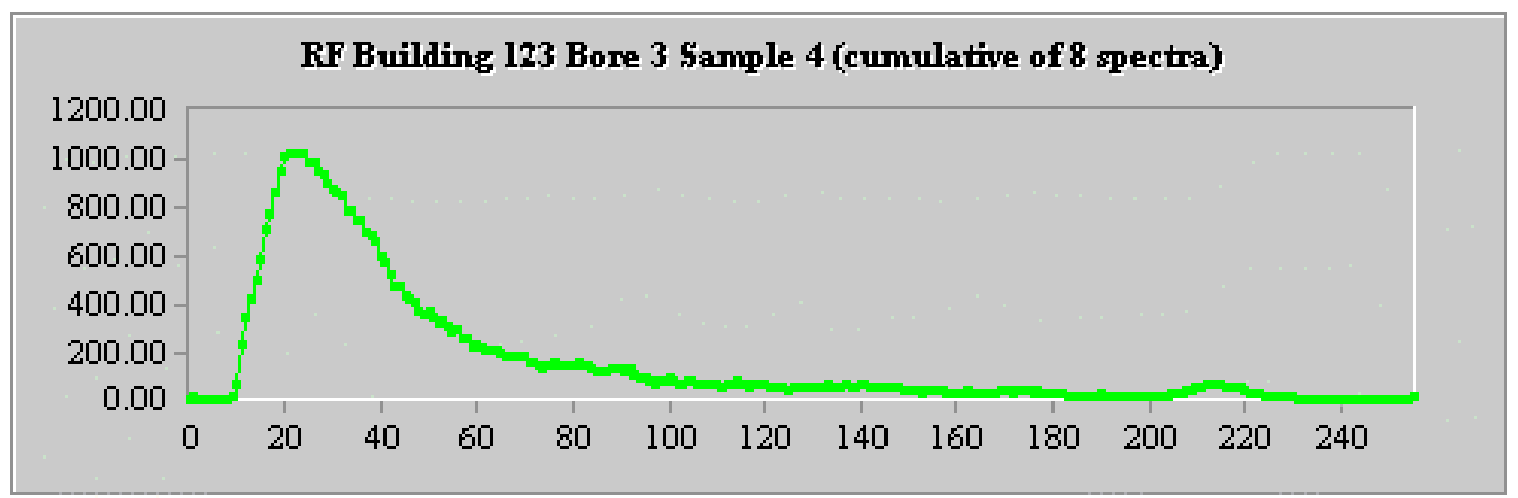


Figure D 3-5a: Gamma Spectrum from Bore 3 Sample 5.

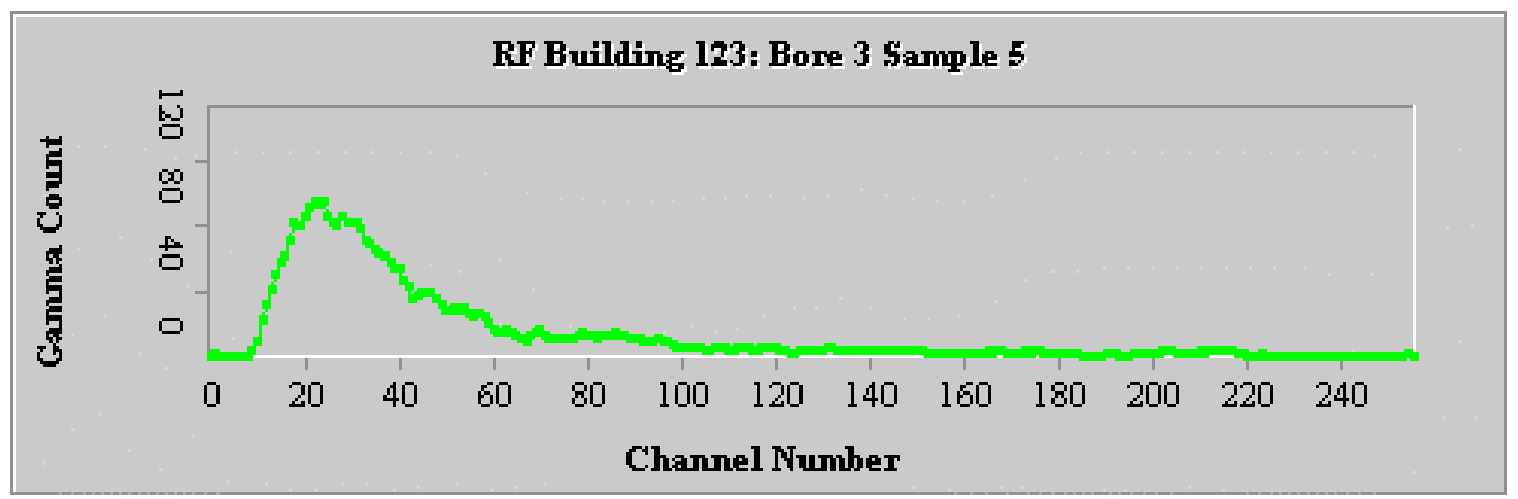

Figure D 3-5b: Cumulative Gamma Spectrum (10 spectra) from Bore 3 Sample 5.

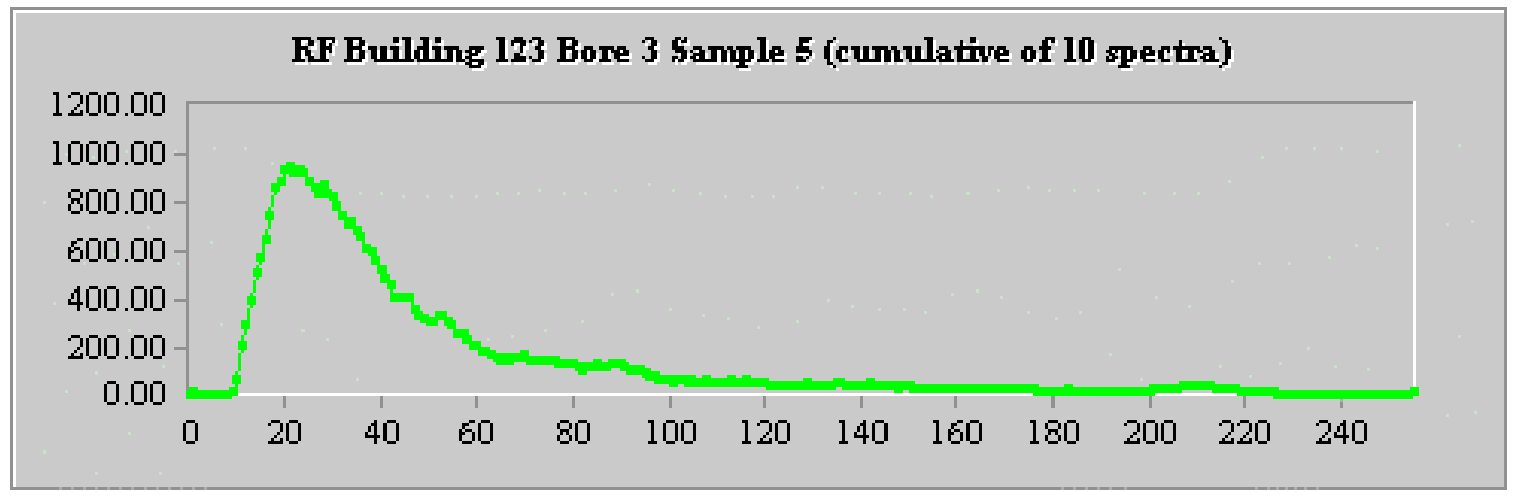




\section{UBC 123-Bore Number 4}

Figure D 4-1a: Gamma Spectrum from Bore 4 Sample 1.

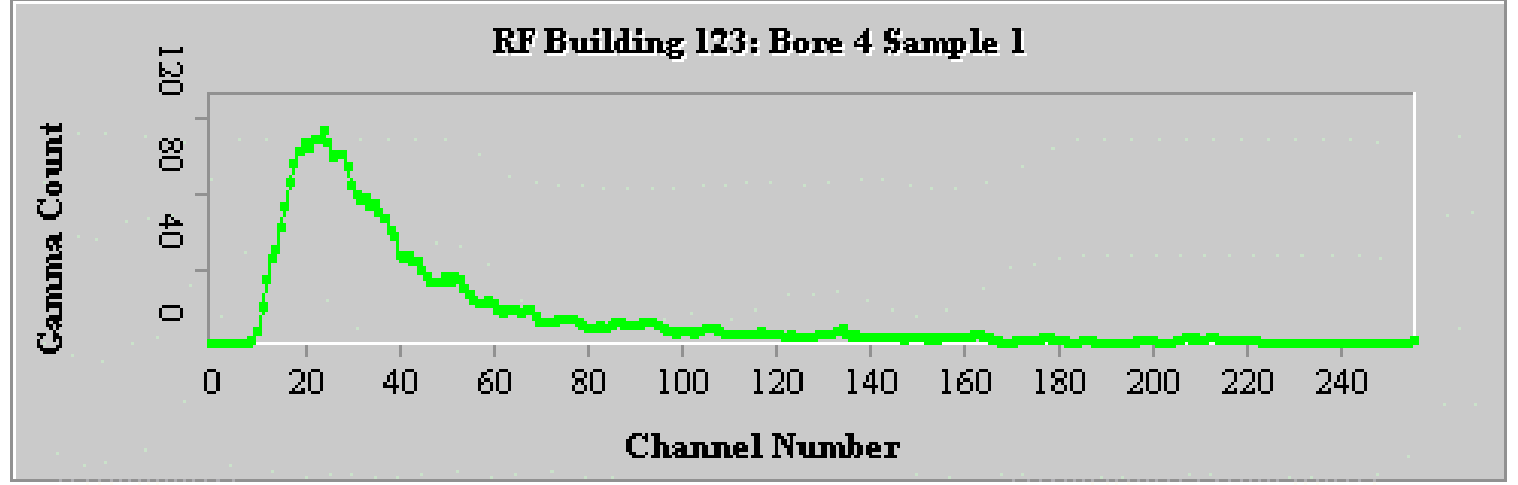

Figure D 4-1b: Cumulative Gamma Spectrum (15 spectra) from Bore 4 Sample 1.

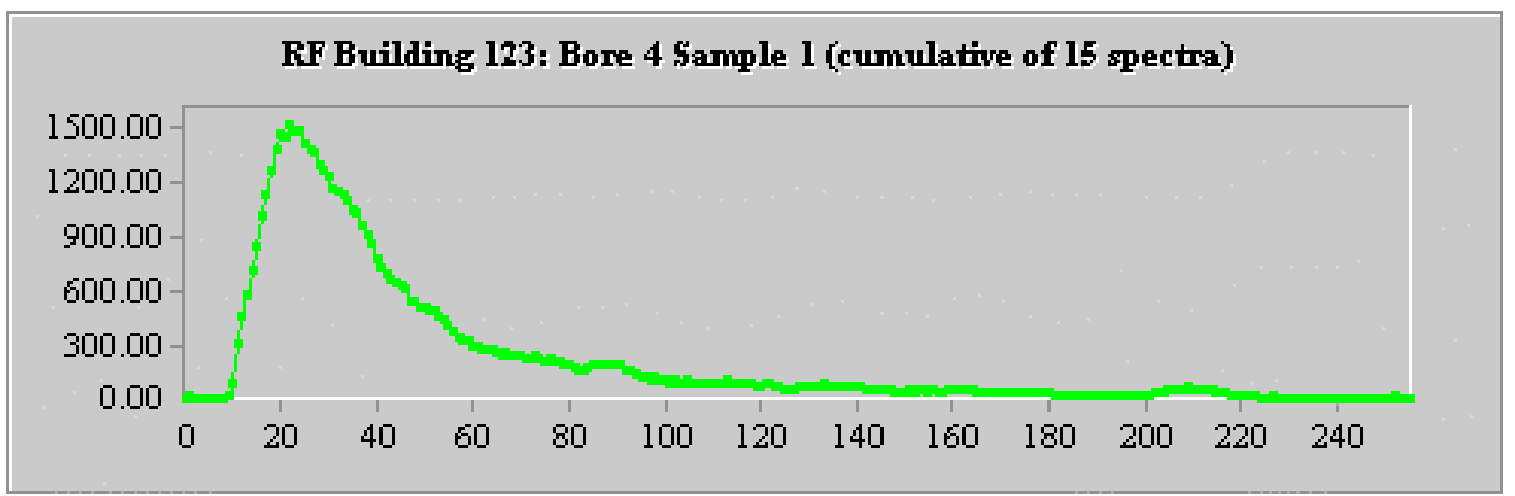

Figure D 4-2a: Gamma Spectrum from Bore 4 Sample 2.

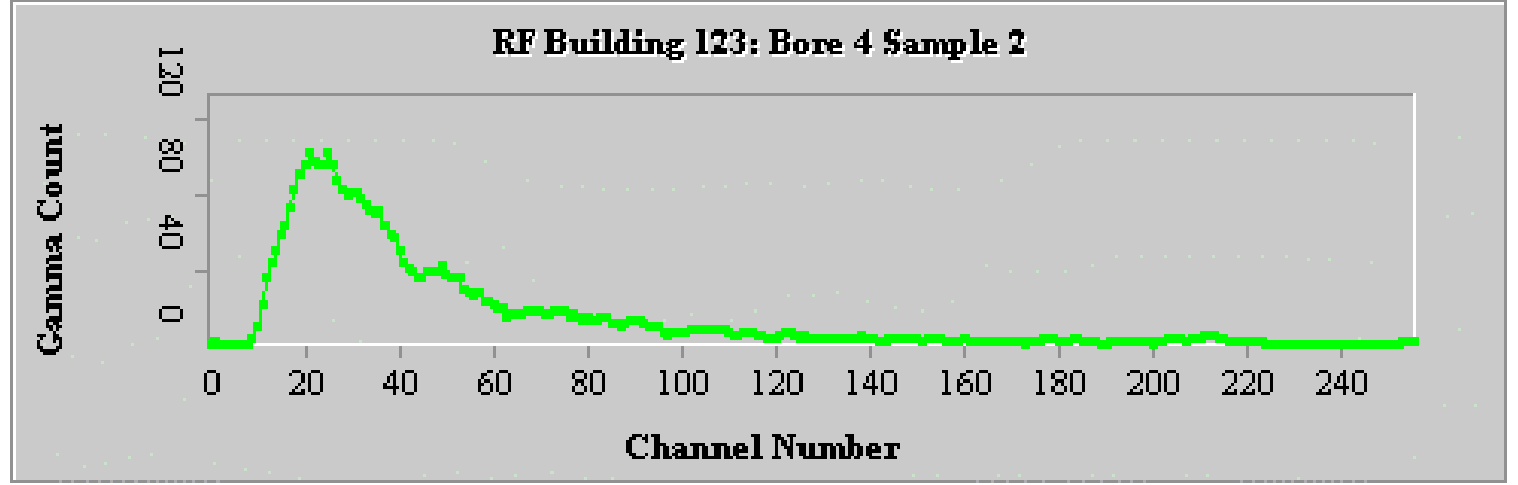


Figure D 4-2b: Cumulative Gamma Spectrum (10 spectra) from Bore 4 Sample 2.

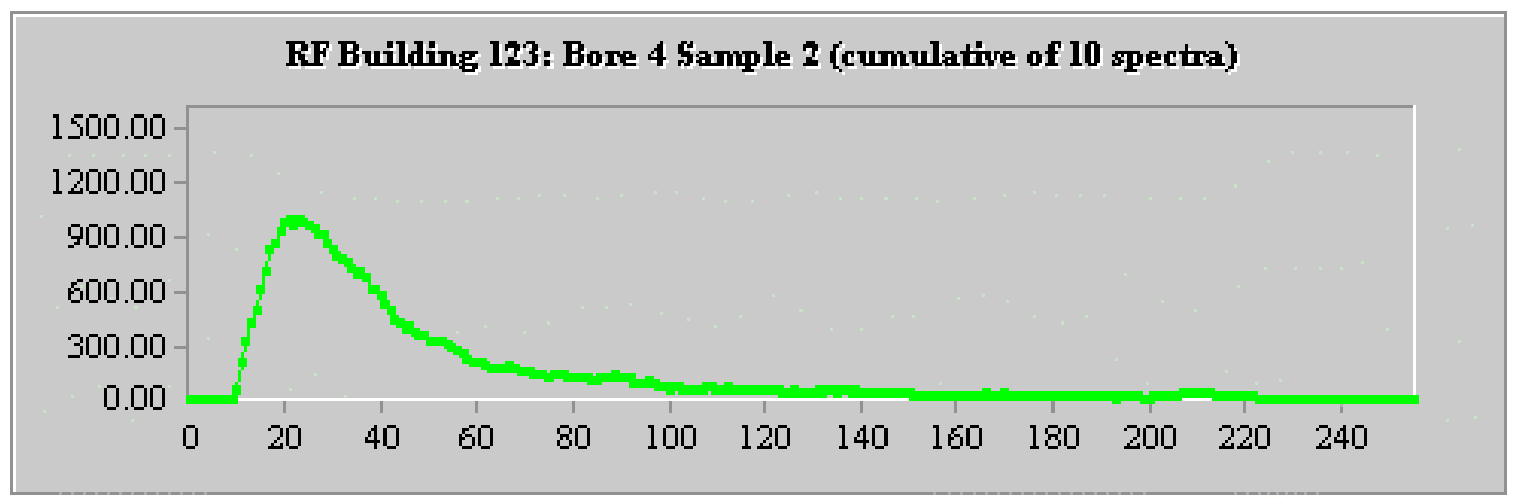

Figure D 4-3a: Gamma Spectrum from Bore 4 Sample 3.

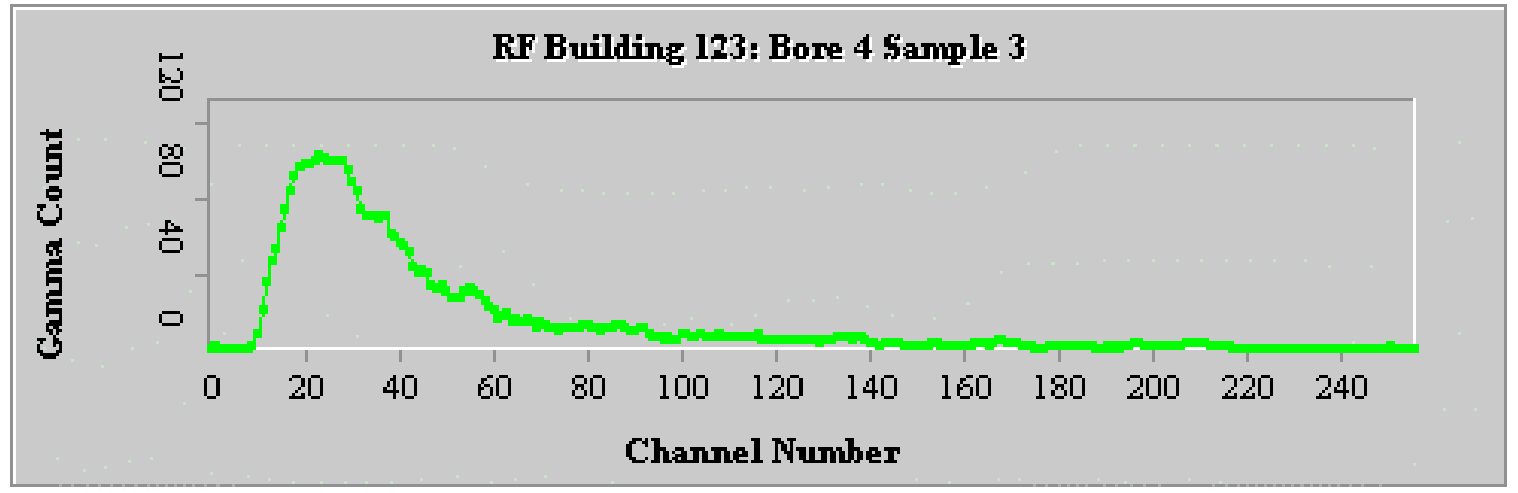

Figure D 4-4a: Gamma Spectrum from Bore 4 Sample 4.

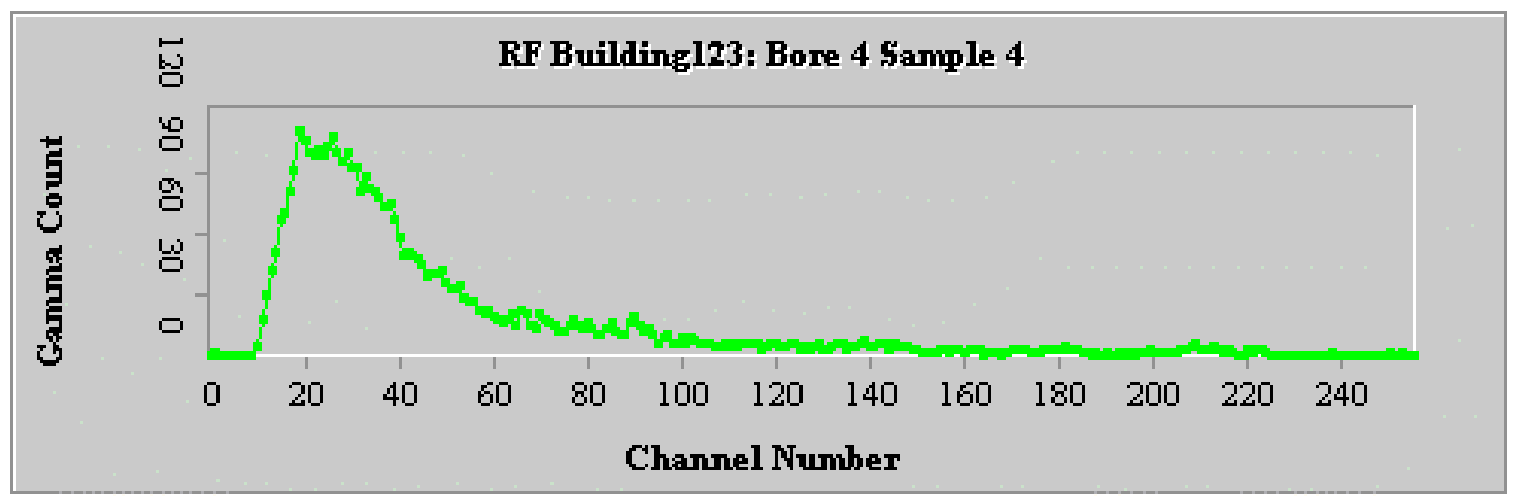


Figure D 4-4b: Cumulative Gamma Spectrum (10 spectra) from Bore 4 Sample 4.

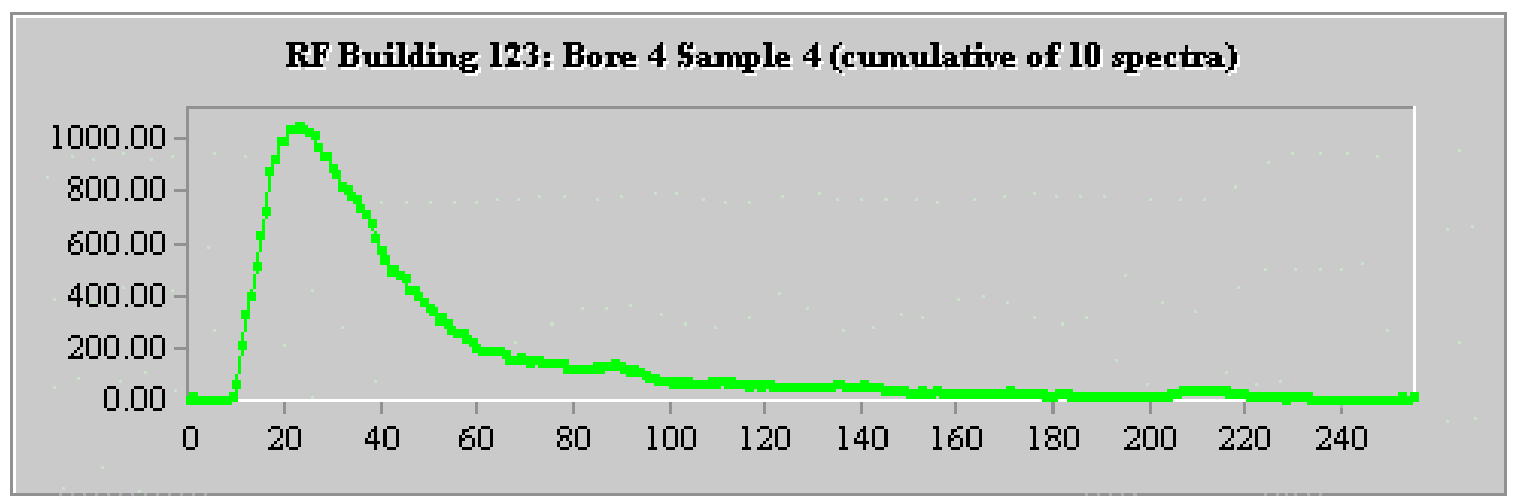

Figure D 4-5a: Gamma Spectrum from Bore 4 Sample 5.

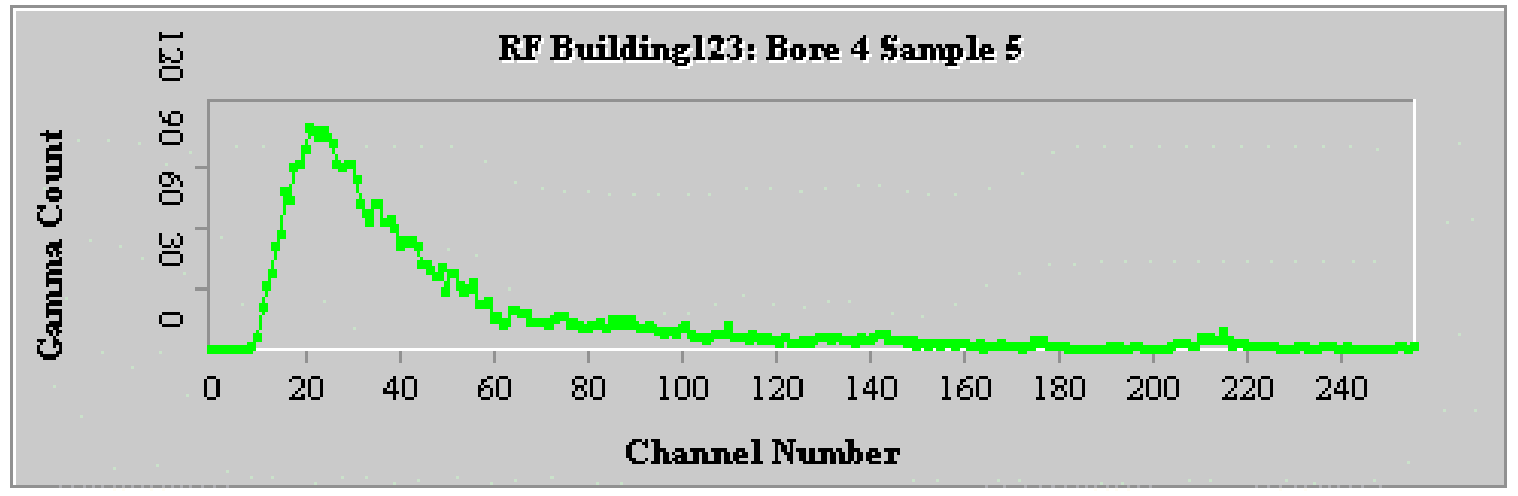

Figure D 4-5b: Cumulative Gamma Spectrum (10 spectra) from Bore 4 Sample 5.

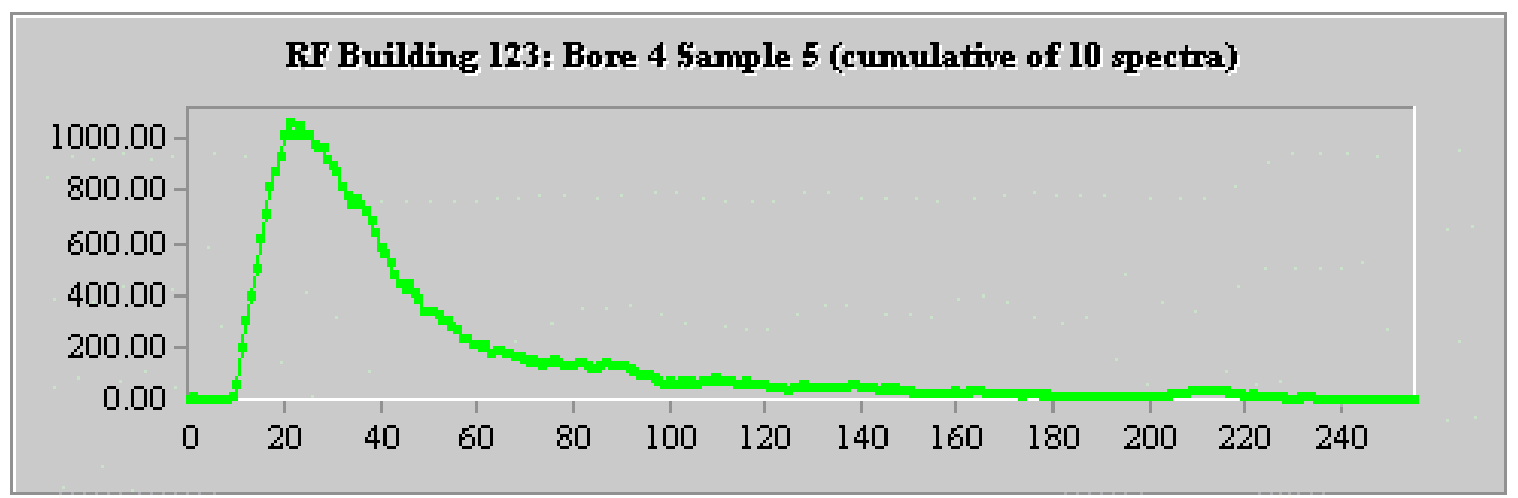


Figure D 4-6a: Gamma Spectrum from Bore 4 Sample 6.

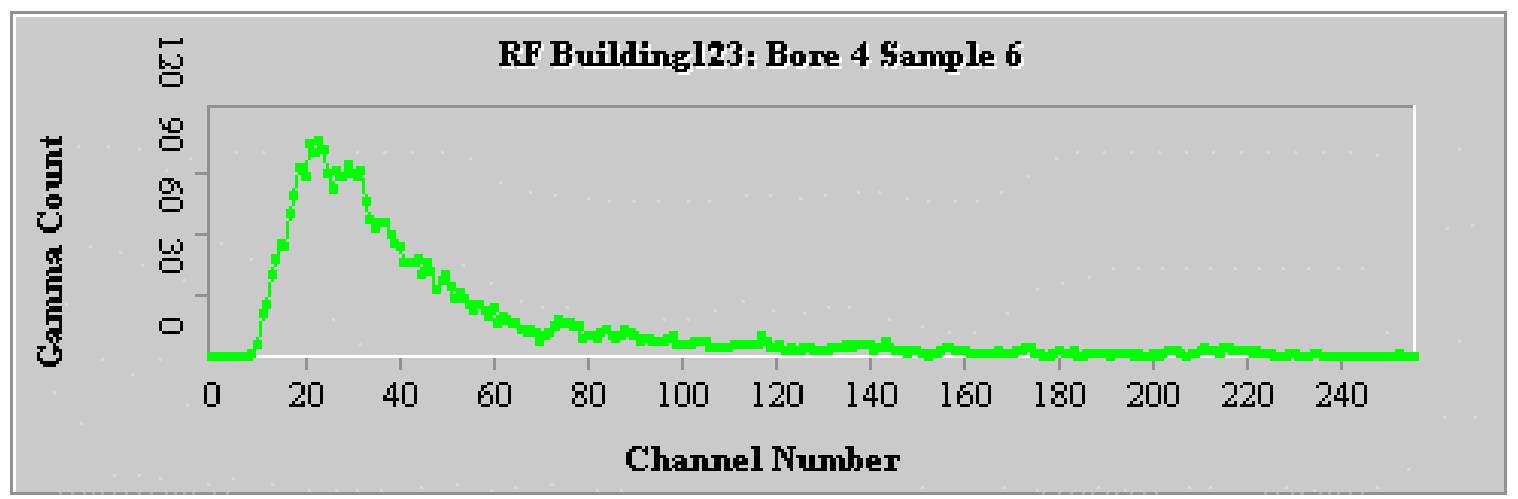

Figure D 4-6b: Cumulative Gamma Spectrum (10 spectra) from Bore 4 Sample 6.

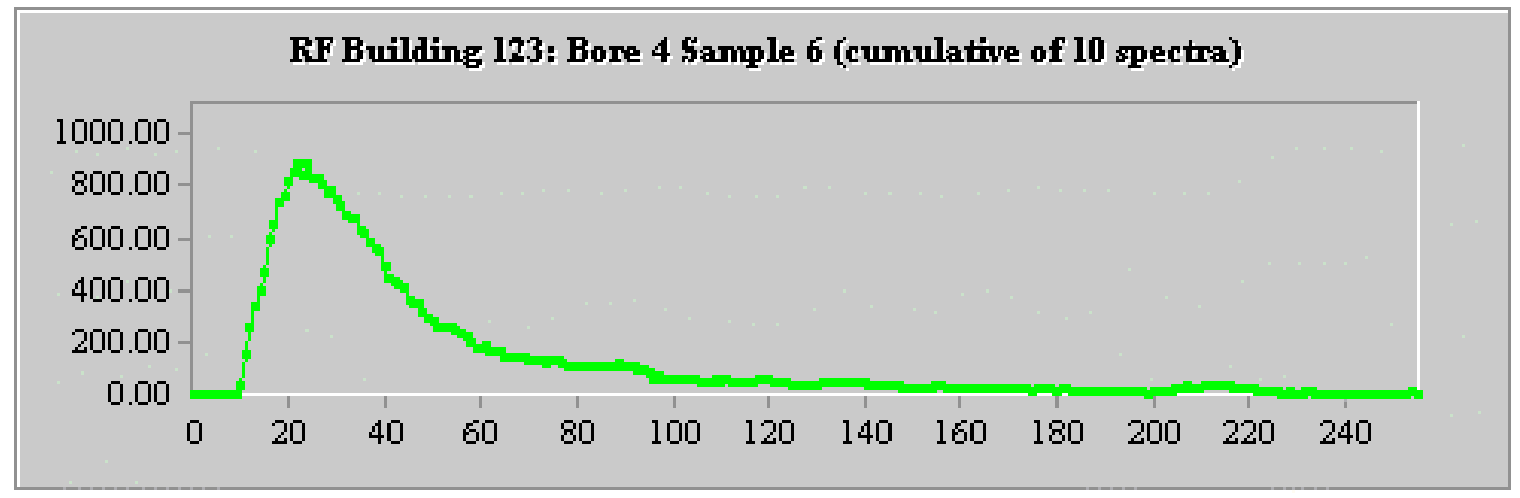


APPENDIX E - EMWD Background Gamma Spectra (Bldg 886)

\section{EMWD Background Gamma Spectra: \\ Building 886}


Figure E 1a: Lab Calibration-Gamma Spectrum of K-40

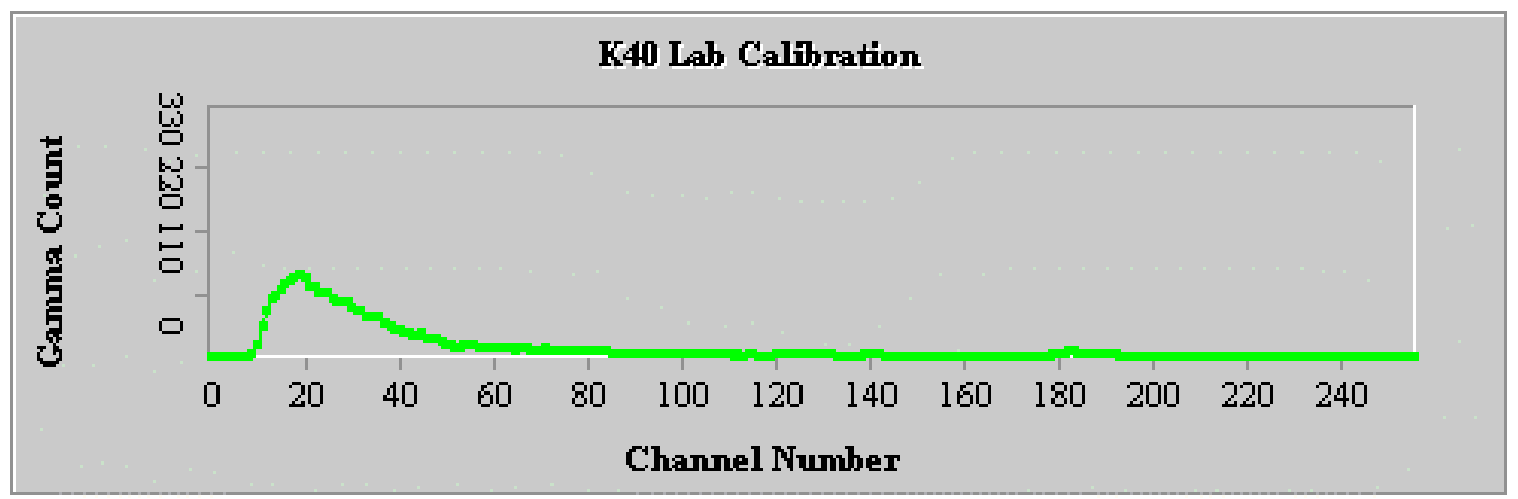

Figure E 1b: Lab Calibration-Cumulative Gamma Spectrum (14 spectra) of K-40.

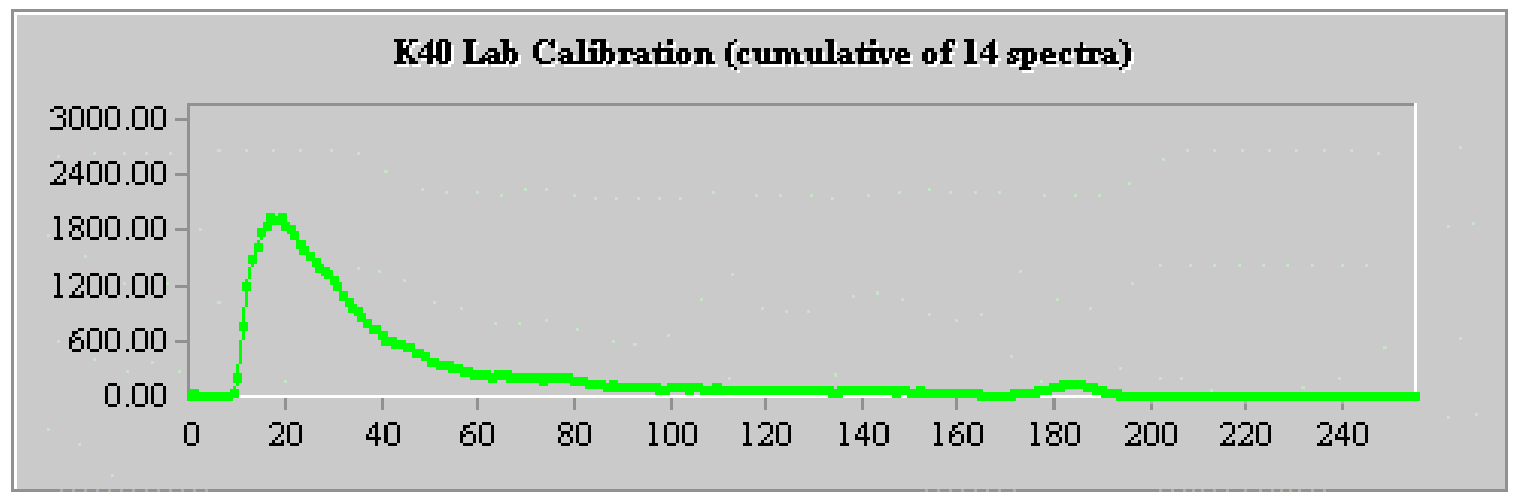

Figure E 2a: Field Calibration-Gamma Spectrum of K-40 at Building 886

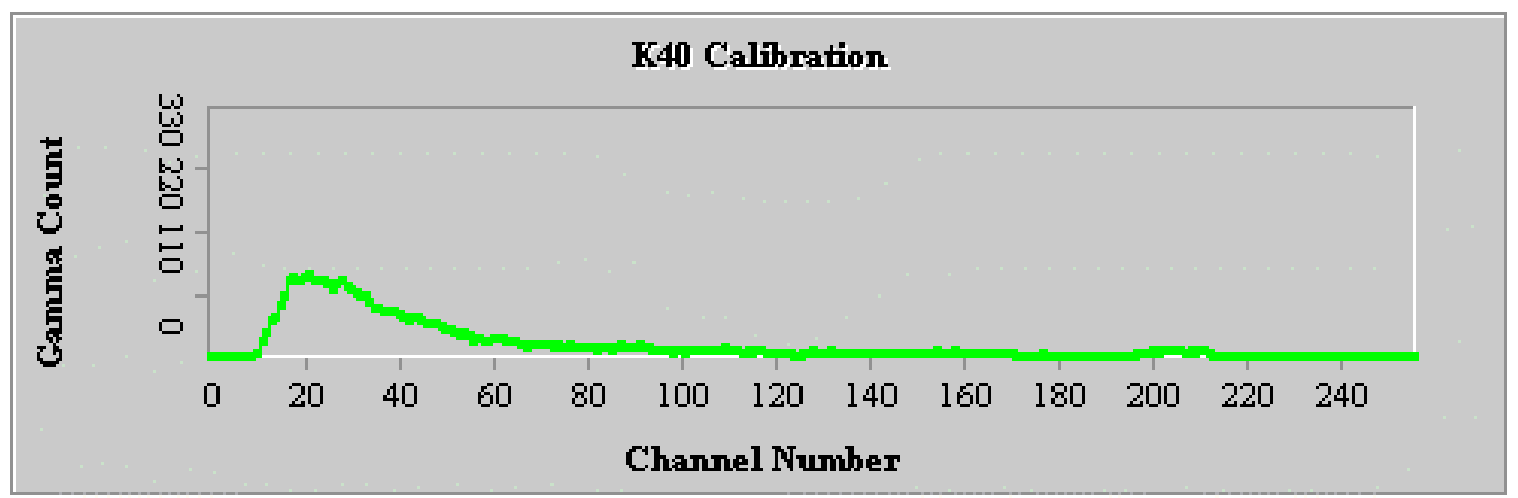


Figure E 2b: Field Calibration-Cumulative Gamma Spectrum (20 spectra) of K-40 at Building 886

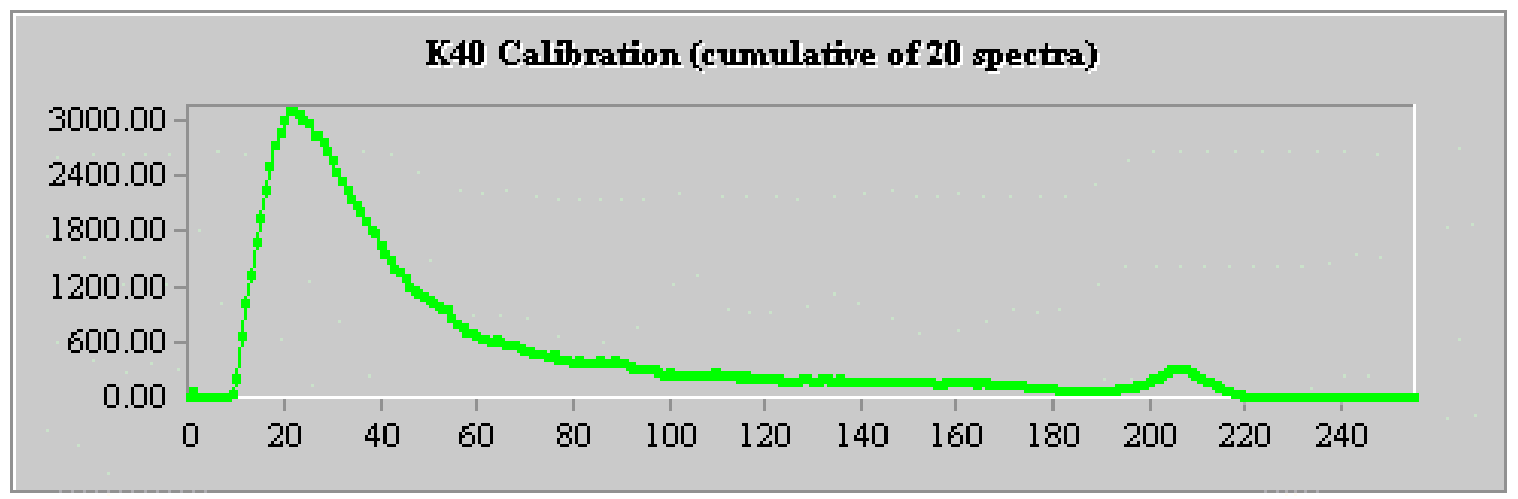

Figure E 3a: Field Calibration-Gamma Spectrum of K-40 at Building 886 next to wall

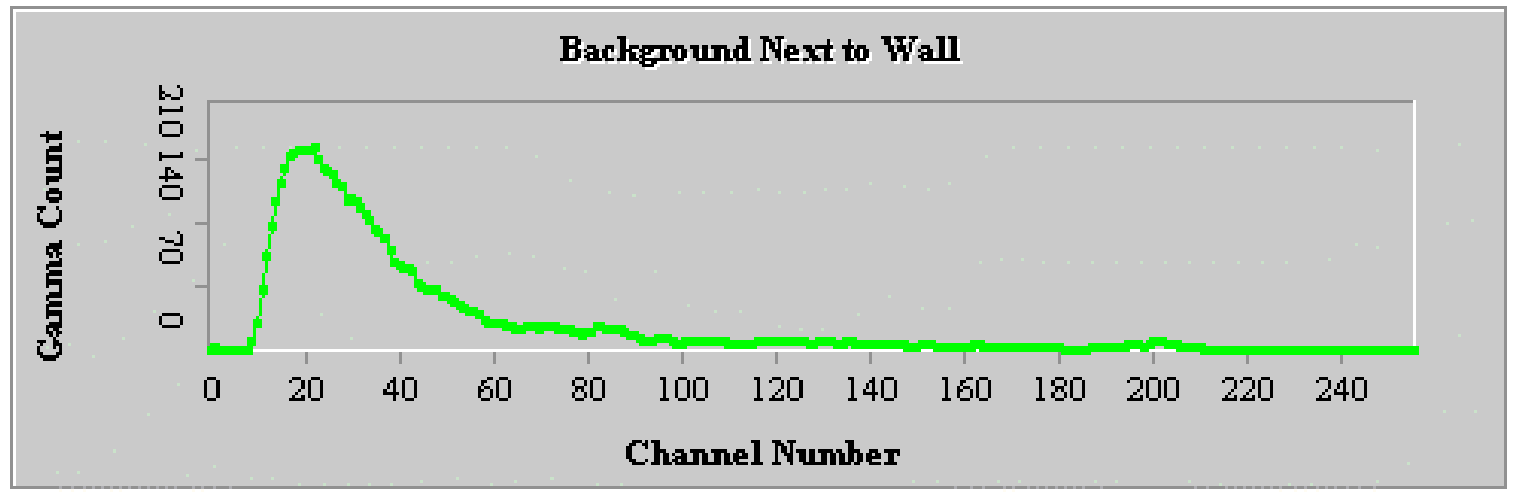

Figure E 2b: Field Calibration-Cumulative Gamma Spectrum ( 8 spectra) of K-40 at Building 886 next to wall.

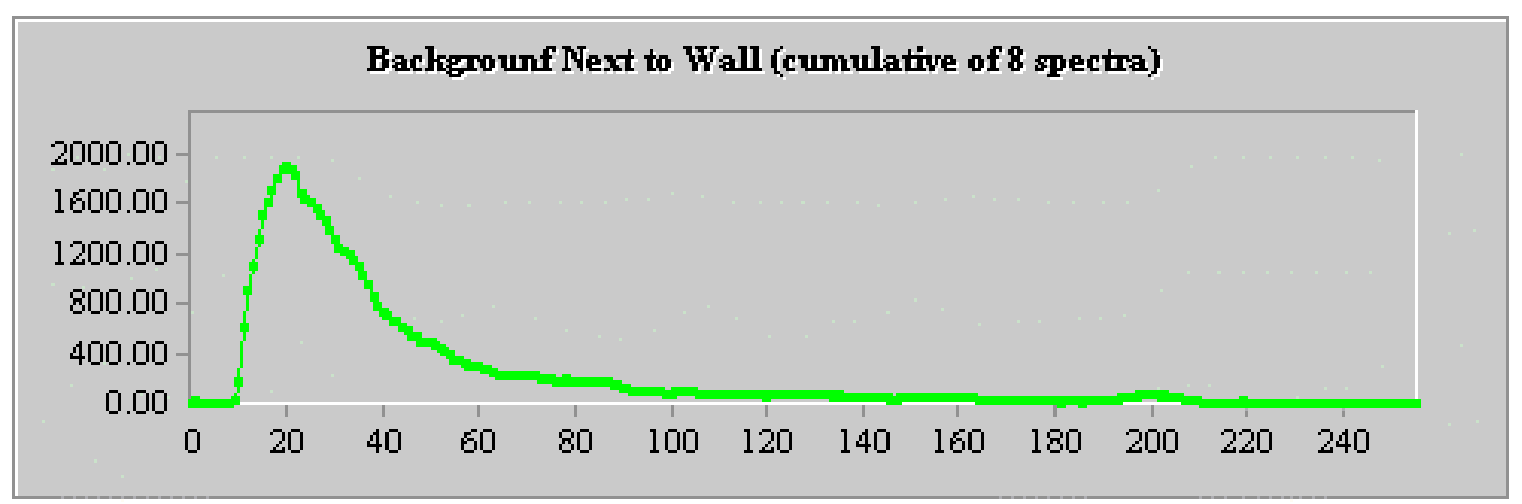


APPENDIX F - EMWD Gamma Spectra (BIdg 886)

EMWD Gamma Spectra for Building 886 
Building 886-Bore Number 5: This bore was not carried out.

\section{Building 886-Bore Number 6}

Figure F 6-1a: Gamma Spectrum from Bore 6 Sample 1

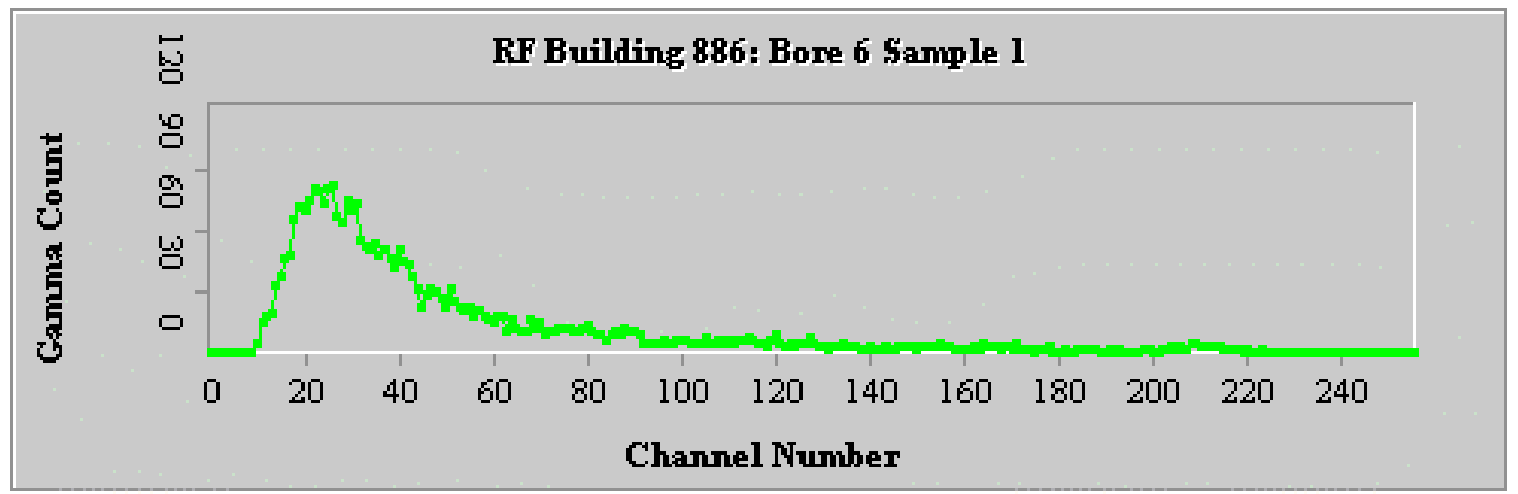

Figure F 6-1b: Cumulative Gamma Spectrum (10 spectra) from Bore 6 Sample 1.

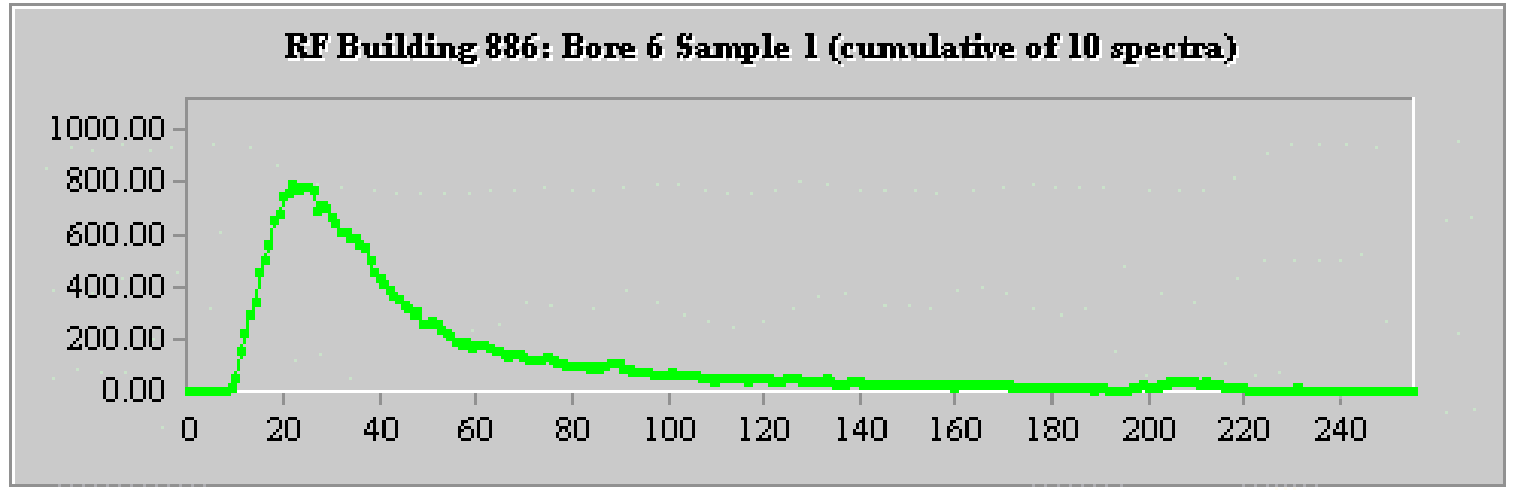

Figure F 6-2a: Gamma Spectrum from Bore 6 Sample 2.

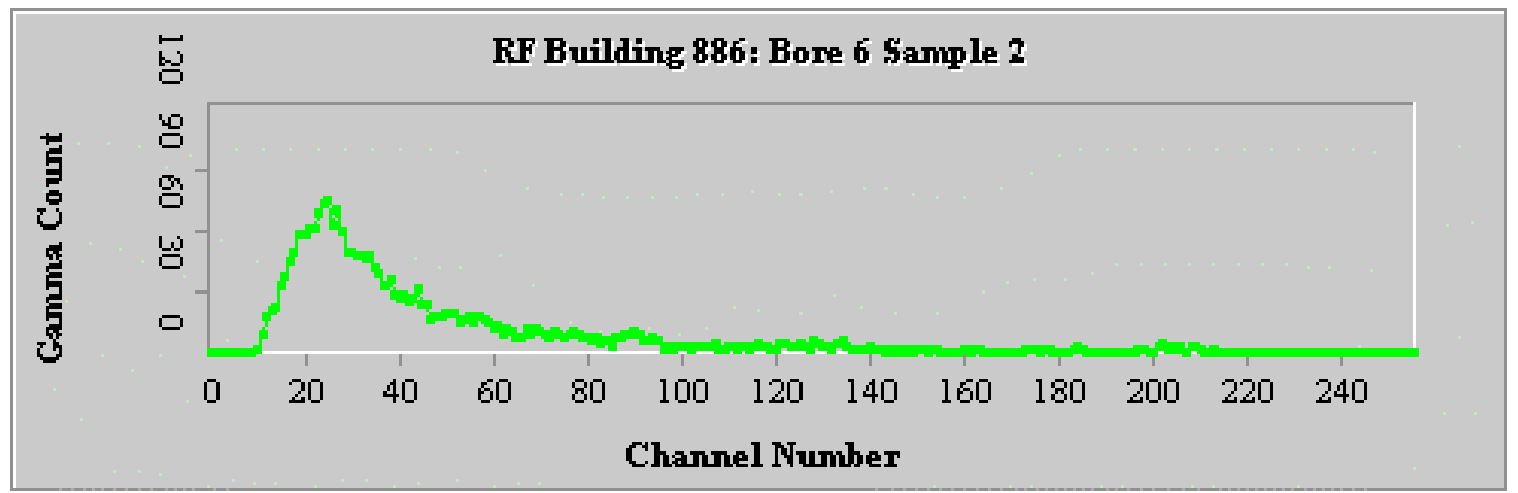


Figure F 6-2b: Cumulative Gamma Spectrum (10 spectra) from Bore 6 Sample 2.

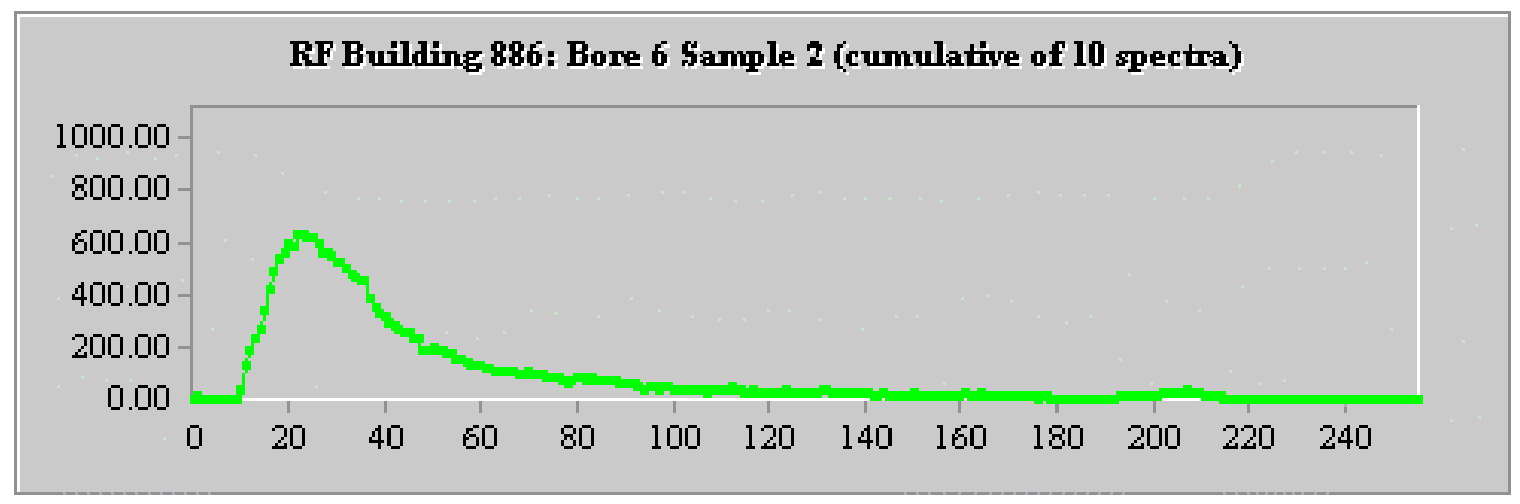

Figure F 6-3a: Gamma Spectrum from Bore 6 Sample 3.

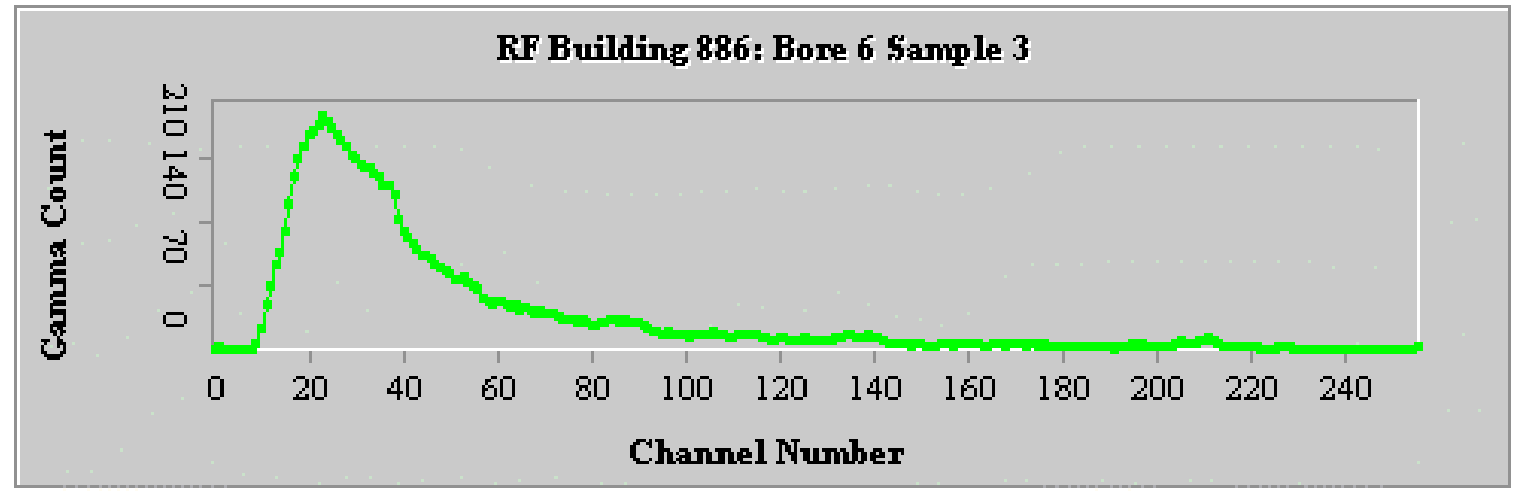

Figure F 6-3b: Cumulative Gamma Spectrum (10 spectra) from Bore 6 Sample 3.

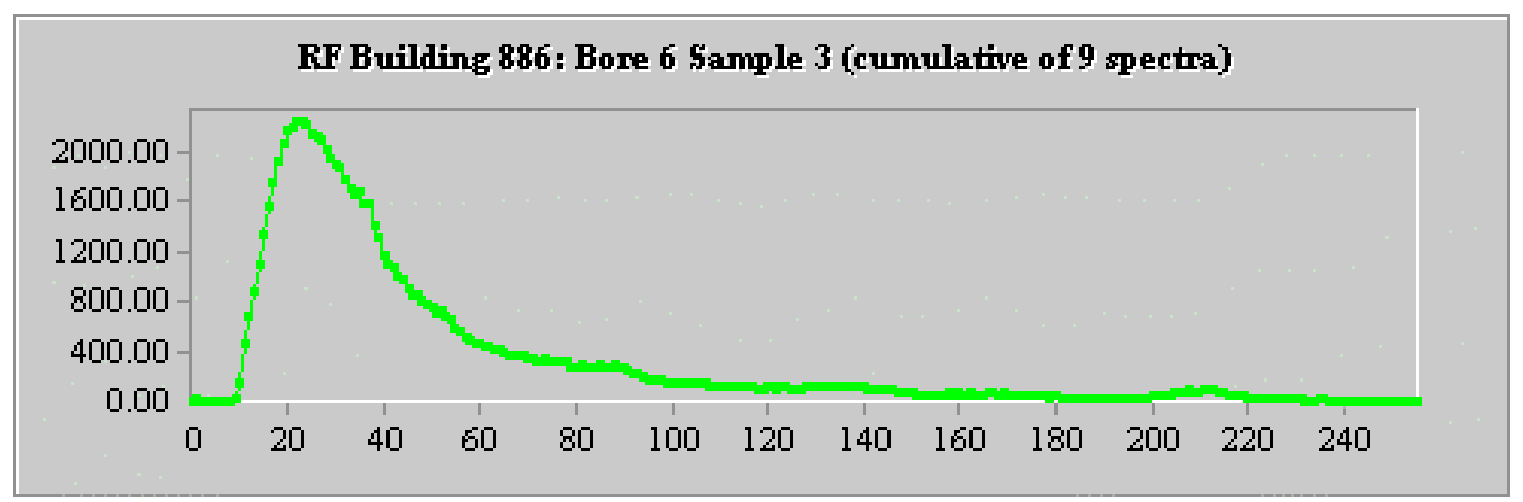


APPENDIX G - EMWD Gamma Ray Spectrometer Methodology

\section{EMWD Gamma Ray Spectrometer \\ Calibration Methodology}




\section{EMWD Spectral Gamma Calibration and Field Measurement}

\section{Introduction}

There are two main elements for converting spectral gamma energy readings into an indication of soil contamination levels. First is the linear correlation of gamma energy Vs channel location. In general this correlation can be determined in the lab using known source material emitting gamma particles at differing energy levels. Second is the calibration of gamma flux density Vs contamination levels. This second process is not directly determined by laboratory standards. In fact this second step is under investigation at many DOE waste sites.

In this report a calibration process is looked at for the spectral gamma NaI detector used in the Environmental Measurement-While-Drilling system (EMWD). A quick look at linear channel calibration is given, using actual EMAD laboratory data. To better understand the unfolding process for calculating radionuclides, a short explanation for unfolding naturally occurring radionclides for uranium exploration is given. This process is also used to gage the performance of newly developed spectral systems for environmental work. Following the unfolding process for natural radiation will be a look at actual spectral logging data from a waste site and an unfolding method for cesium and cobalt.

The final goal of this work is to justify and document reasoning for taking a simpler approach concentrating on cesium detection.

\section{Gamma Energy Vs Channel Location}

This function very closely matches a straight line with a zero intercept, measured gamma energy $=\mathrm{a} *$ (Channel Number) $+\mathrm{b}$. The NaI crystal sensor is exposed to differing radio nuclide, emitting gamma particles of differing energy levels. Exposure is continued until peaks appear in the spectrum at count levels assuring accurate peak channel measurement, normally $>100$ counts or X10 background. Below are the laboratory-measured values for the given sources.

Table 1: Linear Calibration Results

$\begin{array}{lccc}\text { Source Element } & \begin{array}{c}\text { Peak Energy } \\ (\mathbf{M e V})\end{array} & \begin{array}{c}\text { Peak Channel } \\ \text { Number }\end{array} & \begin{array}{c}\text { \% Difference } \\ \text { From Calc. }\end{array} \\ \text { Cs } 137 & 0.662 & 92 & 1.1 \\ \text { Co } 60 & 1.173,1.332 & 163,186 & 0.7,0 \\ \text { Mn } 54 & 0.835 & 115 & 1.7 \\ \mathrm{Na} 22 & 0.511,1.275 & 74,178 & 2.9,0\end{array}$

The resulting linear regression for energy Vs channel number is: $\mathrm{Y} \mathrm{MeV}=7.18 \times 10^{-3} \mathrm{MeV} *$ (Channel Number) - 4.90XIO-3 $\mathrm{MeV} @$ room temperature. Working backwards using the given channel number and the known energy gamma the percent deference was calculated. The correlation coefficient of Table I values is 0.9996 . The linear response of a NaI detector is very good. However, a number of factors can cause the slope 'a' to change while drilling, primarily temperature, high voltage drift, and photon-multiplier tube aging. Controlling these parameters is critical to proper measurement. 


\section{Flux Density Vs Contamination Levels}

Gamma counts rate is a relative measure of gamma flux, dependent on many factors as detector size, housings, etc. This flux is proportional to the amount of radioactive material in the soil. Thus, the measured flux is converted to $\mathrm{pCi} / \mathrm{g}$ by calibration coefficients derived from calibration models. These models have known amounts of source material distributed in a large enough volume to appear infinitely large to traveling gamma rays, about a two to four foot radius about the sensor.

However, soil conditions infinitely vary for moister content and physical make up. Moister and soil types influence the measured gamma flux Limitations in calibration for flux density Vs contamination levels in soil result in an assumption that all soil conditions are consistent with the calibration models.

The most commonly used calibration models are maintained for Doe's Grand Junction Projects Office in Grand Junction Co. by contract with Rust Geodic Inc ${ }^{a}$. These models were built to calibrate instrumentation used for uranium exploration. As such these models contain three naturally occurring elements, K-40, Ra-226, and Th-232, (KUT). Because these models are well characterized and documented they are used to set baseline accuracy for all subterranean gamma instrumentation. Stromswold (1981) uses gamma count windows centered about energy peaks of the three naturals that unfold from highest energy to lowest. Table 2 shows his suggested windows.

\section{Table 2 Spectral Energy Windows for Unfolding KUT}

\section{Element}

Potassium (K40)

Uranium (Ra-226)

Thorium (Th-232)

\author{
Unique Gamma Ray (MeV) \\ 1.46 \\ $1.76 \& 2.20$ \\ 2.61
}

Energy Window (MeV)
$1.320-1.575$
$1.650-2.390$
$2.475-2.765$

In working with subterranean gamma there is a problem of higher energy gamma rays being counted in lower channels, down scattering. By choosing the Thorium. Window about the 2.61 $\mathrm{MeV}$ gamma, Thorium can be solved for because potassium and uranium don't have any gamma rays higher than $2.39 \mathrm{MeV}$. Once thorium is known then the solution for uranium can be found because potassium is below the $1.65 \mathrm{MeV}$ window used for uranium. This process is called unfolding. The Grand Junction B models are well suited for this unfolding process. The B model concentrations listed in Table 3 below.

\section{Table 3. Grand Junction B-Model Concentrations}

$\begin{array}{lccc}\text { Model } & \begin{array}{c}\text { Concentration Th } \\ (\mathbf{P c i} / \mathbf{g})\end{array} & \begin{array}{c}\text { Concentration Ra } \\ \mathbf{( P c i / g )}\end{array} & \begin{array}{c}\text { Concentration K } \\ \mathbf{( P c i / g )}\end{array} \\ \text { BT Upper } & 58.78 \pm 1.53 & 10.46 \pm 0.51 & 10.13 \pm 1.34 \\ \text { BU Upper } & 0.65 \pm 0.06 & 194.59 \pm 5.94 & 10.63 \pm 1.00 \\ \text { BK Lower } & 0.10 \pm 0.02 & 1.03 \pm 1.67 & 54.00 \pm 1.67\end{array}$

By placing the spectrometer into each of the three models, subtracting electrical noise, and counting gamma for each of the three windows in Table 2, a rate matrix $\mathrm{R}$ is produced. Matrix $\mathrm{R}$ is guaranteed to be nonsingular because of the window selection process assures an upper triangular form. Using the concentrations of Table 3 a set of coefficients relating window count 
rates to concentrations ( $\mathrm{pCi} / \mathrm{g}$ ) can be solved for using Eq1. An important note on counting periods; The statistical nature of gamma counting requires long enough counting periods to gain a meaning full count rate. The standard deviation of the gamma count is equal to its square root, i.e. 100 counts has a 10 count sdv.

$$
\begin{gathered}
\mathrm{A}=\mathrm{CR}^{-1} \mathrm{Eq} 1 \\
\text { A is a } 3 X 3 \text { Matrix of Calibration Coefficients } \\
R \text { is a } 3 X 3 \text { Matrix of Count Rate reading for each of the three windows } \\
C \text { is a } 3 X 3 \text { Matrix of Known model concentrations from Table } 3
\end{gathered}
$$

Once A is known then the system is tested against a forth model (BM) which is a mix of all three elements. A properly calibrated spectrometer then solves for concentration levels for KUT using equation Eq2.

$$
\mathrm{C}=\mathrm{AR} \mathrm{Eq} 2
$$

Equation 2 is used to convert gamma flux rates to density measurements in $\mathrm{pCi} / \mathrm{g}$ as the system is drilling or logging. There are a number of additional considerations to the process which should be addressed. First, the linear calibration relating gamma energy peaks to channel numbers in the spectrum is used for setting the KUT windows of Table 2. Anything that alters this calibration affects the calculated concentration levels. The measure of the gamma rate is dependent on concentration levels but also the MCA conversion rate. Low power MCAs normally employ slow conversion methods increasing dead time (DT). Where DT and R are both in units of seconds, Eq3 below is used compensate for a slow MCA.

$$
\begin{gathered}
\mathrm{R}^{\prime}=\mathrm{R}^{*} 1 \mathrm{sec} /(1 \mathrm{sec}-\mathrm{DT}) \mathrm{Eq} 3 . \\
D T \text { is a function of MCA total counts and conversion time } \\
R^{\prime} \text { is a new MCA compensated rate matrix }
\end{gathered}
$$

In the general solution of converting gamma count rates to KUT soil concentrations, a basic assumption was made; Only naturally occurring gamma sources are found in the soil. The manmade radioactive waste creates a new set of gamma mitters in contaminated soils.

In the case of Cesium (Cs-137), its' gamma ray is at $0.66 \mathrm{MeV}$. Using this unfolding process Cesium would be unfolded after potassium. Too follow this logic; every radioactive element distributed within the soil must be accounted for in the unfolding process. The dominant waste radionuclides generally found in the soils at Hanford and Savannah River are Cesium- 137, Europium- 154, Europium-1 52, and Cobalt-60. Ina Westinghouse Savannah River 1994 report on H-Area retention basin list maximum concentrations as shown in Table 4 . Table 4 is by no means a complete list of man-made waste, radioactive or otherwise.

\section{Table 4. Example of found Radionuclides at a Waste Site}

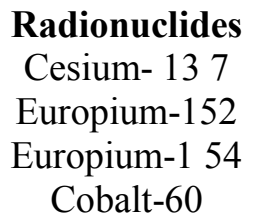

Max. Concentration, $\mathbf{p C i} / \mathbf{g}$
33000
47
33
1.8

Figure 1 is log data taken with a HPGe detector used at Hanford, (C.J. Koizumi, 1993). There are two important attributes demonstrated by this data. First, the total count is a good indicator of waste radionuclides in the soil. Second, cesium waste maybe independent of other radionuclides. 
A complete gamma spectrum is shown in Figure 2. This spectrum was taken at $16.8 \mathrm{~m}$ depth in the $\log$ run shown in Figure 1. Here the spectrum is scaled out to $2.8 \mathrm{MeV}$. By scaling out so high the thorium peak at $2.61 \mathrm{MeV}$ can be monitored for changing backgrounds. The measured concentrations for this spectrum at as follows: $3 \mathrm{pCi} / \mathrm{g}$ of Co- $60,29 \mathrm{pCi} / \mathrm{g}$ of Eu- 154 and $8 \mathrm{pCi} / \mathrm{g}$ of K-40. The vast majority of spectral activity is below the K-40 peak at $1.46 \mathrm{MeV}$.

Looking again at Figure 2, the down scattering of higher energy gamma into the $0.66 \mathrm{MeV}$ energy channel is a concern. Because of the low energy Cs-137 gamma virtually all background and other man-made radioactive waste interferes with the cesium measurement.

\section{Unfolding Co and Cs From Background, An Example}

Unfolding the three naturals along with cesium and cobalt (Randall and Stromswold, 1995) used windows 1.105 to $1.420 \mathrm{MeV}$ for cobalt and 0.590 to $0.715 \mathrm{MeV}$ for cesium. Lumping the background $\mathrm{Th}$ and $\mathrm{U}$ counts as a single constant term, the Cs and Co unfolding formulas are shown below.

$$
\begin{aligned}
& C_{c o}=\mathrm{aR}_{\mathrm{co}} \cdot-\mathrm{bR}_{\mathrm{K}}-\mathrm{cR}_{\mathrm{CS}}-\mathrm{BKG}_{\mathrm{C} 0} \quad \mathrm{Eq} 4 . \\
& C_{c s}=\mathrm{dR}_{\mathrm{cs}}-\mathrm{ER}_{\mathrm{cs}}^{2}-\mathrm{fR}_{\mathrm{co}}-\mathrm{BKG} \text { Eq5. } \\
& \text { Terms “ } a ”-~ " f " \text { are unique coefficients. }
\end{aligned}
$$

$B K G$ is the constant background subtraction of each element. In all cases BKGcs, > BKGco.

Both equations 4 and 5 use the K40 rates directly. This is done because the cobalt upper gamma is very near that of potassium. The NaI detector resolution will overlap gamma counts. In Eq5 has a cobalt count rate term for calculation of cesium. Often cesium and cobalt are found together and the down scattering of the higher energy cobalt is a significant. Eq5 incorporates a squared term for pile up correction at very high count rates.

\section{Suggested Approaches For EMWD}

The EMWD MCA is a 256 channel multi-channel analyzer. The NaI crystal is (at present) a four by one inch cylinder. Complete spectrums are transmitted to the surface every 30 seconds. Spectrums are not being taken while data is being transmitted. The actual sample period is $\sim 20$ seconds. Spectrums can be summed at the surface to longer sample periods.

The main focus of the EMWD system is to detect and measure cesium contamination levels while drilling. There are no cesium waste models for calibration of spectral gamma logging systems. Even if such a model existed there are too many types of mixed radionuclides at each DOE site for any $\mathrm{NaI}$ system to accurately unfold. Two methods are suggested for calibrating a system to unfold Cs-13 7 from natural background spectrums. In both cases, total gamma counts will be used to detect increased levels of man-made waste. The total count might also help detect when count rates are increased by manmade waste other than Cs-13 7 by the simple relationship in Eq6.

TC

$$
\begin{aligned}
& \begin{array}{llllll} 
& a R_{c s}- & b R_{K} & - & B_{K G} &
\end{array} \quad \text { Eq6 } \\
& T C=\text { total counts } \\
& B K G_{T C} \text { taken from reading is a clean area } \\
& a \& b \text { coefficients derived from field testing. }
\end{aligned}
$$




\section{Calibration Method I}

This method would treat the spectrum readings in the same fashion as calibrating any spectral gamma logging system as addressed earlier in this report.

Set the linear range to $2.8 \mathrm{OmeV}$, full scale. Choose windows for all three naturals plus Cs- 137 . Eq1 is now composed of $4 \mathrm{X} 4$ matrixes. B-models can be used where the model concentration of Cs-137 is assumed zero. To solve for matrix A, a fourth model of known concentration of Cs-137 must be used. This Cs-137 model may actually be a characterized well as logged in Figure 1 at a waste site. This approach is heavily dependent on the quality of the Cs-137 model. The matrix inversion simultaneous solution of linear equations produces a least squares fit to given data. The solution maybe sensitive to slight changes in concentration levels, non-robust. This problem is compounded by the lack of a properly configured mixed model to help test the solution.

\section{Calibration Method 2}

The energy range will be low, upper end limited at $1.6 \mathrm{MeV}$. This is done to utilize system sensitivity about the range of interest, see Figure 2. Gamma rays above this threshold are counted as a total and stored in channel 255. By monitoring this channel normal thorium and uranium background levels can be monitored. These background levels will be characterized at the site by drilling a short bore outside of the contaminated area. Along with channel 255, the potassium and cesium windows will also be characterized for background down scattering. Using the B-model, the cesium window can be characterized for potassium down scattering.

$\mathrm{C}_{\mathrm{cs}}=\mathrm{aR}_{\mathrm{cs}}-\mathrm{bR}_{\mathrm{K}}-\mathrm{BKG}_{\mathrm{cs}} \quad \mathrm{Eq} 7$

Several cesium dominated wells of differing levels will be required to curve fit system response to cesium. If background reading remain constant and Cs-137 dominates all other types of manmade waste then the linear relationship should be well bounded.

\section{Conclusion}

The EMWD spectrometer is capable of linear calibration of gamma energy peaks at room temperature. The logging industry in cooperation with DOE has developed spectral gamma calibration methods and facilities. These method and facilities are not sufficient to fully calibrate spectral gamma systems for subterranean measurement of man-made mixed waste.

Actual logging data taken of radioactive waste by a HPGe system points to the complexity of the problem. For the EMWD system using a NaI detector there is no recognized solution for calibration or unfolding spectrums in man-made radioactive waste sites with unknown radionuclide.

Two methods were looked for calibration and unfolding. One method expands the accepted method used for spectral gamma logging tool calibration used in uranium exploration wells. The second method assumes a fixed background and attempts to equate a linear relationship between gamma count rates in cesium directly. Both methods or some combination of approaches needs to be tested before release for site characterization. 
'R- Leino, D.C. George, B.N. Key, L. Knight, and W.D. Steele, June 1994, Third Edition, Field Calibration Facilities for Environmental Measurement of Radium, Thorium, and Potassium, technical Measurements Center Grand Junction Projects Office. 
APPENDIX H - EMWD Gamma Ray Spectrometer Calibration

EMWD Gamma Ray Spectrometer Calibration 
The EMWD Gamma Ray Spectrometer (GRS) was calibrated in the laboratory and in the DOE calibration models at the Grants Facility. These models were built to calibrate instrumentation used for uranium exploration. As such these models contain three naturally occurring elements, K-40, Ra-226, and Th-232, (KUT).

The calibration in the laboratory was conducted in a steel pipe to simulate the steel housing. The results for calibration with Cs-137, Co-60, and $\mathrm{Na}$ are shown in Figure $\mathrm{H} 1$. The Cs-137 peak occurs between channels 80-100. The Co-60 spectra contains two peaks occurring in the range of channels 160-200. The Na spectra is bimodal with predominant peak occurring in $\sim$ channel 75 and a second broader peak occurring at about channel 180 .

The EMWD-GRS also was calibrated using the calibration models at the DOE Grants Calibration Facility. The results for the Th and K-40 calibrations are shown in Figure H-2. The Th spectra occur as a shoulder in the area of channels 85 and 121. The K-40 spectra show a broad peak in the range of channels 200 . 
Figure H-1: Laboratory calibration of the EMWD-GRS using Cs-137, Co60, and Na.
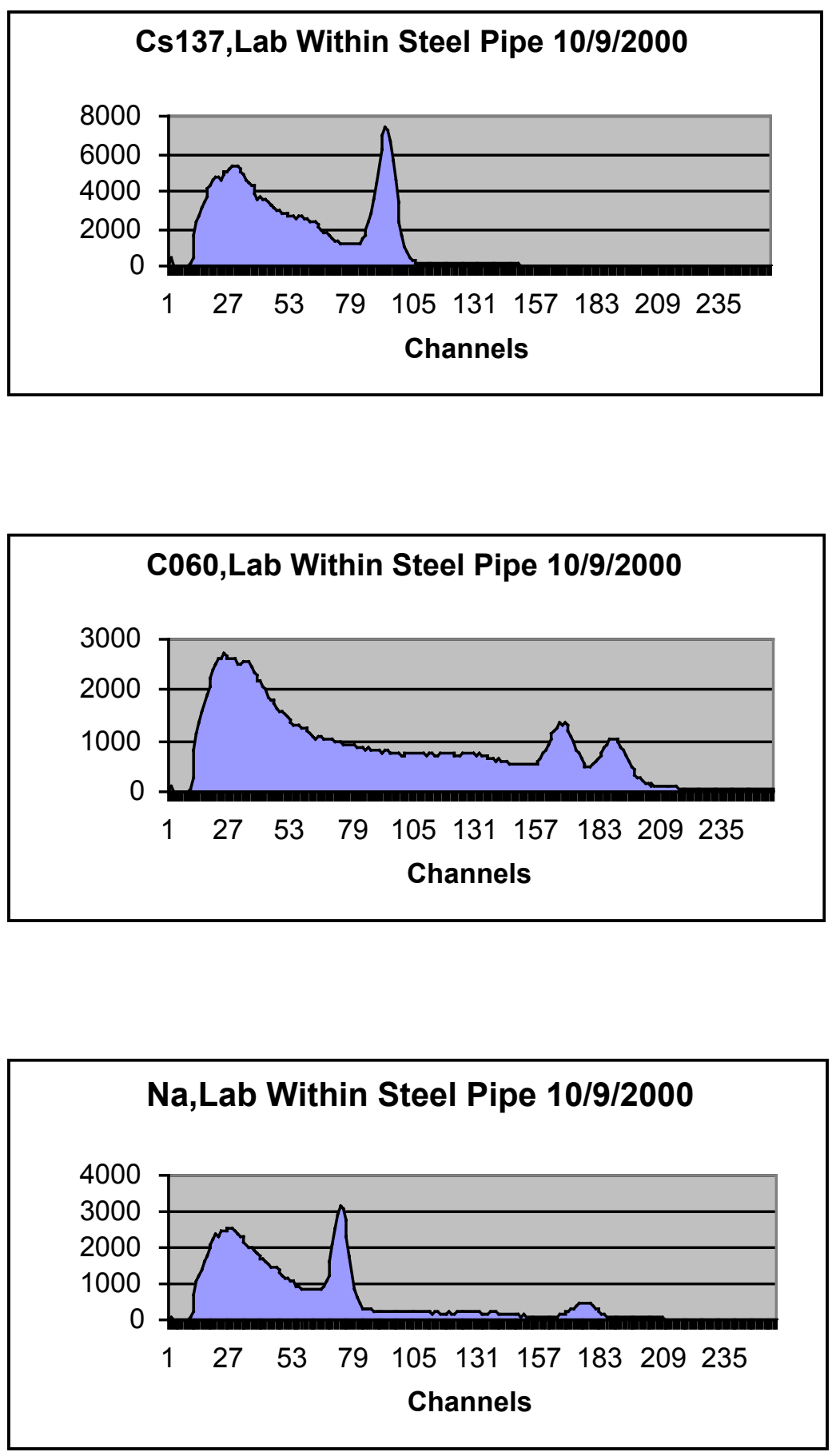
Figure H-2: EMWD-GRS calibration curves for Th and K-40 using the calibration models at the DOE Grants Calibration Facility
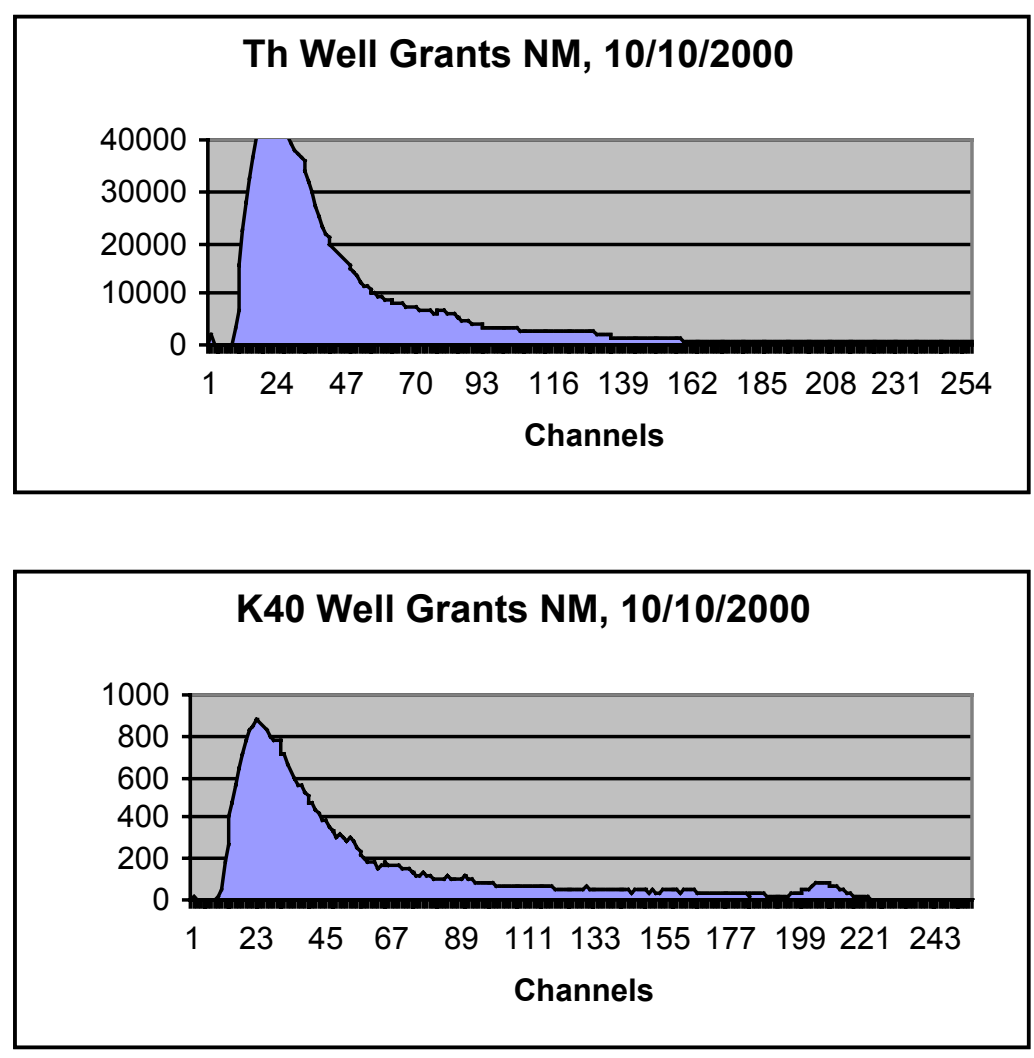


\section{APPENDIX I - Rocky Flats Field Data}

\section{Rocky Flats UBC 123 and Building 886}

\section{Field Data}




\section{I-1: UBC 123 Bore \#1}




\section{Rocky Flats EMWD Deployment}

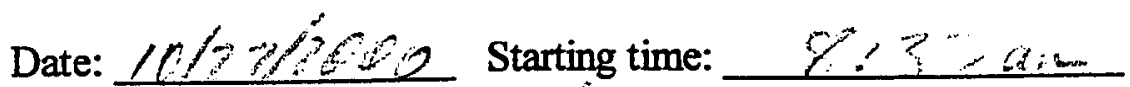

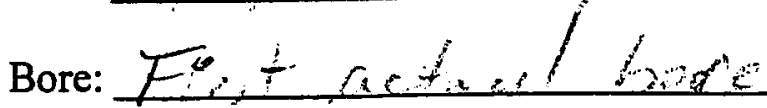

File Name: SER 1.PR

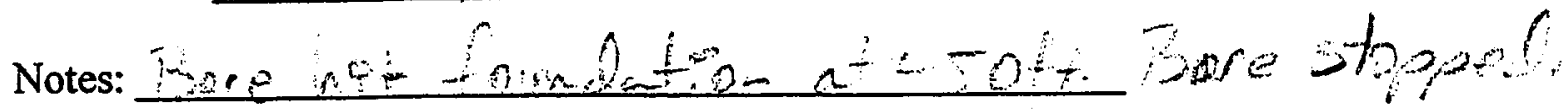

Spectrum \#

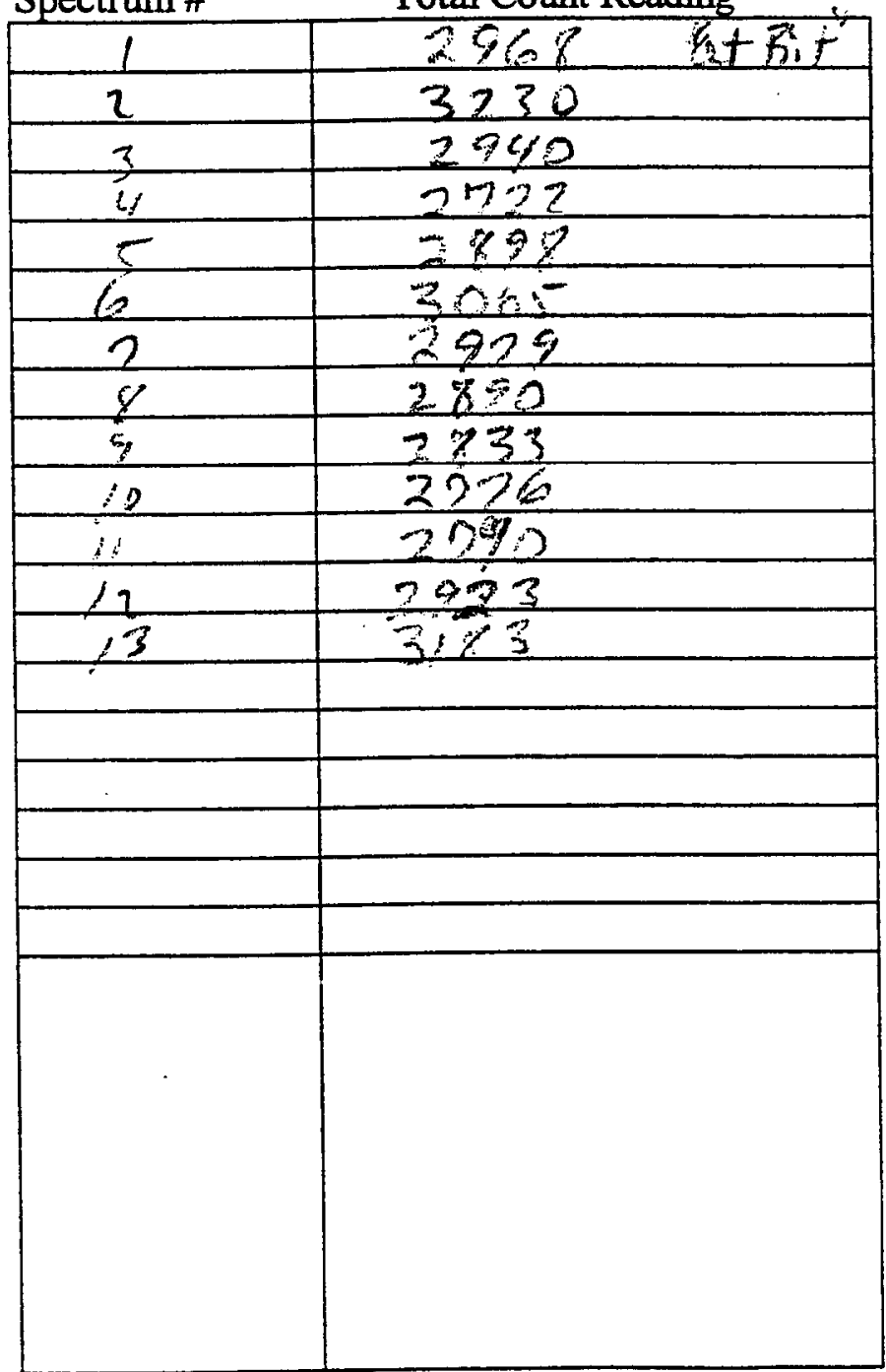

Fist attempted $\log \cdot 5^{20}$ Toiplaind in hole. (2 spectrem, takeat bit) B.+1.pen)

Tool tion pulled out a1f for con restige Fitoi SER $1,3,13$ are in selies Cowng at the ention 50 Ct. The operater ased a $2 f t$ murk on the groweld to heas arer $2 \mathrm{ft}$. His eye Wra sootly eft as we have anl 39 spectroms. 


\section{Rocky Flats EMWD Deployment}

Date: $10 / 22 / 2000$ Starting time: $\quad 92.23$

Bore: Fut actual bece Reali. for the bit at 250 ty

File Name: Bit 2

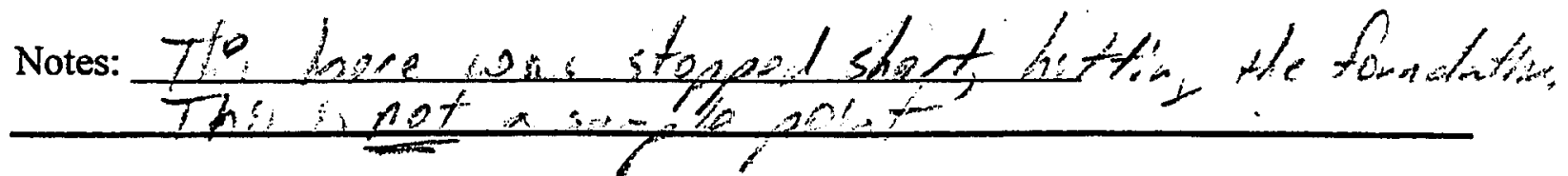
Spectrum \# Total Count Reading

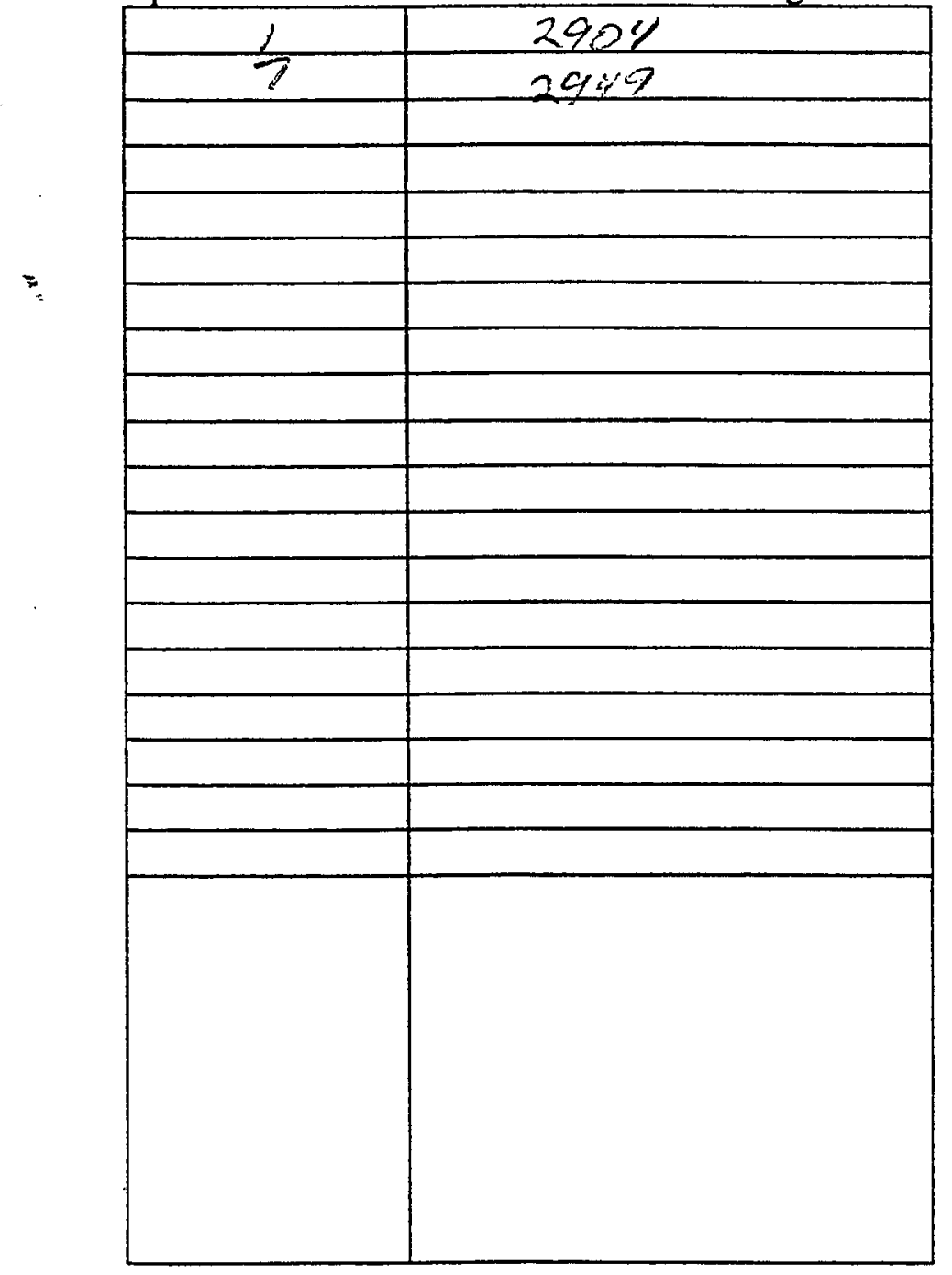


Rocky Flats EMWD Deployment

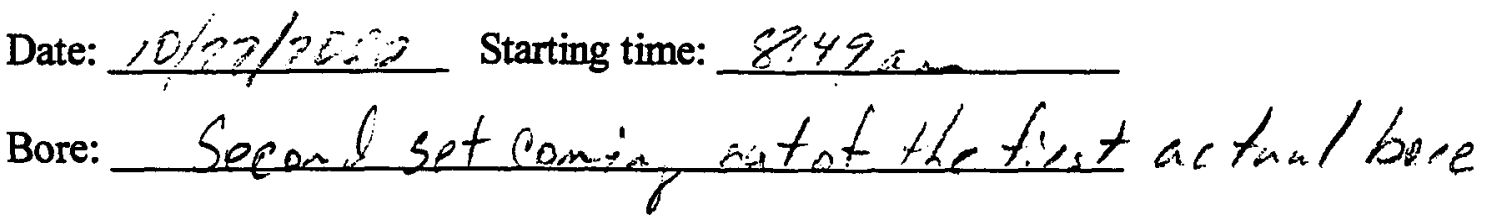
File Name: SER Z

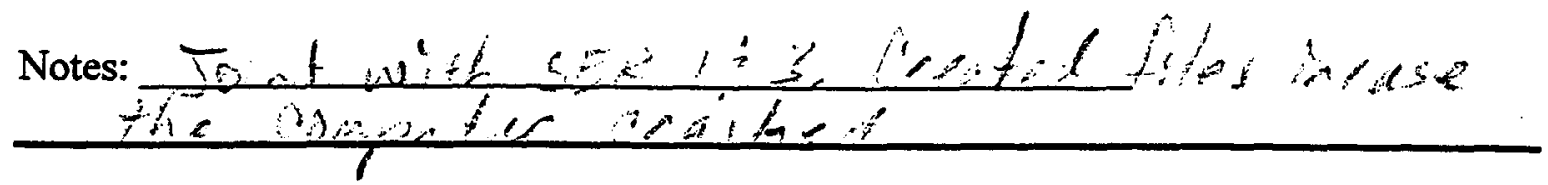

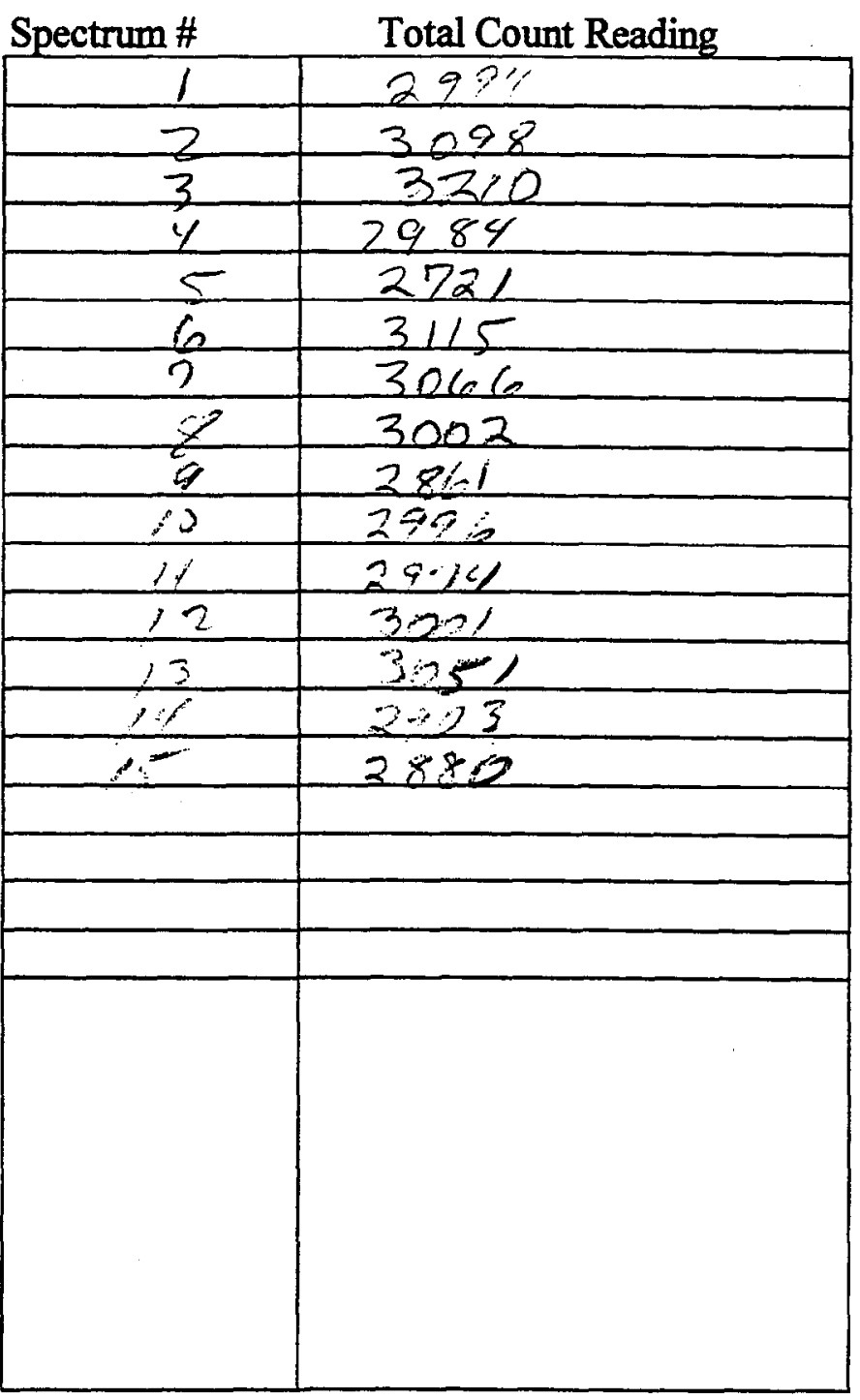

68 


\section{Rocky Flats EMWD Deployment}

Date: $10 / 23 / 202$ Starting time: $8: 5 ?$

Bore: $:= \pm, 1,+1, B_{0} 0$

File Name: $S E R 3$

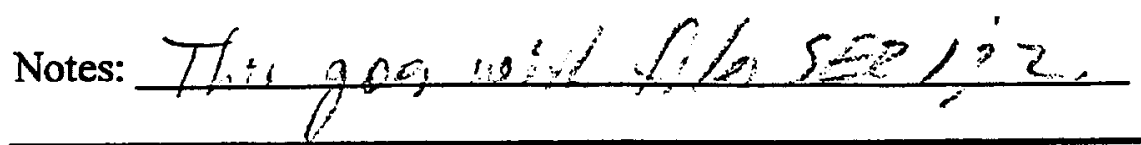

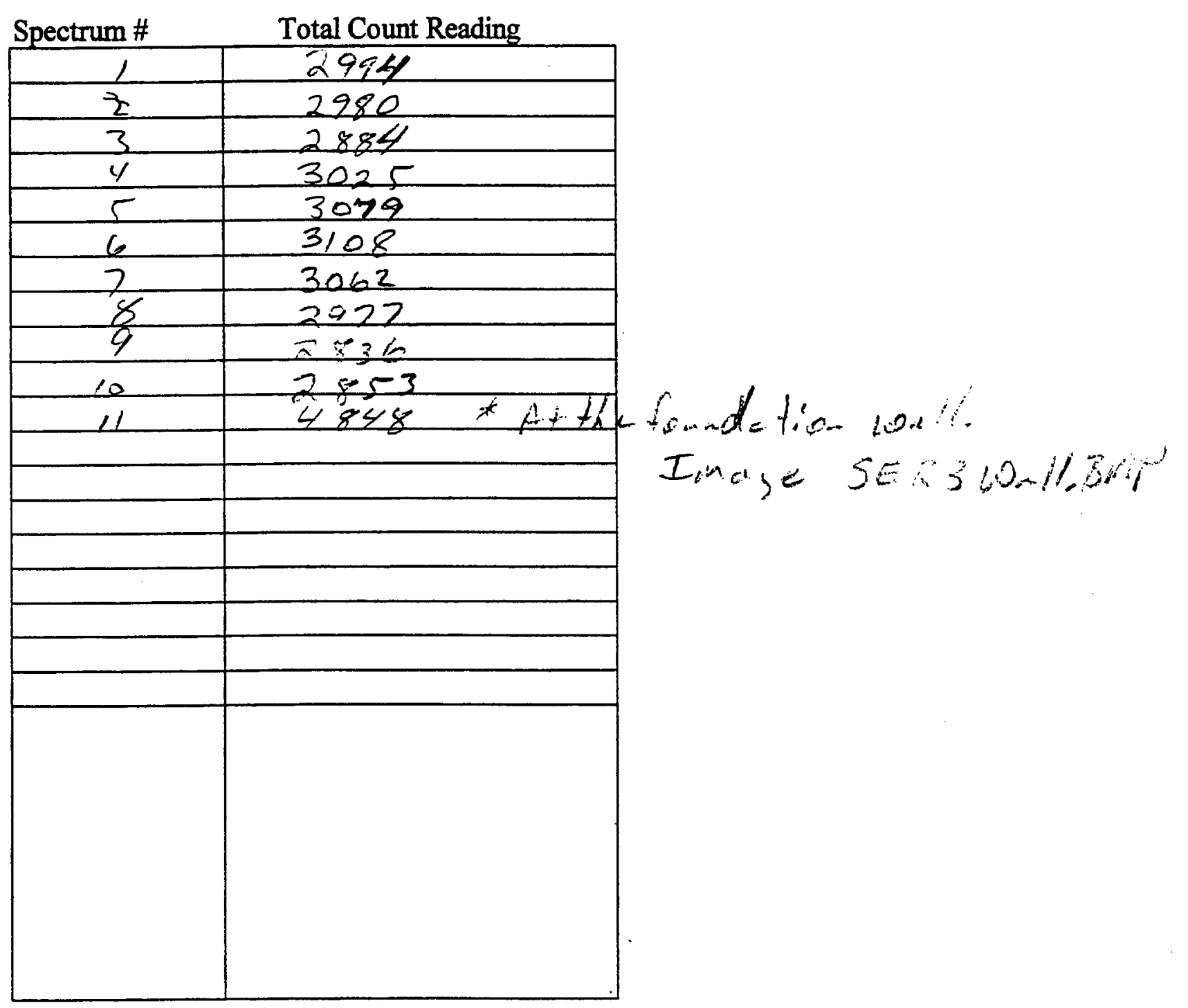


I-2: UBC 123 Bore \#2 


\section{Rocky Flats EMWD Deployment}

Date: $11-7-00$ Starting time:

Bore: $21^{\text {st }}$ SAMPLE@ $10^{\prime \prime}$

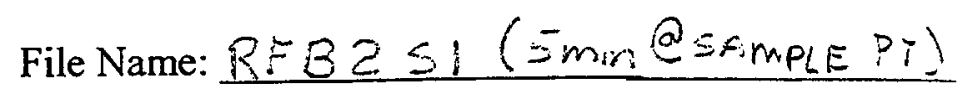

Notes: AT OI PLATEZ BUILDVG 23 HDDLINES

\section{SI}

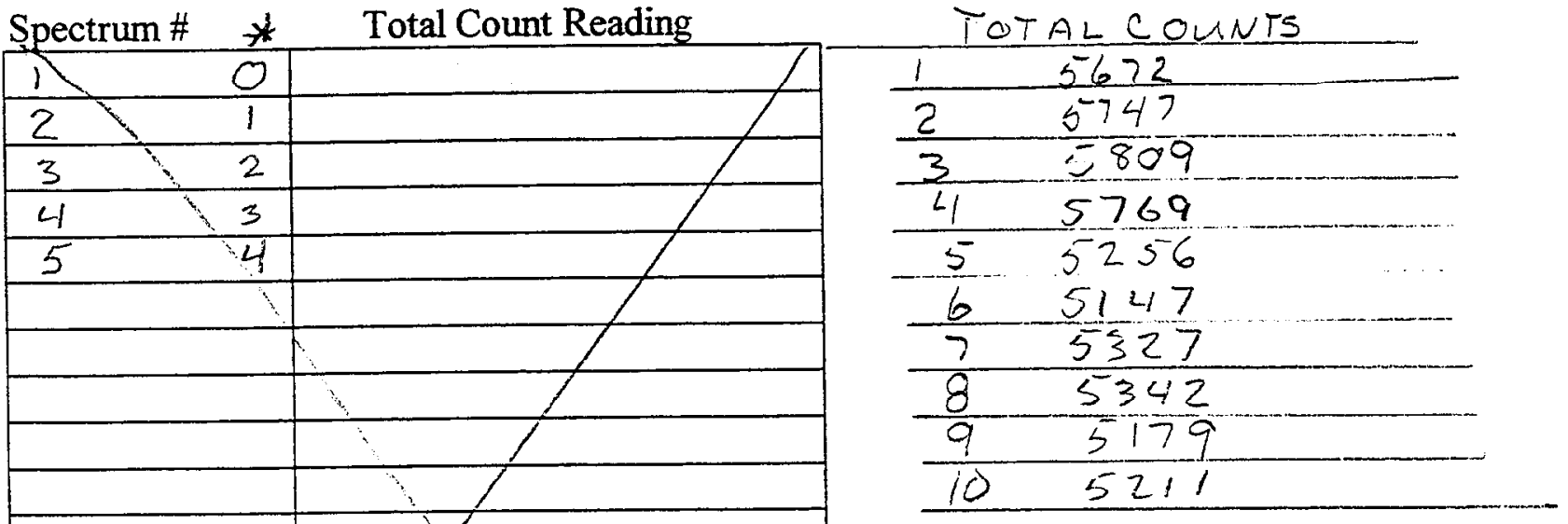

NOTE: 1.46 MeV $187 \mathrm{~cm}$

$$
\begin{gathered}
R=\begin{array}{c}
B=K O \quad \begin{array}{c}
\text { TOCLONGNDW/ } \\
\text { sationtop }
\end{array} \\
4908
\end{array} \\
4863 \\
4820 \\
4878 \\
4869 \\
4708 \\
4940 \\
4732 \\
4894 \\
4001
\end{gathered}
$$

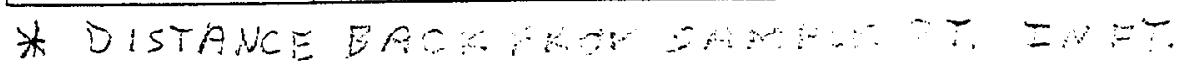

NOTE: DETECTOR IN CON:D WO: A 
Rocky Flats EMWD Deployment

Date: $11-7-00$ Starting time:

Bore: $22^{n d}$ SAMPLE@27'

File Name: RFBZSZ (5min S SAMPLPt.) RFBZS3 (eI'INTERVALS)

Notes: $A T$ T $3^{+}$PLATEZ BULDING 123 HDDLINES

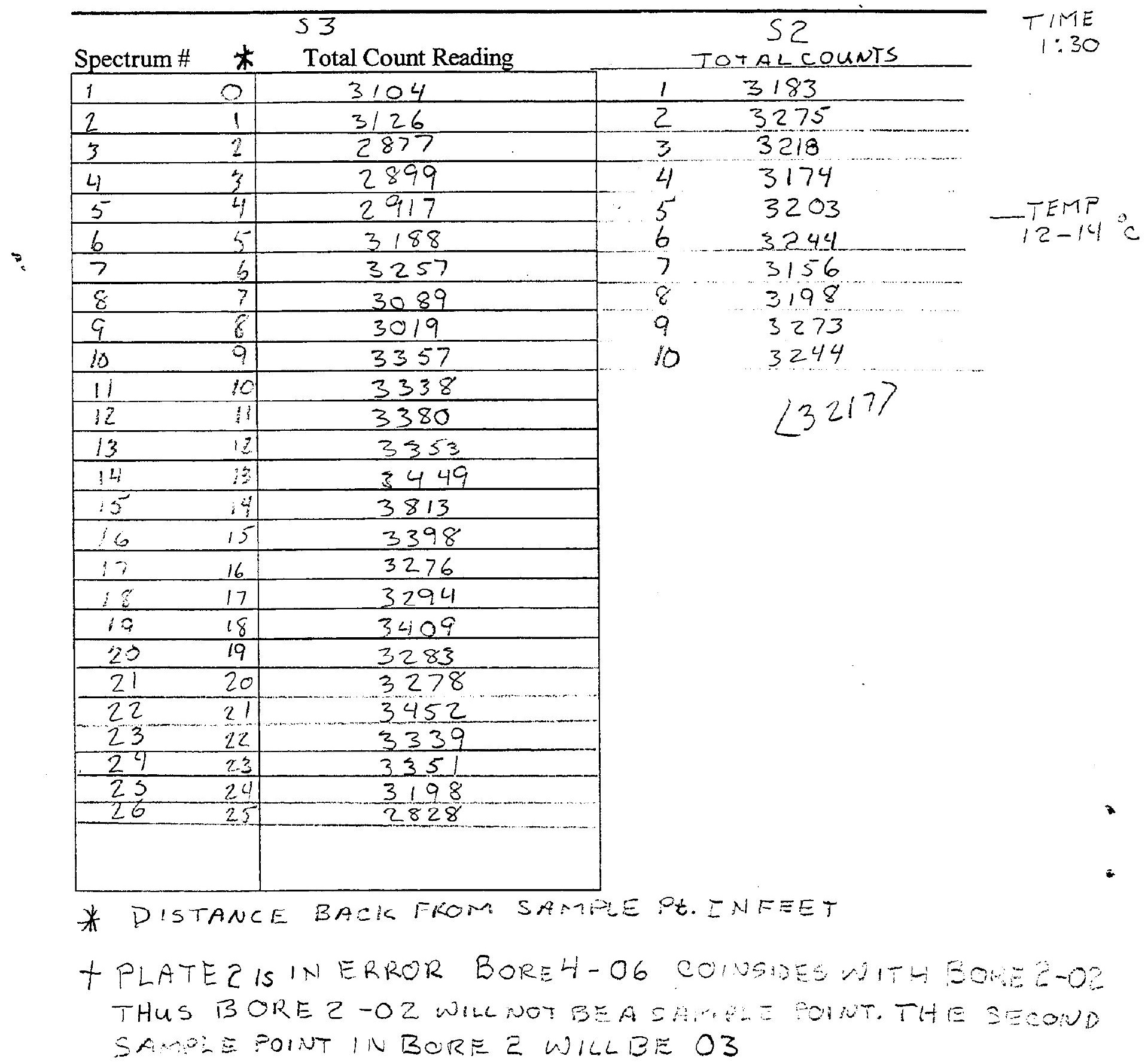

72 


\section{Rocky Flats EMWD Deployment}

H:1l:: $11-7-00$ Starting time:

WW: \#2 $3^{\text {rd }}$ SAMPLE $@ 4 / 2.3^{\prime}$

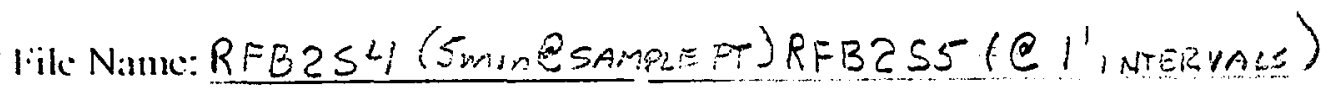

Noles: AT O4 PLATE 2 BUILDING 123 HDDLINES

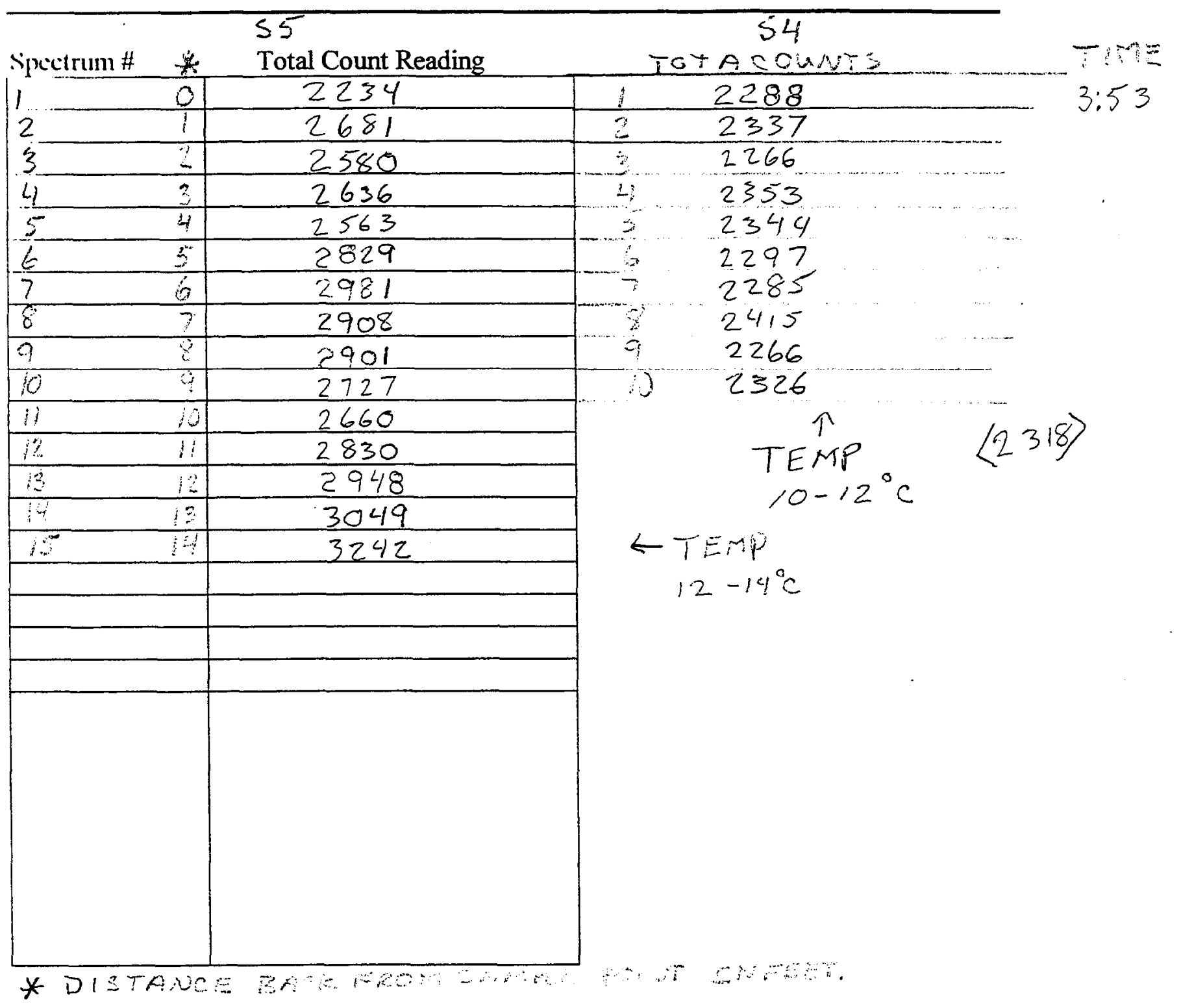




\section{Rocky Flats EMWD Deployment}

Date: $11-8-\infty$ Starting time:

Borc: \#2, $4^{\text {th }}$ sample@ $54.4^{\prime}$

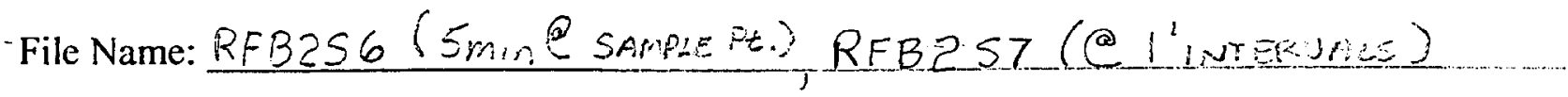

Notes: AT O 5 PLATE 2 BUILDING 123 HDOLIMES

\begin{tabular}{l}
\hline \\
Spectrum \#
\end{tabular}




\section{Rocky Flats EMWD Deployment}

Date: $11-9-00$ Starting time:

Bore: $\# 2,5^{\text {th }}$ SAMPLE (2) $74^{\prime}$

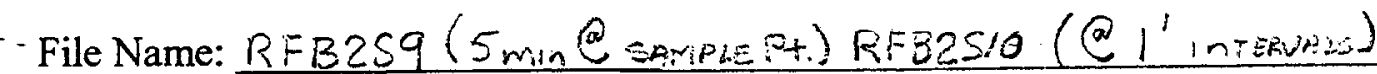

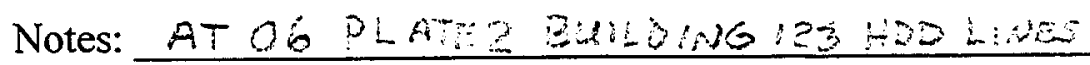

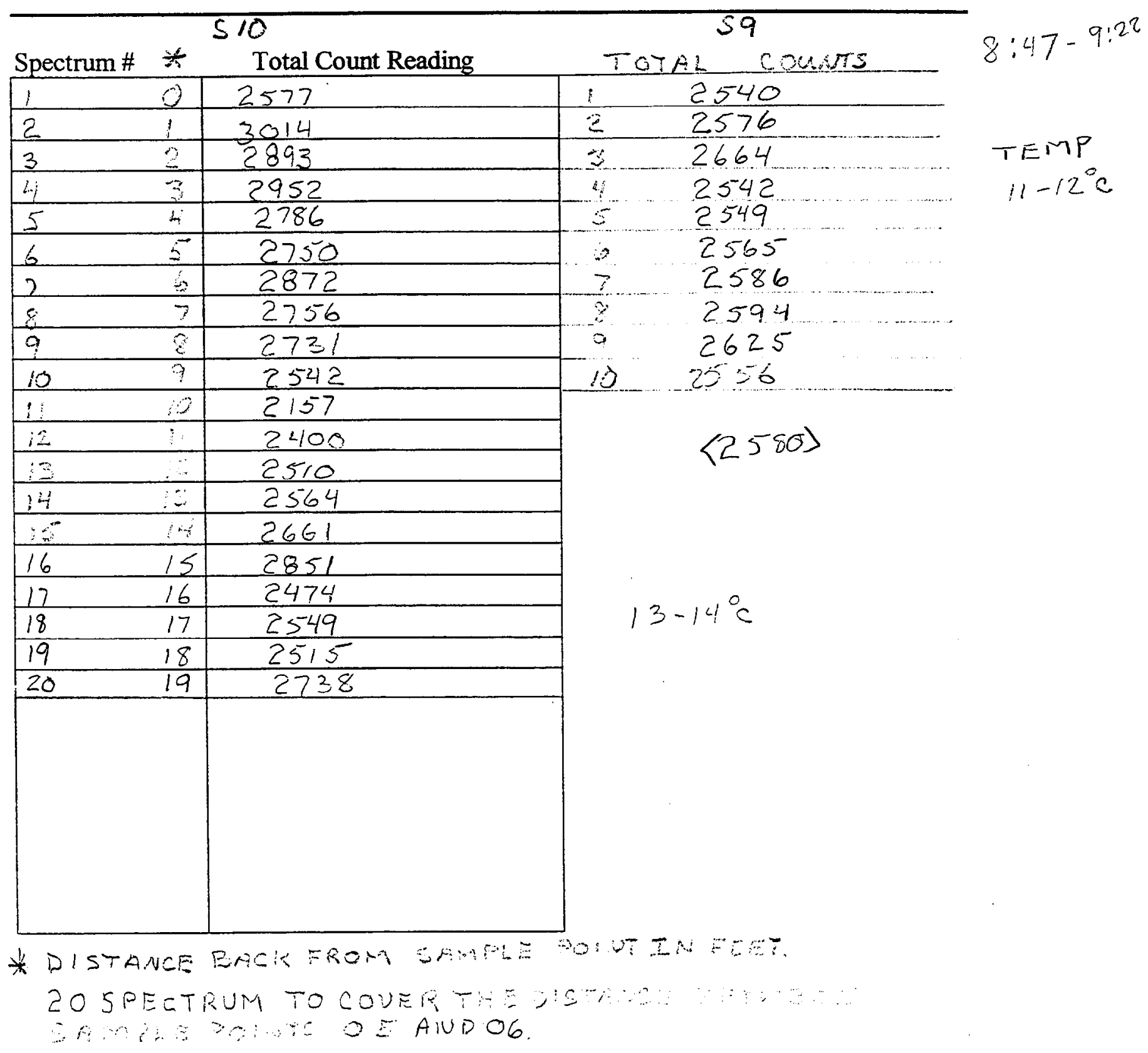




\section{Rocky Flats EMWD Deployment}

Date: $11-9-\infty \quad$ Starting time:

Bore: ${ }^{\# 2} 6^{\text {th }}$ SAMPLE@92.3

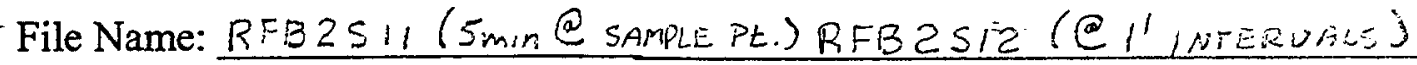

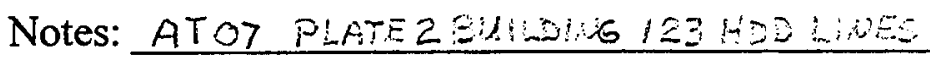

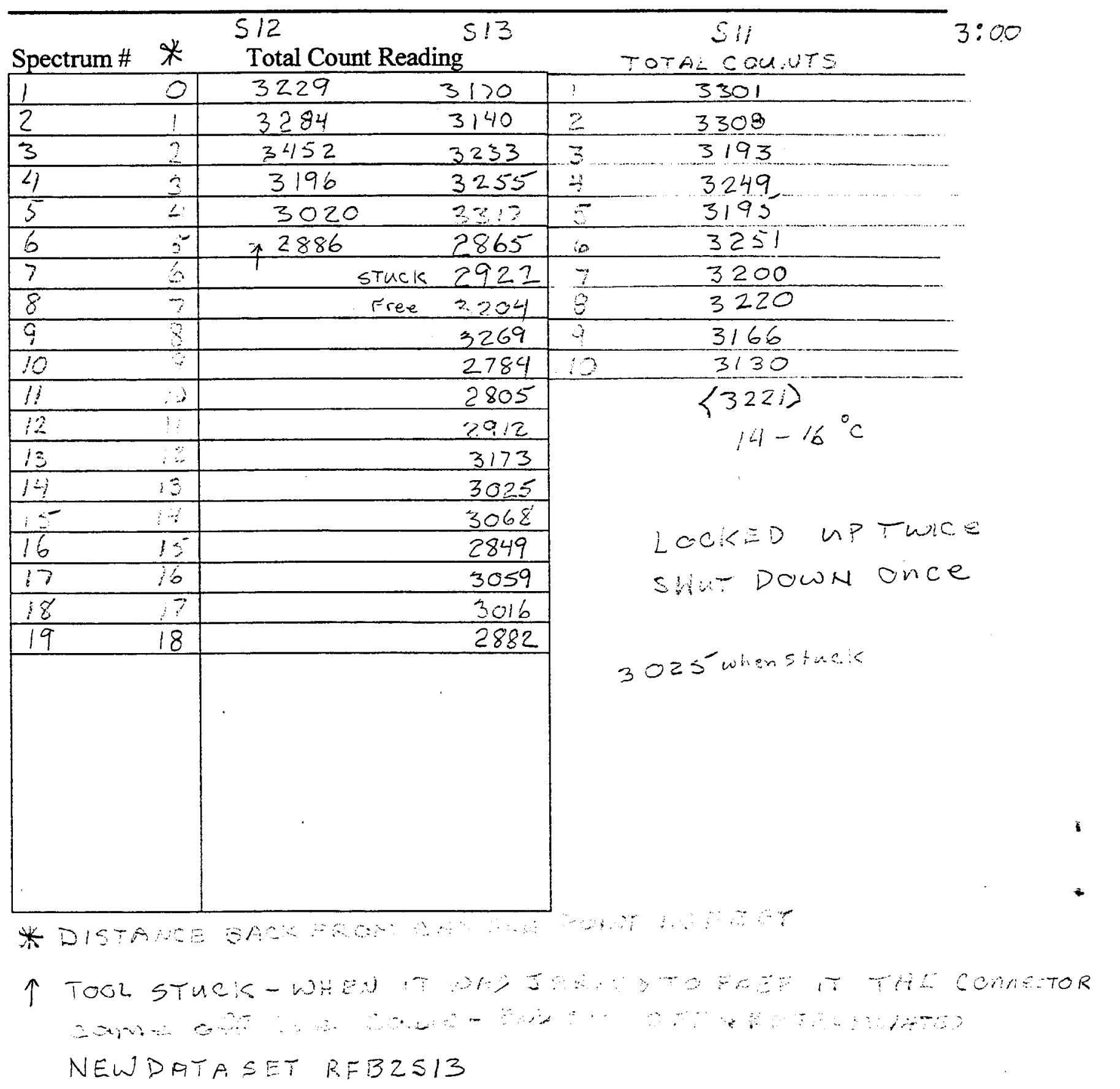




\section{Rocky Flats EMWD Deployment}

Date: $11-10-00$ Starting time:

Bore: $\# 7^{\text {th }}$ SAMPZE @ $100^{\prime}$

- File Name: RFB2S:4 (5mine SAMPLE PE.) RFB250(

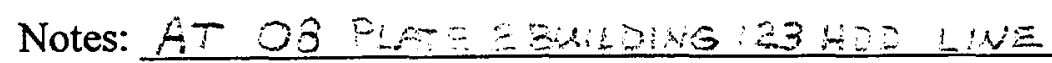

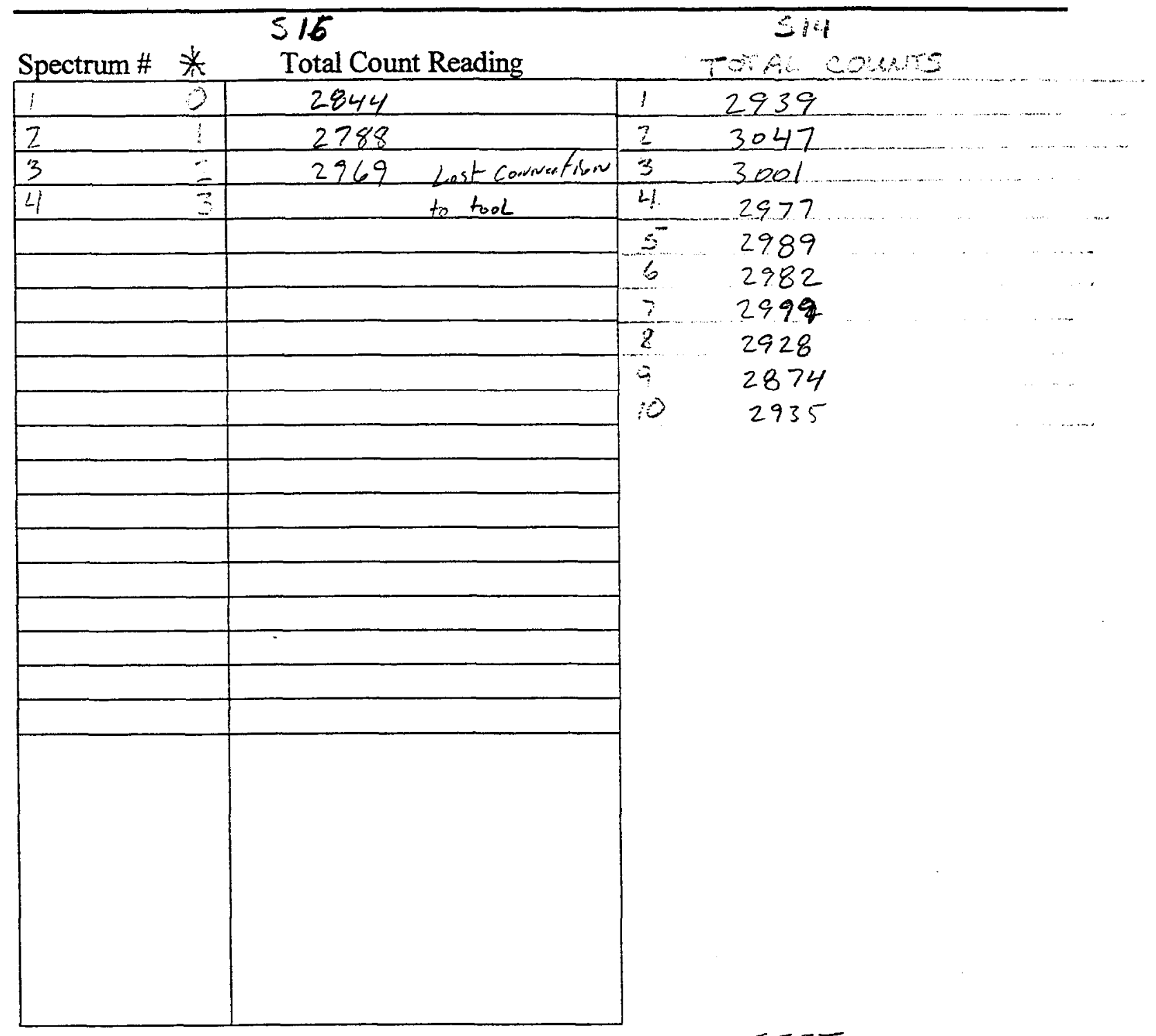

* DISTANCE back From SAMPIE pOINT IN FEET

Splice conuection in poly Tubing broke, will pull and repair or replace. 


\section{Rocky Flats EMWD Deployment}

Date: $11-13-00$ Starting time:

Bore: \#2 $8^{\text {th }}$ sam,le $e 102^{\prime \prime}$

File Name: REB 2517 (5mine sample point) RFBZ:S18 (el'intervals)

Notes: AT o\& PLATE 2 BHILONAC 123 HDD LINE

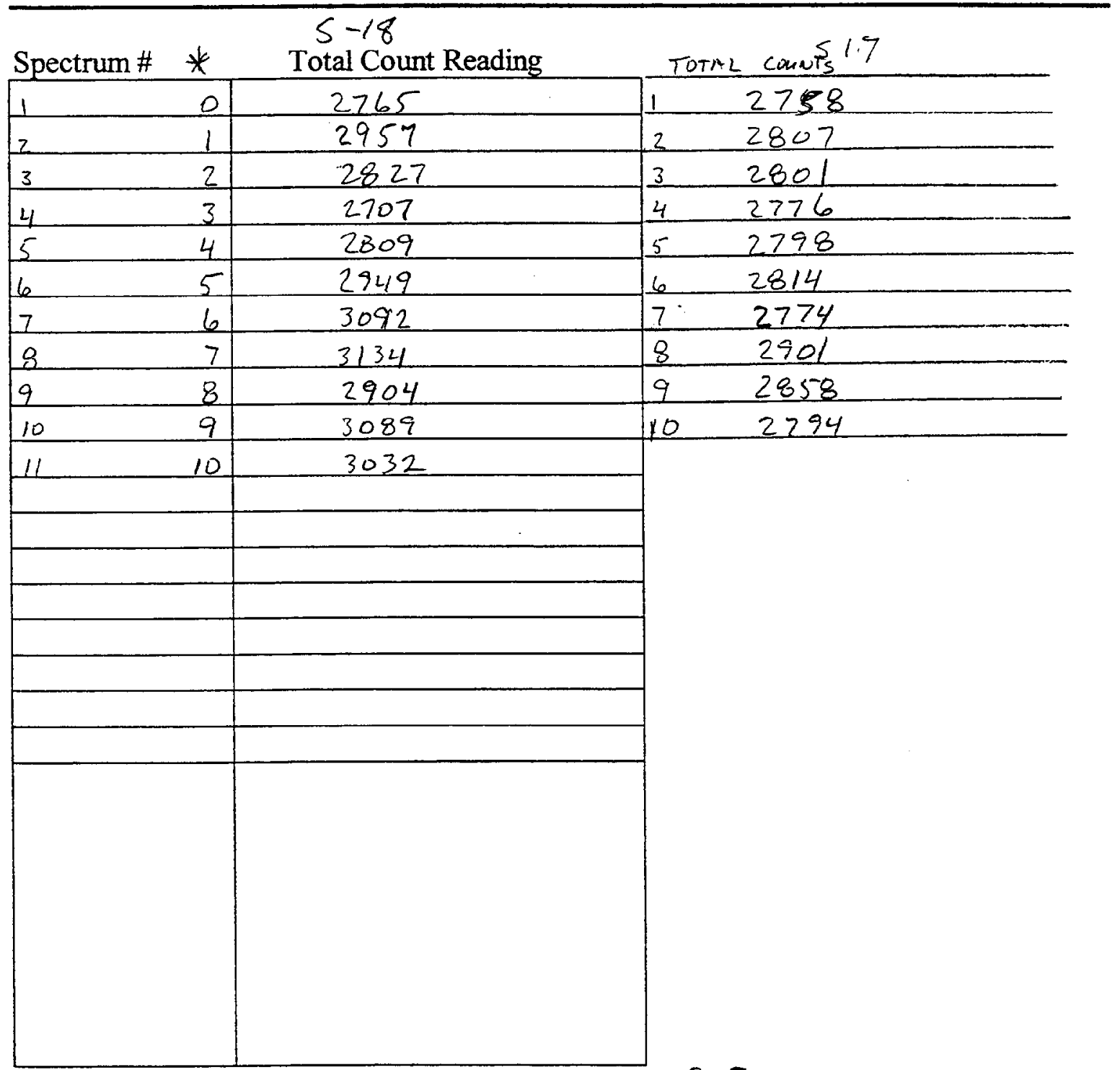

* Distance back from sample point in felt

pulled New cable thres poly and Tevnisiveted both ends Testod-oK!' 


\section{Rocky Flats EMWD Deployment}

Date: $11-14-00$ Starting time: $12: 55$

Bore: \#2 9 sample e $126^{\prime}$

- File Name: RFB 2519(5min @ Sample joint) RER2520 (el'intervals)

Notes: AT 10 P PLATE 2 BUILDING 123 HDD LINES

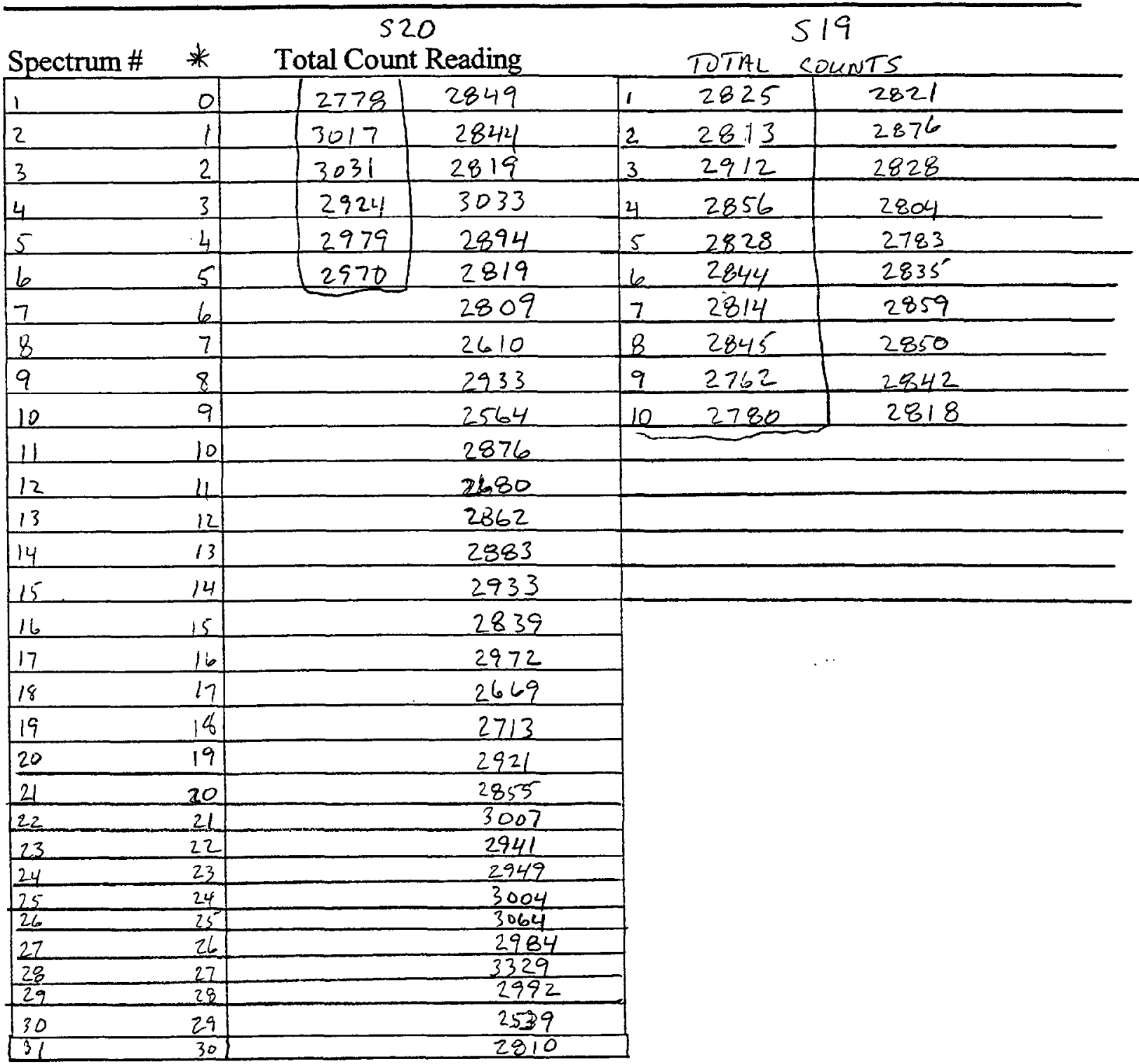


I-3: UBC 123 Bore \#3 


\section{Rocky Flats EMWD Deployment}

Date: $11-28-00$ Starting time: $2: 20$

Bore: \#33rample@331

File Name: RFB3S3 (5minesumple point) REB3S4(@1'1nTERUALL)

Notes: AT PLITE 2 BUILDING 123 HDD LINE 3

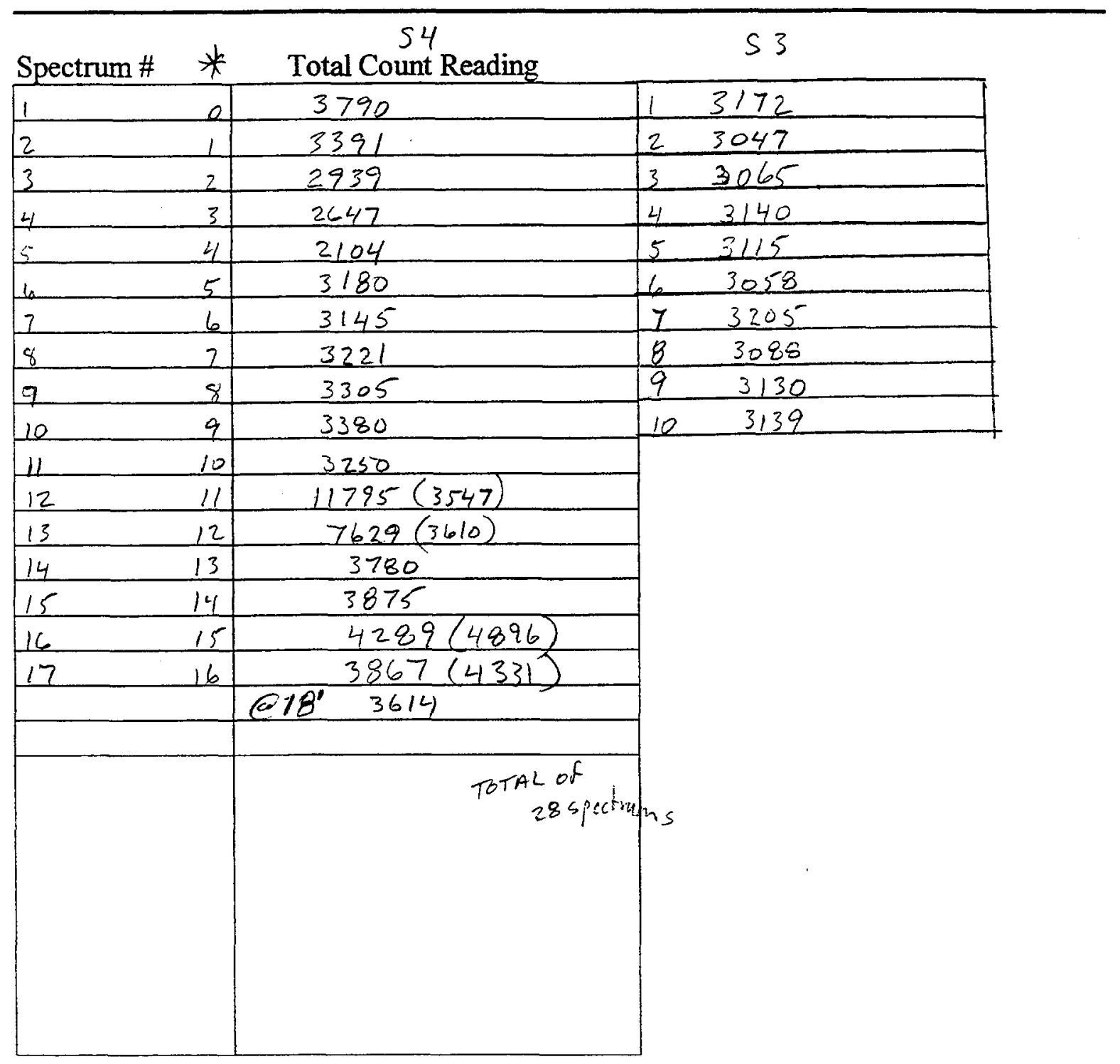

* Distance back from samide point in flet 


\section{Rocky Flats EMWD Deployment}

Date: $11.29-00$ Starting time: $8: 50$

Borc: 3

File Name: RFB 3 UT

Notes: UTLITY LINE PUC @ O'

Spectrum \# $\quad$ Total Count Reading

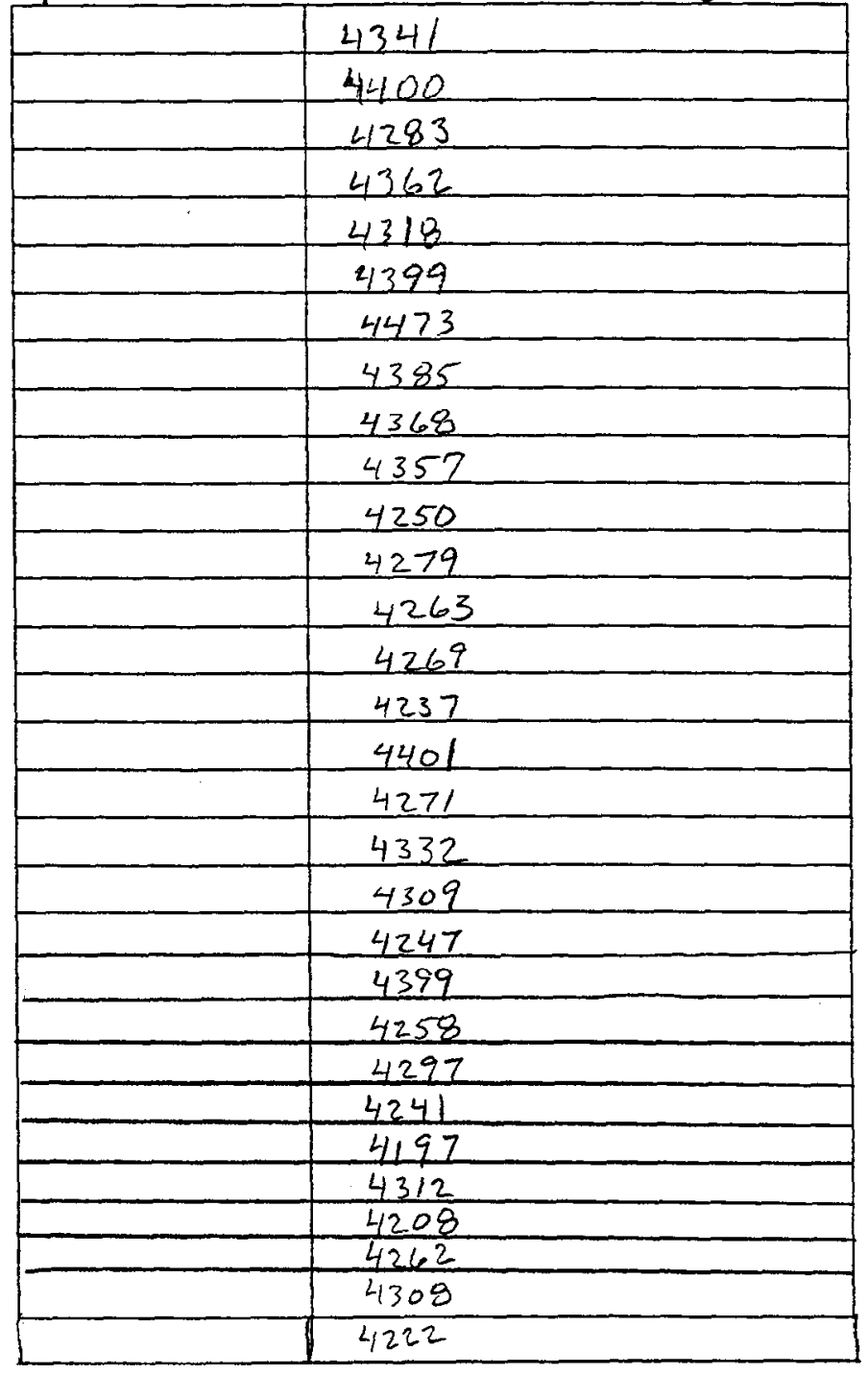

* Survey of Atrltity Live 


\section{Rocky Flats EMWD Deployment}

Date: $|2-0|-00 \quad$ Starting time: $\quad 2: 45$

Bore: $\# 3$ 4 sanple $\oplus 48^{\prime}$

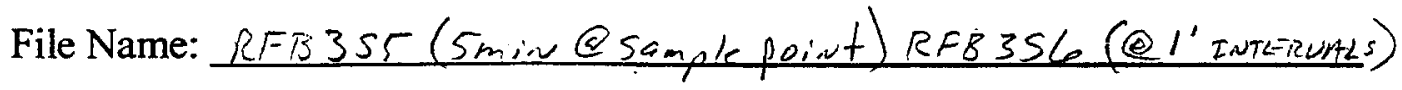

Notes: AT PLATE2 BULDING 123 HDD LINE 3

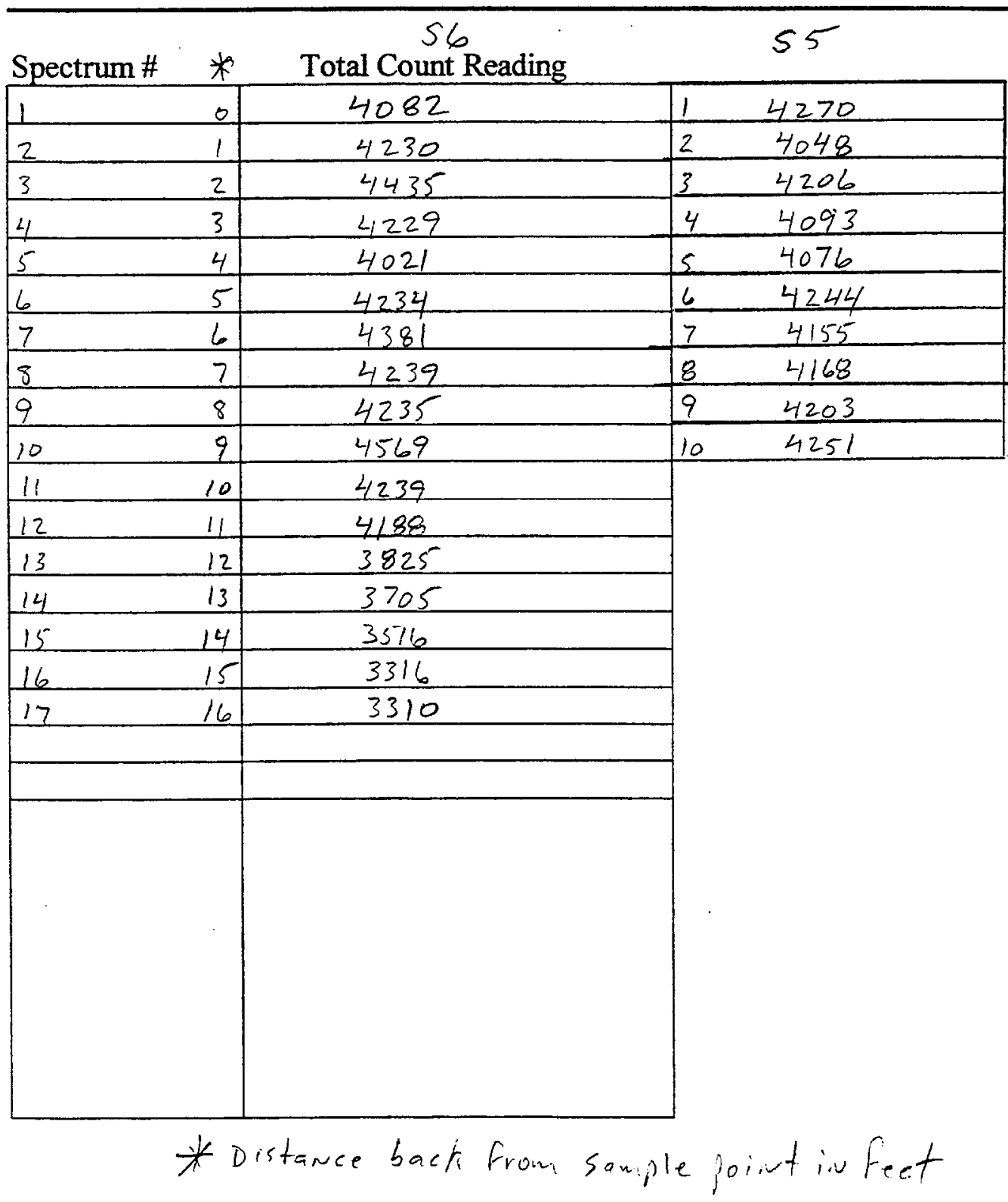




\section{Rocky Flats EMWD Deployment}

Date: $12-0 \mid=00$ Starting time:

Bore: \#3 5 Sample point @ $63^{\prime}$

File Name: REB3S7 (5min e Sample foint) RFB 358 (e1' NTLERUALS) Notes: AT PLATE2 BUILDING 123 HDD LINE 3

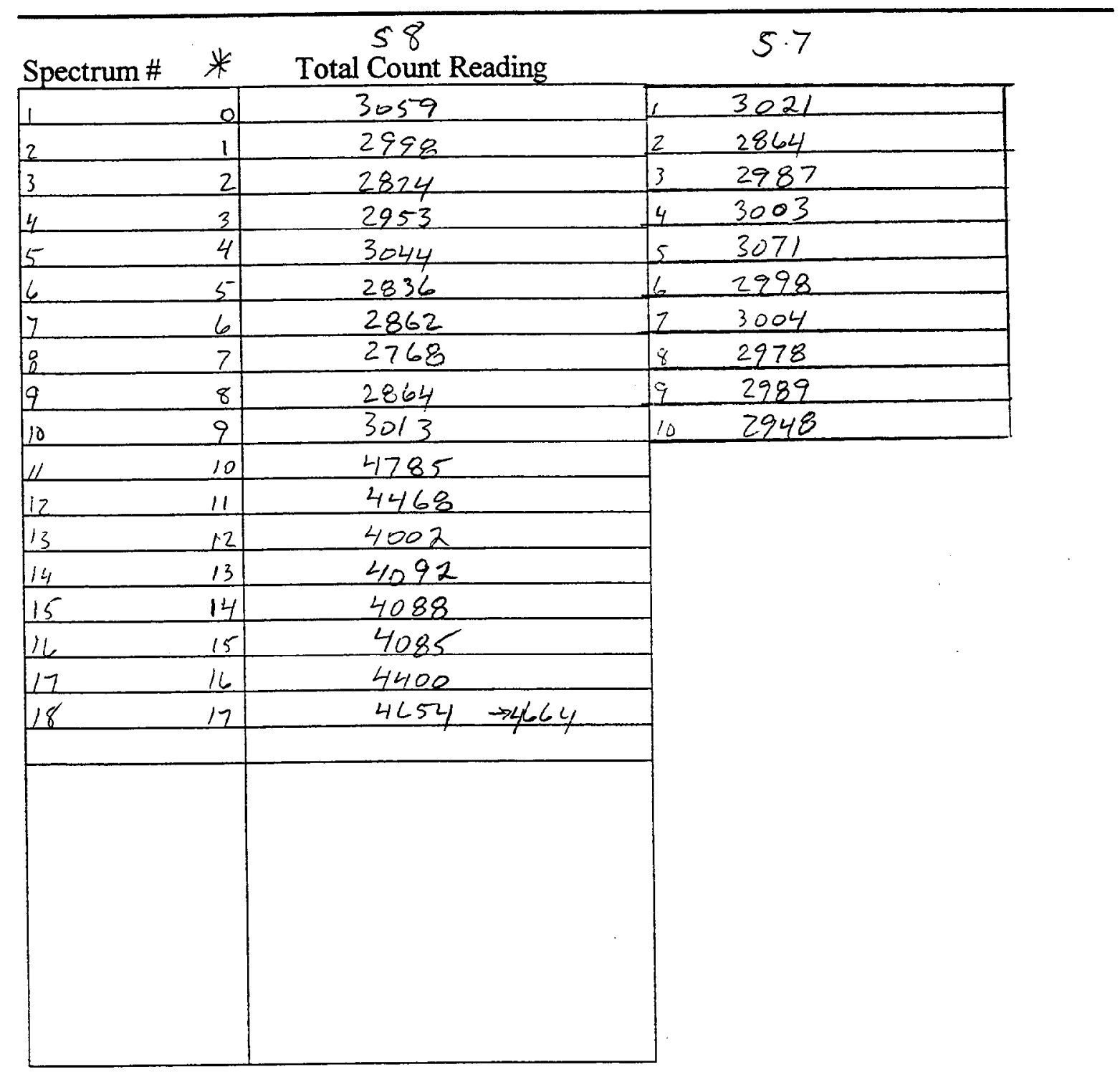

* Distance Back from samiple point in felet. 
I-4: UBC 123 Bore \#4 


\section{Rocky Flats EMWD Deployment}

Date: $10-31-00$ Starting time: $2: 28$

Bore: RFB 4 (SI $5 \mathrm{~min})$ (S2 15@30s:sea)

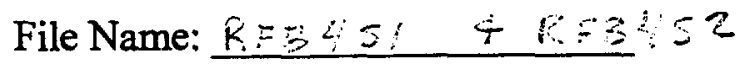

Notes: $\frac{1^{\text {ST }} \text { SAMPLE POINT @ } 42^{\prime}}{a \text { TOG PLATE } 2 \text { BLDE IZ3 }}$

\begin{tabular}{l} 
Spectrum \# \\
\begin{tabular}{|c|c|}
\hline 1 & Total Count Reading \\
\hline 2 & 3486 \\
\hline 3 & 3446 \\
\hline 4 & 3366 \\
\hline 5 & 3100 \\
\hline 6 & 2963 \\
\hline 7 & 3173 \\
\hline 8 & 3977 \\
\hline 9 & 2762 \\
\hline 10 & 2528 \\
\hline 11 & 3015 \\
\hline 12 & 3280 \\
\hline 13 & 3041 \\
\hline 14 & 2914 \\
\hline 15 & 3111 \\
\hline & \\
\hline & \\
\hline & \\
\hline & \\
\hline & \\
\hline & \\
\hline & \\
\hline
\end{tabular} \\
\hline
\end{tabular}

$$
\begin{aligned}
& \begin{array}{l}
\text { DURING } 5 \text { min run } \\
\text { THESE ane Some }
\end{array}
\end{aligned}
$$

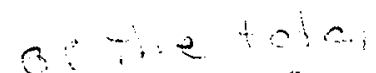

$$
\begin{aligned}
& =00 x^{3}+9=
\end{aligned}
$$

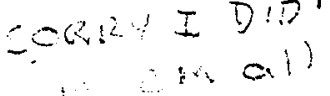

$$
\begin{aligned}
& 306 \\
& 43 \\
& 3 \\
& \text { : 16 } \\
& \text { a } \\
& 3440
\end{aligned}
$$




\section{Rocky Flats EMWD Deployment}

Date: $11-1-00 \quad$ Starting time:

Bore: $\# 4$

File Name: $R E B 4 \leq 3, R F B S 4$

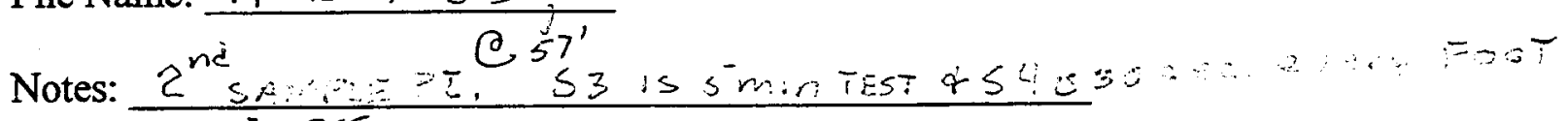

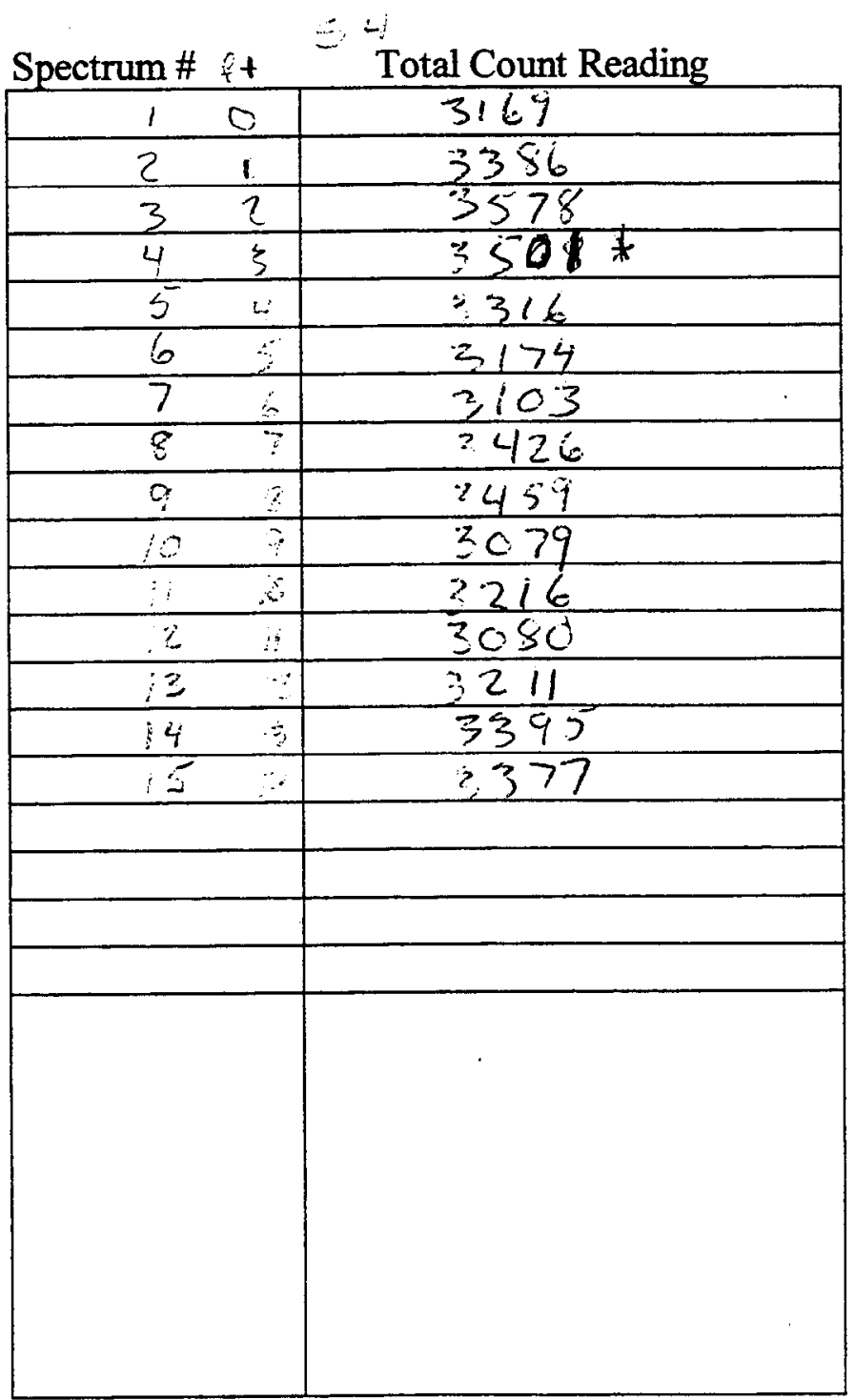

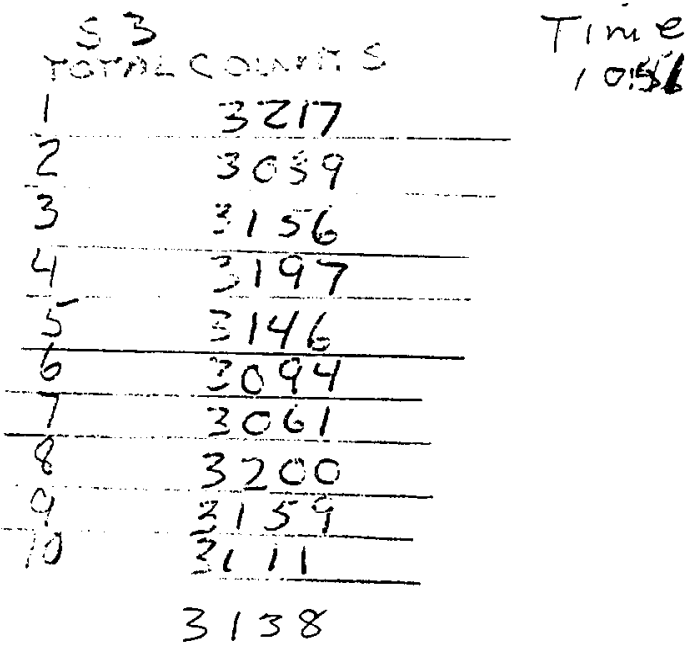

3431
+3349
3344
2399 


\section{Rocky Flats EMWD Deployment}

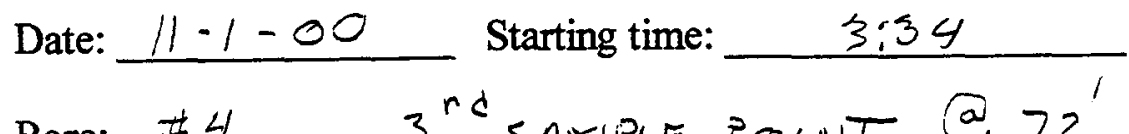

Bore: \#4 $3^{\text {rd }}$ SAMPLE POINT @ $72^{\prime}$

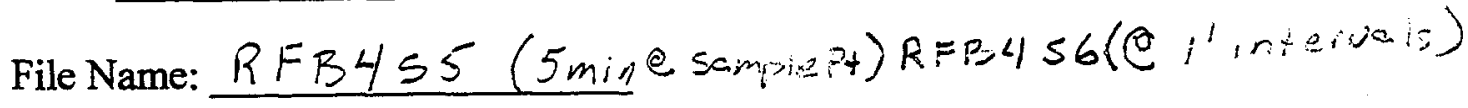

Notes: At o4 Plate 2 Bunldina :23 HoD lines

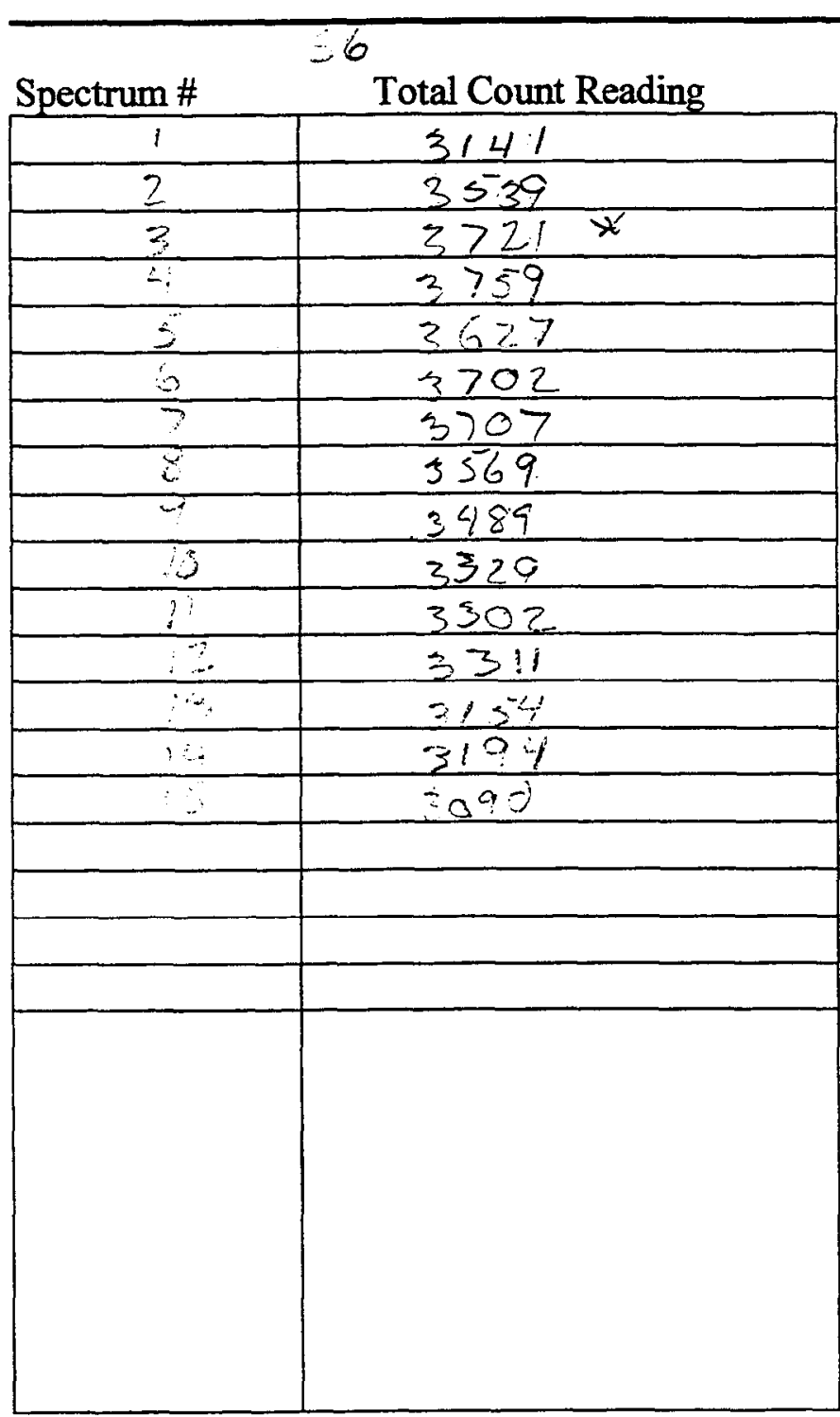

\begin{tabular}{ll}
1 & 3206 \\
2 & 3165 \\
\hline 3 & 3225 \\
\hline 4 & 3176 \\
\hline 5 & 3073 \\
6 & 3304 \\
7 & 3171 \\
3 & 3206 \\
3 & 3173 \\
31119 & 3182 \\
3 & 3763 \\
$*$ & $3>60$ \\
3794 \\
3764 \\
3851
\end{tabular}




\section{Rocky Flats EMWD Deployment}

Date: $11-2-00 \quad$ Starting time: $\quad 10: 50-10,50$

Bore: $44^{\text {th }}$ SAMPLE POWT@ C.

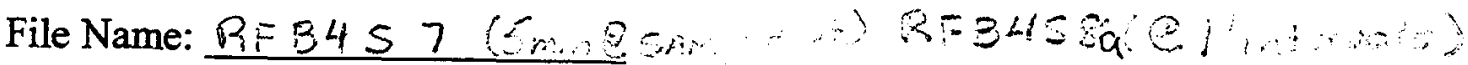

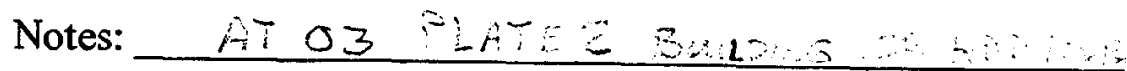

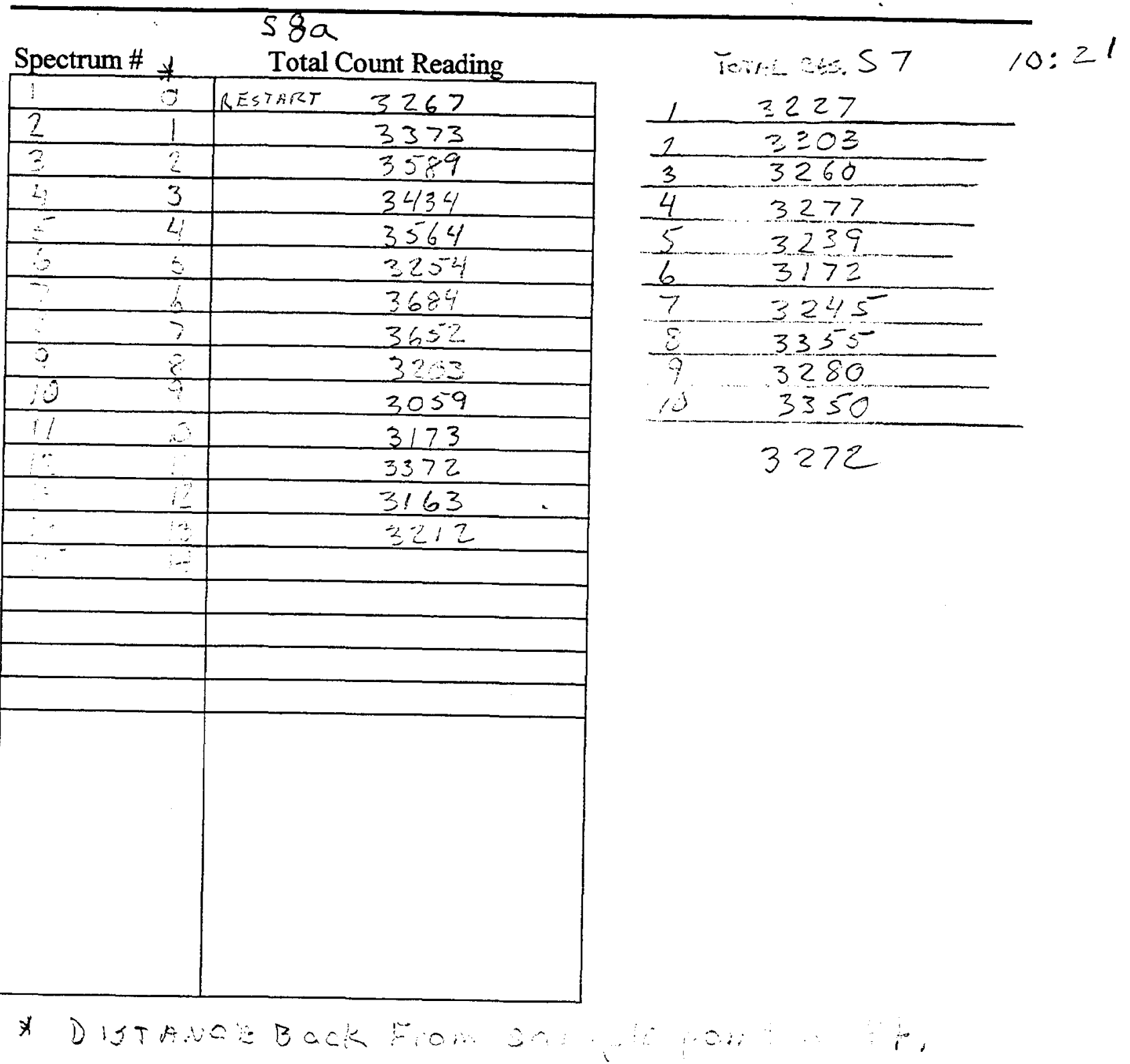




\section{Rocky Flats EMWD Deployment}

Date: $11-2-00$ Starting time:

Bore: $45^{\text {th }}$ sampie pt, $0102^{\prime}$

File Name: RFB4s9 (5min@sam, -t) EFH

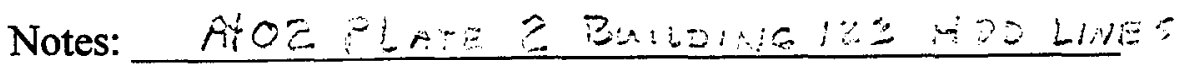

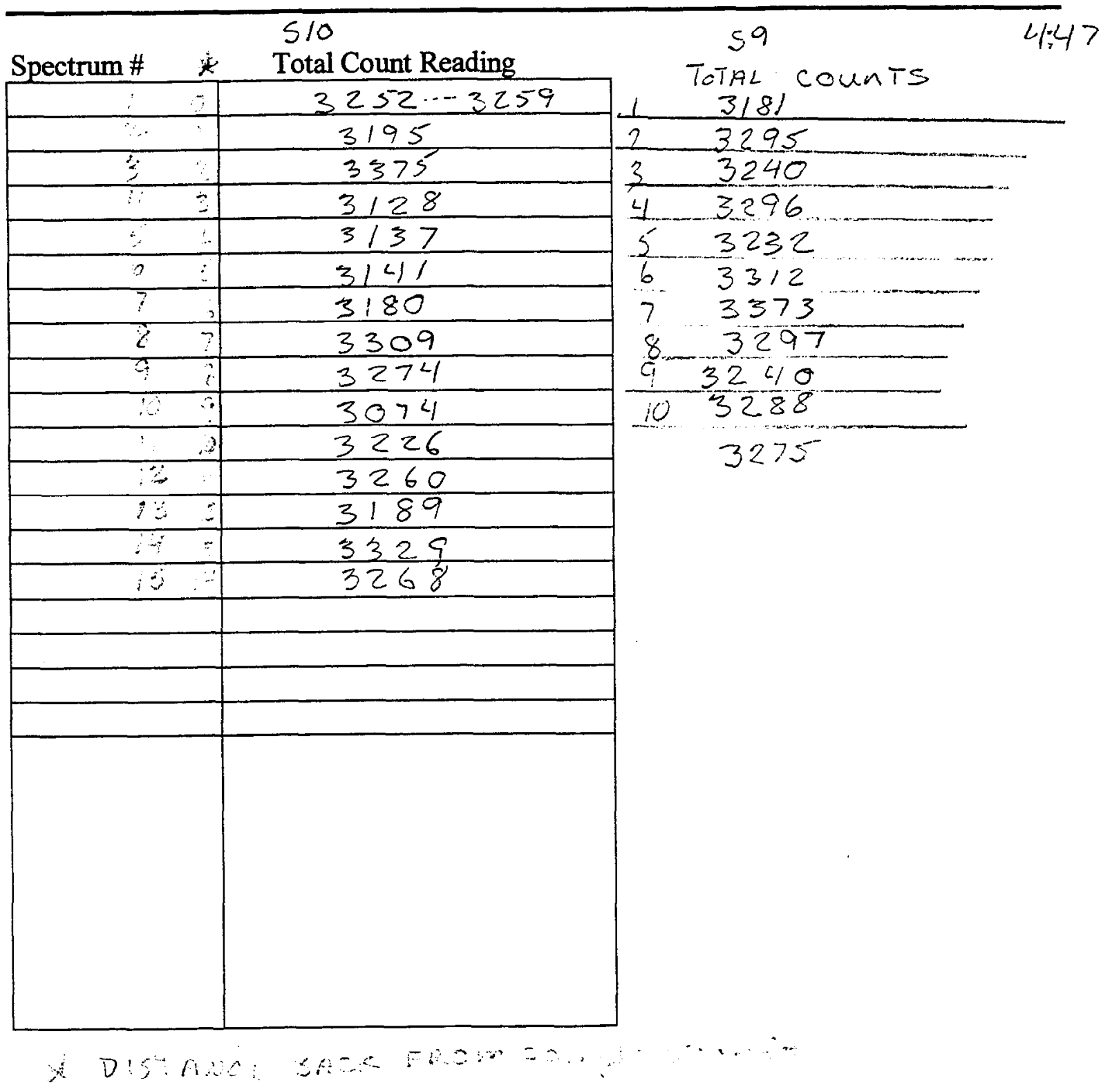




\section{Rocky Flats EMWD Deployment}

Date: $11-3.00$ Starting time:

Bore: $46^{\text {th }}$ SAMPLE PT @ $112^{\prime}$

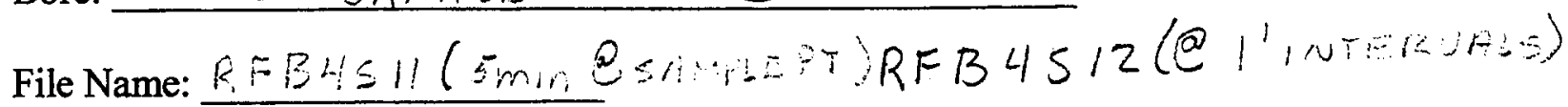

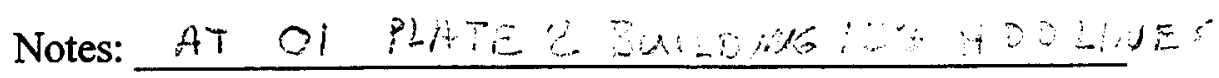

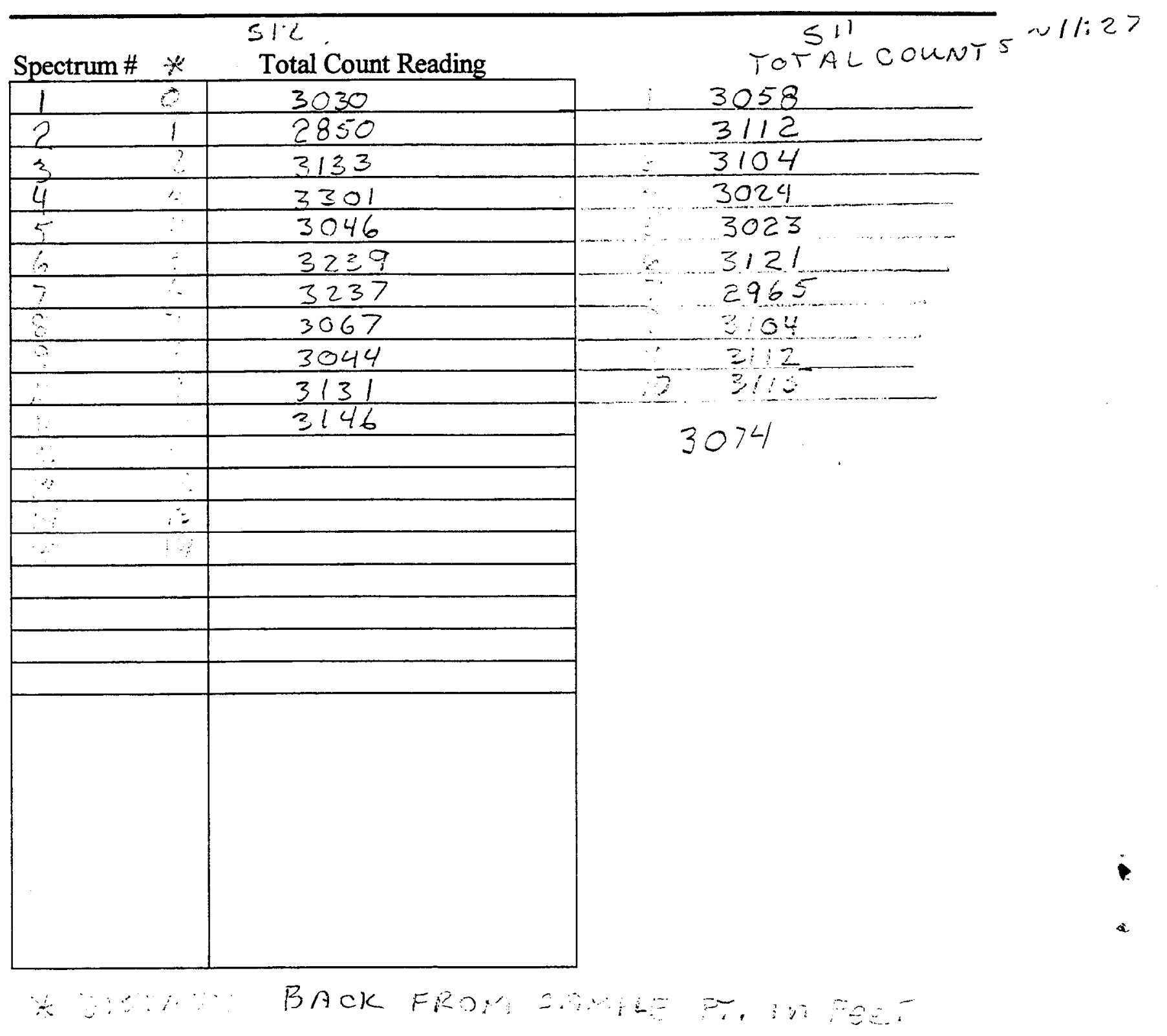


I-5: Building 886 Bore \#6 


\section{Rocky Flats EMWD Deployment}

Date: $7 \operatorname{Dec} 2000$ Starting time: $\quad 4: 40 \quad T=13-14^{\circ} \mathrm{C}$

Bore: 6 8865ampl@18+7

File Name: RF886s1; RF88652

$8+a w$

Notes: Dush $10 \div+$, sempled, pushel jeFt more d losged hol

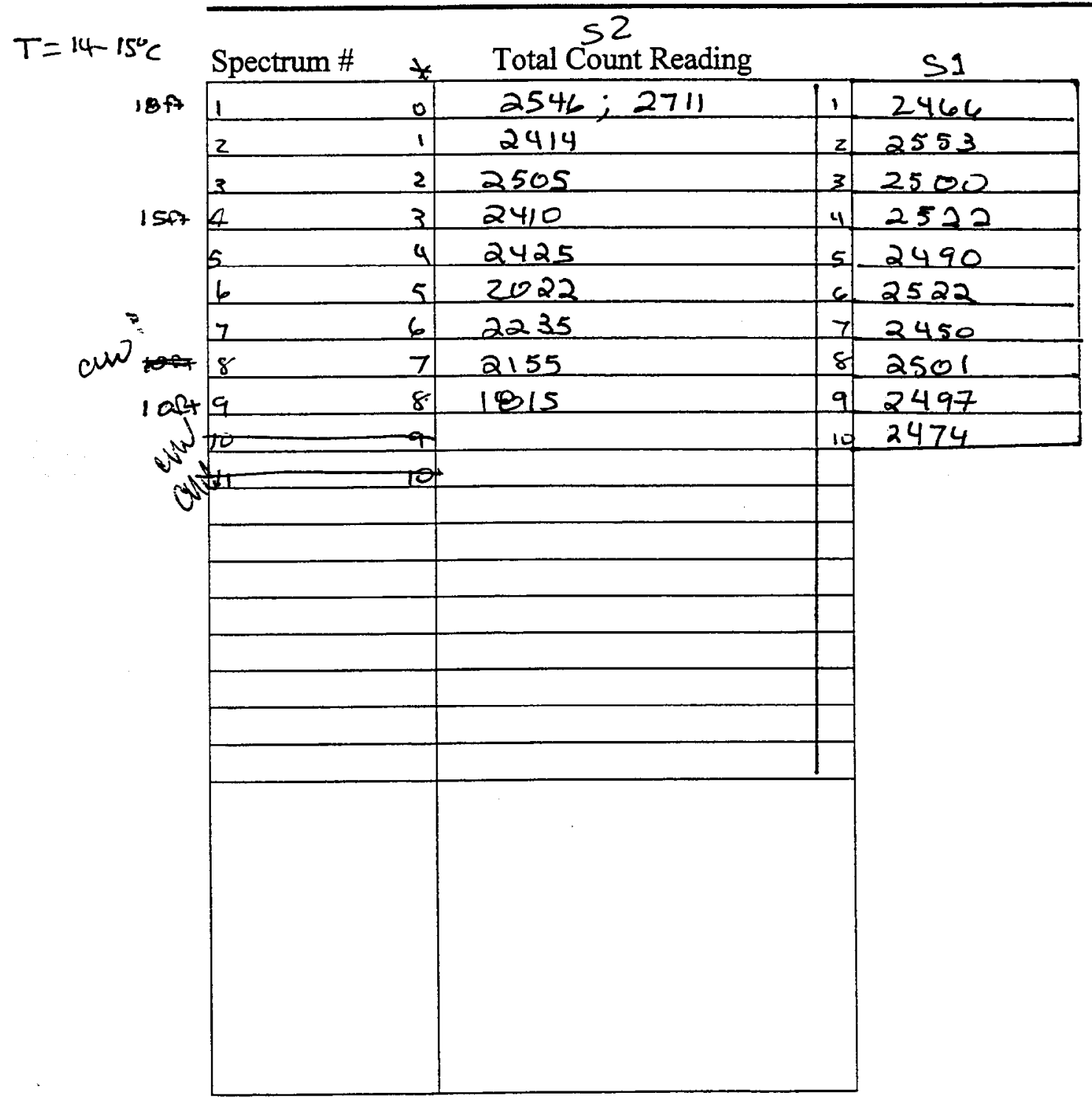

* distance back from scenpe at in feet

Othen Dila:

Airs RE8865

K40: RF $8965 K$

Flour: RF B8bSF

Wall: RF886s W 
Rocky Flats EMWD Deployment

Date: $7 \mathrm{Nec}_{2000}$ Starting time: 5:08

Bore: 68865 sample $610 \mathrm{ft}$

File Name: RF886s3; RF88654

$$
T=15-16^{\circ} \mathrm{C}
$$

Notes: Butter Vol tag $=24$ for 53

$v_{24.4}^{N}$

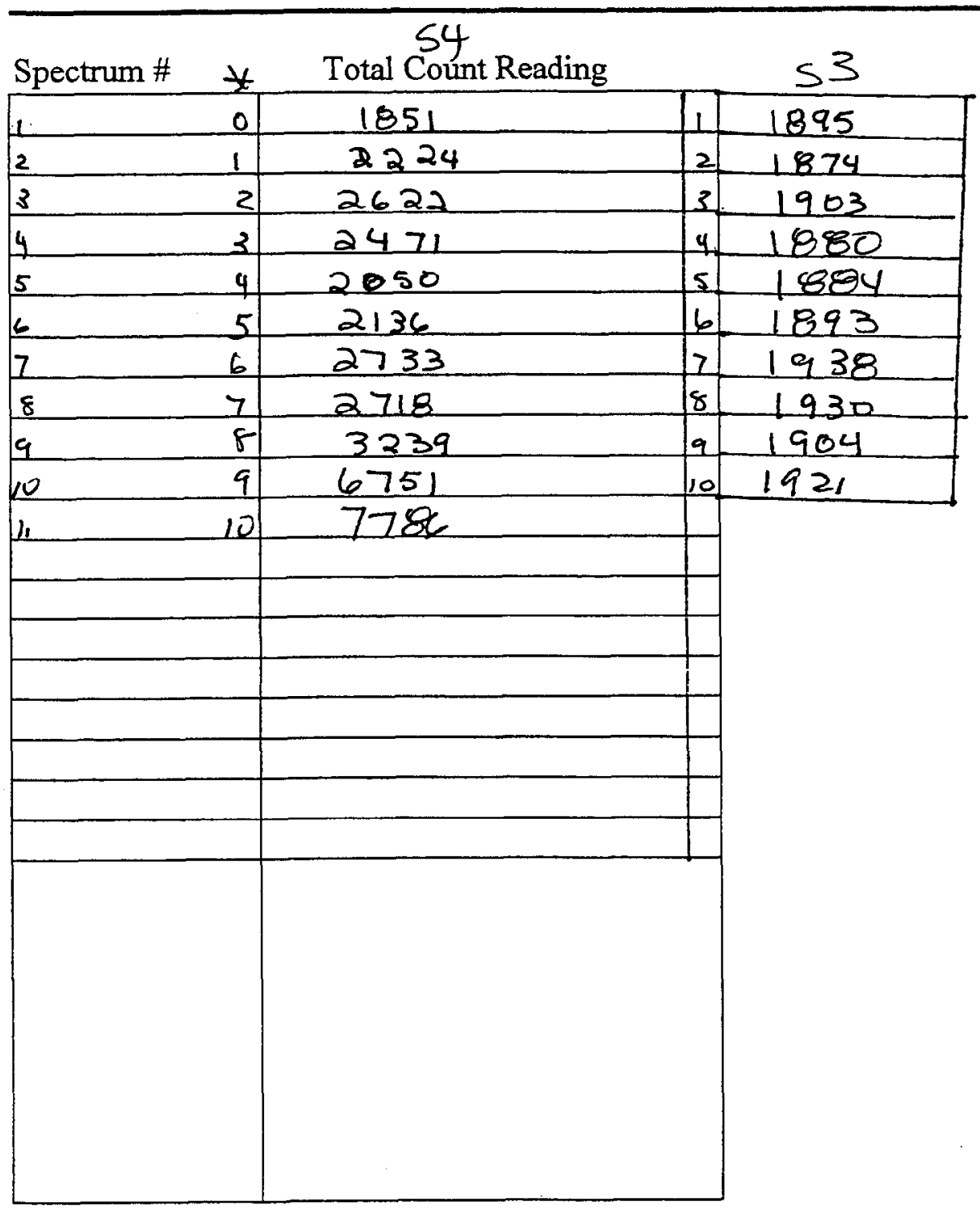

* distaraback from sample pt in feet

Note: Lockstep each time thy to Record

95 


\section{Rocky Flats EMWD Deployment}

Date: IDec 2000 Starting time: $5: 23$

Bore: H6 886 Sample (2Oft

File Name: Rf 88655

Notes:

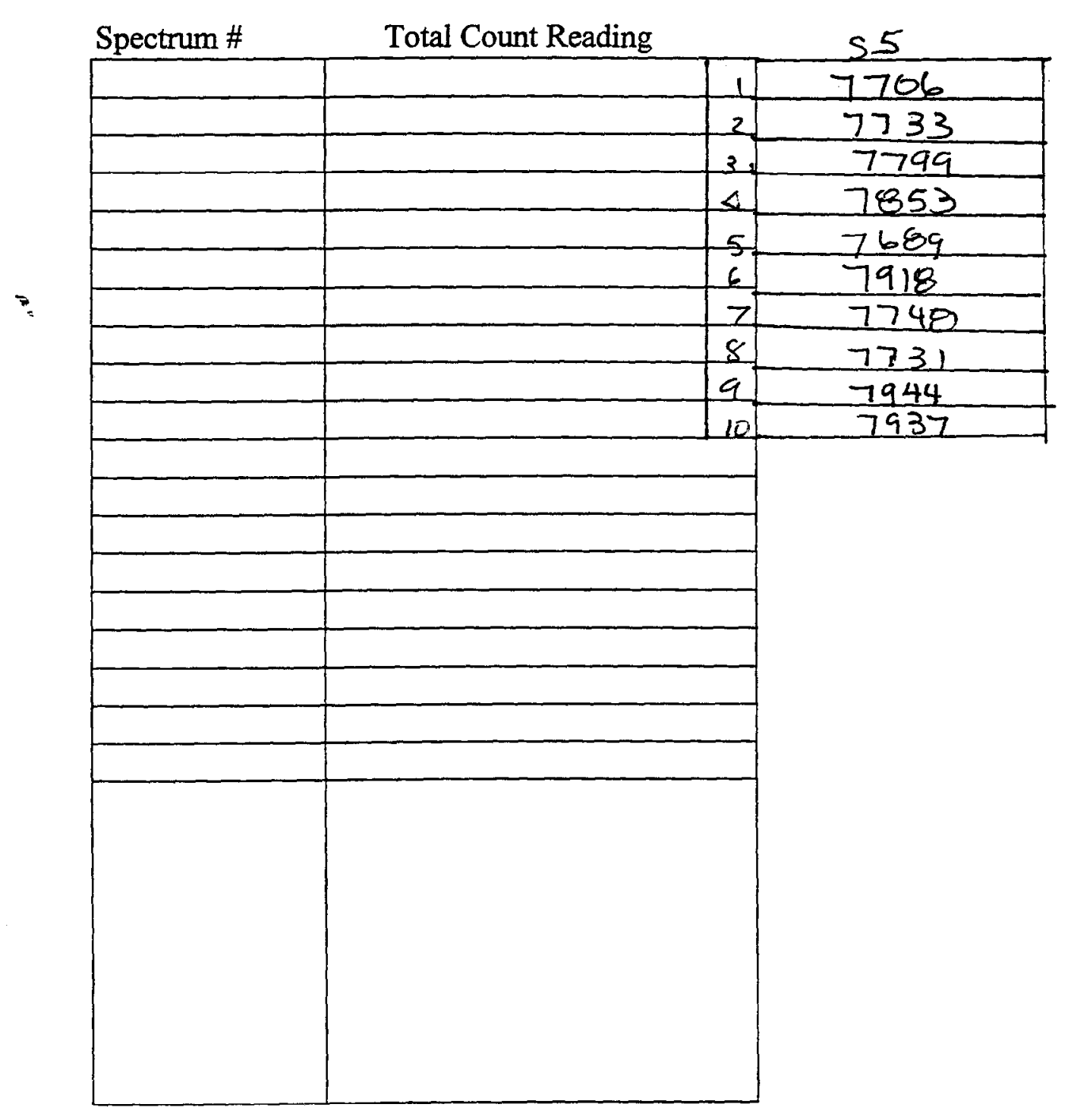




\section{DISTRIBUTION}

1 U.S. Department of Energy

Attn: Skip Chamberlain

EM-53

Cloverleaf Building

19901 Germantown Rd.

Germantown, MD 20874

1 U.S. Department of Energy

Attn: Thomas Hicks

Savannah River Operations Office

Bldg. 703-46A

P.O. Box A

Aiken, SC 29802

1 U.S. Department of Energy

Attn: Scott McMullin

Savannah River Operations Office

P.O. Box A

Aiken, SC 29802

1 U.S. Department of Energy

Attn: Pam Saxman

Albuquerque Operations Office

P.O. Box 5400

Albuquerque, NM 87185

1 U.S. Department of Energy

Attn: Jef Walker

EM-53

Cloverleaf Bldg. 19901 Germantown Rd.

Germantown, MD 20874

1 U.S. Department of Energy

Attn: James Wright

Savannah River Operations Office

Bldg. 703-46A

P.O. Box A

Aiken, SC 29803

1 U.S. Department of Energy

Attn: Paul Zielinski

EM-443

Cloverleaf Bldg. 19901 Germantown Rd.

Germantown, MD 20874

1 U.S. Environmental Protection Agency Attn: Eric Koglin

National Exposure Research Laboratory Characterization Research Division/ORD

P.O. Box 93478

Las Vegas, NV 89193-3478

20 Thomas Lindsey

Rocky Mountain Remediation Services, LLC

10808 Highway 93 Unit B Bldg. 116

Golden, CO. 80403-8200

1 MS0701 P.D. Davies, 6100

5 MS0734 C.V. Williams, 6803

1 MS0719 Susan Howarth, 6131

1 MS0724 R.J. Eagan, 6000

1 MS0741 M. Tatro, 6200

5 MS1033 R.A. Normann, 6211

1 MS1165 W. Guyton, 15300

1 MS1159 M.A. Hedeman, 15344

5 MS1159 G.J. Lockwood, 15344

1 MS1159 M.M. Selph, 15334

1 MS0612 Review \& Approval Desk, 9616 for DOE/OSTI

2 MS0899 Technical Library. 9616

1 MS9018 Central Technical Files, 8945-1 